\title{
ANÁLISE DAS DEFORMAÇÕES DO CONCRETO E DO COMPORTAMENTO DE VIGAS SUBMETIDAS A FLEXÃO SIMPLES
}

SOLANGE APARECIDA FERNANDES

Dissertaçăo apresentada à Escola de Engenharia de São Carlos, da Universidade de Săo Paulo, como parte dos requisitos para obtenção do Título de Mestre em Engenharia de Estruturas.

ORIENTADOR : Prof. Dr. Libânio Miranda Pinheiro

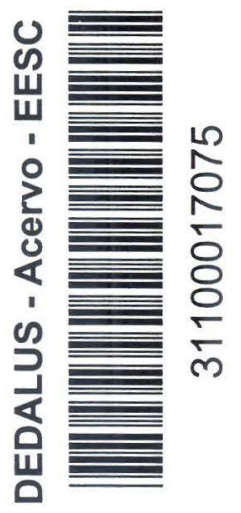

Săo Carlos 1996

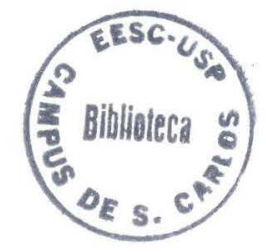


Class.

Cutt.

Tombo

Fernandes, Solange Aparecida

F411a Análise das deformaçöes do concreto e do comportamento de vigas submetidas à flexăo simples/ Solange Aparecida Fernandes São Carlos, 1996.

$142 p$.

Dissertação (Mestrado) - Escola de Engenharia de Săo Carlos - Universidade de Săo Paulo, 1996.

Orientador: Prof. Dr. Libănio Miranda Pinheiro.

1. Concreto armado (Estruturas).

2. Deformaçöes. I. Título. 
A meus pais,

Josias Fernandes (in memoriam) e

Elayla Loyola Fernandes. 
AGRADECIMENTOS

Ao Prof. Dr. Libânio Miranda Pinheiro pela orientação fornecida durante a elaboraçăo deste trabalho.

Á CAPES pela bolsa de estudos.

A todos os professores e funcionarios do Departamento de Engenharia de Estruturas, que colaboraram para a realizaçăo deste trabalho.

Aos meus familiares pelo apoio e incentivo, sempre presente em todos os momentos.

A todos os amigos que contribuiram de maneira direta ou indiretamente para a realizacăo deste trabalmo.

A amiga Flávia Conceiçăo Veneziani Ribeiro, pela amizade e por se fazer presente, principalmente, nos momentos mais dificeis. 
SUMARIO

LISTA DE FIGURAS. ......................

LISTA DE TABELAS.......................

LISTA DE ABREVIATURAS E SIGLAS................

LISTA DE STMBOLOS.......................

RESUMO...............................

ABSTRATT.......................

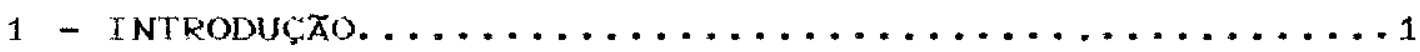

$1.1 \cdots$ GENERALIDADES. . . . . . . . . . . . . . .

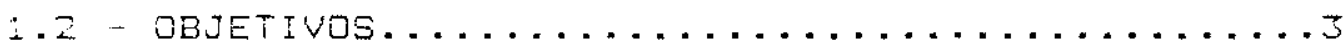

i. $3 \ldots$ ETAPAS do TRABALHO ...............

2 - DEFORMABILIDADE do CONCRETO...............

I. - ESTRLTLRA INTERNA DO CONCRETO..........

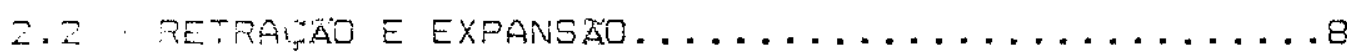

Z.3 DEFORMAGIES PRQVUCADAS POR FURGAS EXTERNAS....?

2.4 DEFORMAGBES TERMILAS............

$=.5 \%$ FATORES QUE INFLUEM NA RETRAGÃO E

NA FLUENCIA................

z.6 parametros considerados no calculo.......14

2.7 MSDULO DE ELASTICIDAdE............

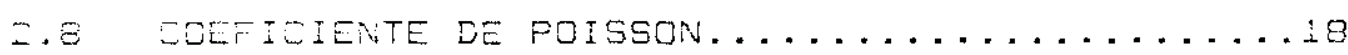

2.9 RSTUDO COMPARATIVO DO CÁLCULO DA RETRAGÃD E

DA DLENCIA.....................

2.7 .1 ... sntrodugă . . . . . . . . . . . 
2.9.2 - Fatores que influem na

deformabilidade.............21

2.9 .3 - Paràmetros para o cálculo.........22

2.9 .4 - Cálculo da retraçăo............24

2.9 .5 - Deformação imediata...........26

2.9 .6 - Valor da fluência.............27

2.9 .7 - Dados do exemplo..............29

2.9 .8 - Analise dos resultados...........30

3 - CARACTERISTICAS MECANI CAS DO CONCRETO........... 31

3.1 - GENERAL IDADES...................

3.2 - RESISTENCIA Á COMPRESST̃................

3.3 - RESISTENCIA A TRAÇÃO...............

3.4 - REsistencia no estado Múltiplo de tensoes....38

3.5 - FATORES QUE INFLUEM................ 41

4 - AÇOS PARA ARMADURA.................. 43

4.1 - OBTENĢÃD DOS AÇOS.................

4.2 - CLASSIFICACAO .................44

4.3 - DIAMETROS ESPECIFICADOS PELA NBR $7480 \ldots \ldots \ldots 50$

4.4 - INFLUENCIA DA TEMPERATURA NOS AÇOS........51

4.5 - ADERENCIA.....................

5 - Fundamentos do cálculo..................... 53

5.1 - Estados LiMITES....................53

5.1 .1 - Estados limites últimos..........53

5.1 .2 - Estados limites de utilizaçăo.......54

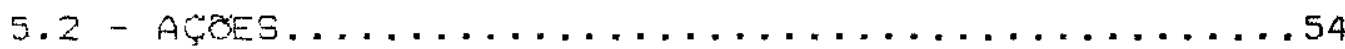

5.2 .1 - Classificação..............

5.2 .2 - Valores representativos para o estado limite ultimo..................

5.2.3- valores representativos para estados limites de utilizaçăo...........59 
5.2 .4 - Valores de cálculo das açöes........59

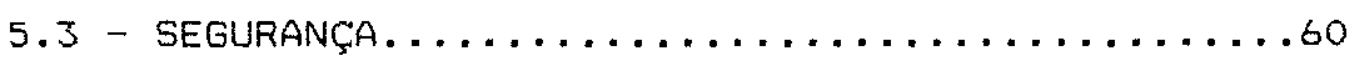

5.3 .1 - Métodos determinísticos..........6.60

5.3 .2 - Metodos probabilisticos...........63

5.3.3 - Método dos coeficientes parciais.....65

5.4 - TIPOS DE SOLICITAÇOES..............66

5.4 .1 - Quanto aos esforços solicitantes.....66

5.4.2 - Quanto ao plano de ação do momento fletor..............68

5.4 .3 - Quanto a direção dos esforços........68

5.4 .4 - Tipos de calculo.............69

5.4 .5 - Deformaçốes de ruptura do concreto....69

5.5 - COMPRESSÃ SIMPLES E TRAÇÃD SIMPLES........70

5.5 .1 - Compressão simples..............71

5.5 .2 - Tração simples..............72

5.6 - FLEXAO PURA.....................

5.6 .1 - Diagrama de tensões............73

5.6 .2 - Definição dos estádios...........75

5.6 .3 - Equações gerais de equilibrio.......77

5.6.4 - Equaçס̃es de compatibilidade de deformaçชes................79

5.6 .5 - Equaçżes constutivas.............80

6 - METODO CLASSICO.......................... 81

6.1 - HOMOGENEIZAÇÃ DA SEÇÃ...............

6.2 - COMPATIBILIDADE dAS TENSOES.............

6.3 - VERIFICAÇAO NO ESTADIO I a..............84

6.3.1 - Determinação da posição da

linha neutra............... 84

6.3 .2 - Momento de inércia.............85

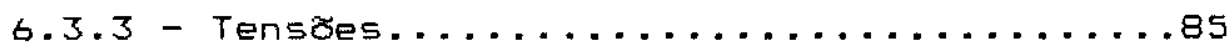

6.3.4. - Deformaçžs.................66 
6.4 -VERIFICAÇAT NO ESTADIO $11 \ldots \ldots \ldots \ldots \ldots \ldots$ 6.4.1 - Determinação da posição da linha neutra..............86

6.4 .2 - Momento de inercia..............87

6.5 - MOMENTO DE FISSURAÇÃO..............67

6.5 .1 - Cálculo segundo a NBR $7197 / 89 \ldots \ldots$...87

6.5 .2 - Calculo segundo o CEB/90...........88

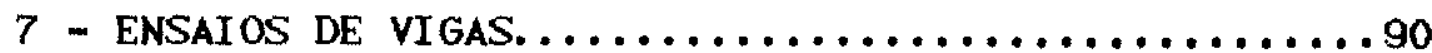

7.1 - ESQUEMA DE ENSAIO...................

7.2 - DADOS INICIAIS..................

7.3 - DIMENSIONAMENTO DO MODELO.............93

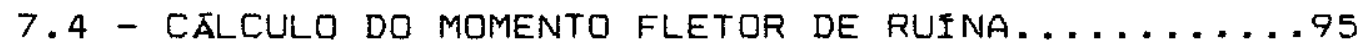

7.5 - CÄLCULO DO MOMENTO FLETOR DE FISSURAÇÃO . . .97

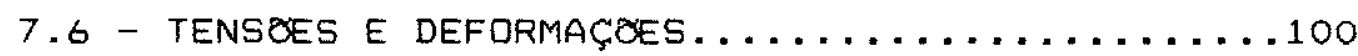

7.7 - FLECHA NO MEIO DO VIO................. 103

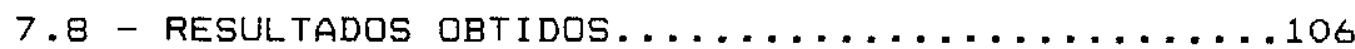

8 - ANALISE dOS RESULTADOS E CONCLUSOES. . . . . . . . 122

8.1 - ANÁLISE dOS RESULTADOS DOS ENSAIOS.......122

8.2 - CONCLUSOES..........................

REFERENCIAS. . . . . . . . . . . . . . . . . . 140 
Figura 2.1 - Estrutura interna do concreto...........6

Figura 2.2 - Tensăo capilar..................

Figura 2.3 - Retração e expansão do concreto.........8

Figura 2.4 - Evolução da deformaçăo total com o tempo..10

Figura 2.5 - Relaxação......................

Figura 2.6 - Deformaçơes recuperáveis e deformações residuais..........12

Figura 2.7 - Diagrama tensão-deformação...........17

Figura 3.1 - Curva de distribuiçăo normal..........34

Figura 3.2 - Determinaçăo da resistencia à traça axial..................

Figura 3.3 - Determinaçăo da resistencia à tração por fendilhamento.........36

Figura 3.4 - Determinação da resistência à traçăo na flexão................

Figura 3.5 - Ensaio triaxial de compressão.........38

Figura 3.6 - Concreto submetido a tensão biaxial.....39

Figura 3.7 - Determinação da resistência Tenszes multiaxiais...........40

Figura 3.8 - Diagrama tensão - deformação carregamento de longa duração....4.41

Figura 4.1 - Diagramas tensão - deformação - aços.....44

Figura 4.2 - Diagramas tensão - deformação aços classe "A".............46

Figura 4.3 - Diagramas tensão - deformação aços classe "B".............47

Figura 5.1 - Curva de distribuiçă.............57

Figura 5.2 - Método das tensores admissiveis........62

Figura 5.3 - Metodo do coeficiente de segurança externo..........63

Figura 5.4 - Probabilidade de ruina.............64

Figura 5.5 - Método dos coeficientes parciais.......66 
Figura 5.6 - Seção retangular submetida a força normal................70

Figura 5.7 - Fases de comportamento de uma seção submetida a flexăo pura............74

Figura 5.8 - Diagramas de tensões.............76

Figura 5.9 - Seção retangular de concreto com armadura dupla.................78

Figura 6.1 - Homogeneizaçăo da seção..............83

Figura 7.1 - Esquema de ensaio.................

Figura 7.2 - Viga em concreto armado............92

Figura 7.3 - Dimensionamento do modelo............93

Figura 7.4 - Cálculo do momento de ruina...........995

Figura 7.5 - Cálculo do momento de fissuração..... . .97

Figura $7.6-$ Diagrama $F \times \varepsilon_{c}-3 \phi 10 \mathrm{~mm} \ldots \ldots \ldots \ldots \ldots$

Figura 7.7 - Diagrama $F \times \varepsilon_{s}-3 \phi 10 \mathrm{~mm} \ldots \ldots \ldots \ldots \ldots 9$

Figura 7.8 - Diagrama $F \times \varepsilon_{0}-5 \phi 10 \mathrm{~mm} \ldots \ldots \ldots \ldots \ldots 111$

Figura 7.9 - Diagrama $F \times \varepsilon-5 \phi 10 \mathrm{~mm} \ldots \ldots \ldots \ldots \ldots 112$

Figura 7.10 - Diagrama $F \times \varepsilon_{c}-7 \phi 10 \mathrm{~mm} \ldots \ldots \ldots \ldots \ldots 14$

Figura 7.11 - Diagrama $F \times \varepsilon_{s}-7 \phi 10 \mathrm{~mm} \ldots \ldots \ldots \ldots \ldots 115$

Figura 7.12 - Diagrama Forças $\times$ Deslocamentos -

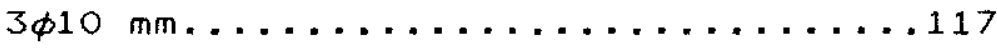

Figura 7.13 - Diagrama Forças $\times$ Deslocamentos -

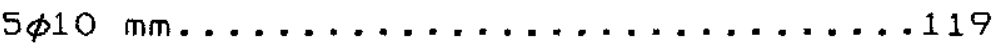

Figura 7.14 - Diagrama Forças $\times$ Deslocamentos $7 \phi 10 \mathrm{~mm} . \ldots \ldots \ldots \ldots \ldots \ldots \ldots \ldots \ldots \ldots \ldots \ldots$

Figura 8.1 - Diagrama $F \times \varepsilon_{c}-3 \phi 10 \mathrm{~mm} \ldots \ldots \ldots \ldots \ldots \ldots 125$

Figura 8.2 - Diagrama $F \times \varepsilon_{s}-3 \phi 10 \mathrm{~mm} \ldots \ldots \ldots \ldots \ldots \ldots$

Figura 8.3 - Diagrama Forças $x$ deslocamentos -

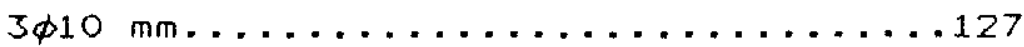

Figura 8.4 - Diagrama $F \times \varepsilon_{0}-5 \phi 10 \mathrm{~mm} \ldots \ldots \ldots \ldots \ldots 129$

Figura 8.5 - Diagrama $F \times \varepsilon_{s}-5 \phi 10 \mathrm{~mm} \ldots \ldots \ldots \ldots \ldots 130$

Figura 8.6 - Diagrama Forças $\times$ deslocamentos -

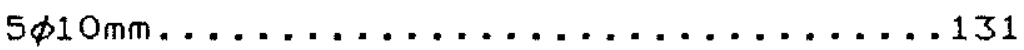

Figura $8.7-$ Diagrama $F \times \varepsilon_{c}-7 \phi 10 \mathrm{~mm} \ldots \ldots \ldots \ldots \ldots 133$ 
Figura 8.8 - Diagrama $F \times \varepsilon_{s}-7 \phi 10 \mathrm{~mm} \ldots \ldots \ldots \ldots \ldots 134$

Figura 8.9 - Diagrama Forças $x$ deslocamentos -

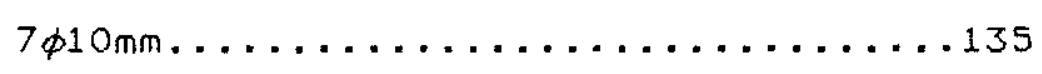




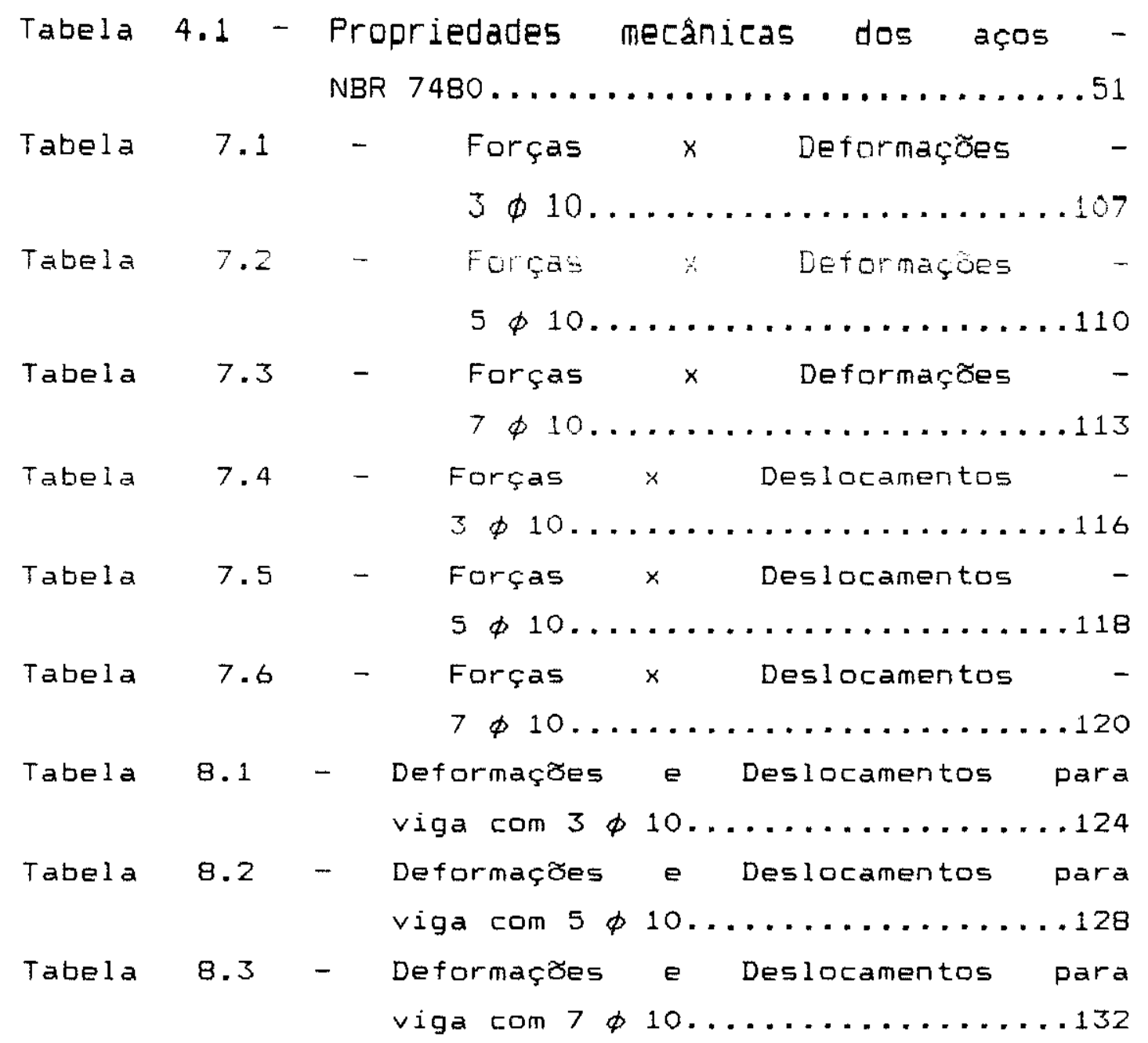


LISTA DE ABREVIATURAS E SIGLAS

$C A$ - concreto armado

CEB - Comite Euro-International du Beton

EC - 2 - EUROCODE N. 2

NB - Norma Brasileira

NBR - Norma Brasileira Registrada 
Letras romanas maiúsculas:

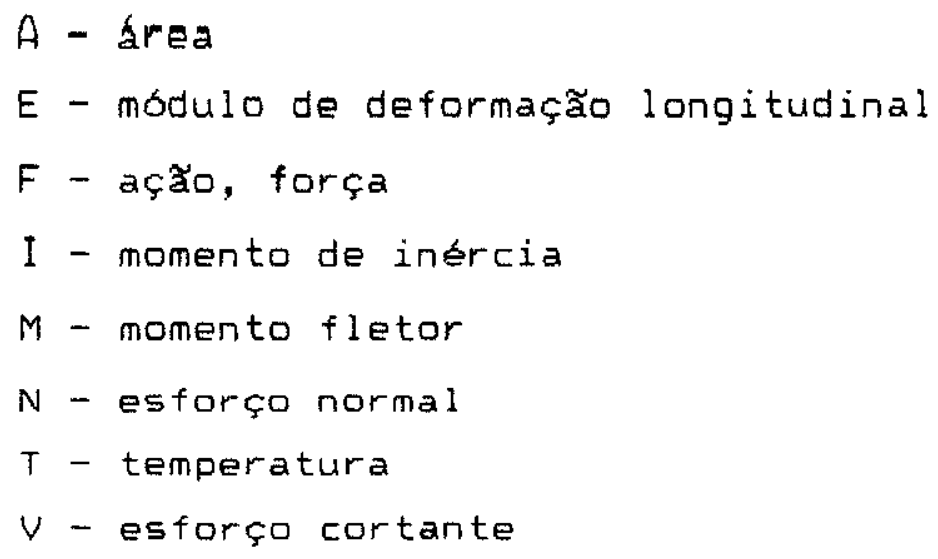


$a$ - relaçชes, coeficientes

$\beta$ - relaçŏes, coeficientes

$\varepsilon$ - deformaçżes

$\gamma$ - peso especifico, coeficiente de majoração ou redução

$\nu$ - coeficiente de poisson

$\rho$ - taxa de armadura

$\sigma$ - tenรวัo normal

$\phi$ - coeficiente de fluência

Prefixos:
$G-10^{\circ}$
$M-10^{\circ}$
$k-10^{3}$
$\mu-10^{-\sigma}$ 
FERNANDES, 5. A. (1996). Análise das deformaçōes e do comportamento de vigas submetidas à flexăo simples, Săo Carlos. 142p. Dissertação (Mestrado) - Escola de Engenharia de São Carlos, Universidade de São Paulo.

Desde o seu surgimento, na França, o concreto armado vem evoluindo, com alteraçzes nos materiais constituintes, nas dosagens e nos processos construtivos. Esta evolução tem como consequência uma variação no seu comportamento. Portanto, torna-se necessaria a atualizaçăo das normas, que são as responsáveis por suas especificaçōes. Com base na evolução do concreto, as normas, como o EC-2/89, CEB/90 e a NB-1, vem sendo substancialmente atualizadas, baseando-se em novos ensaios.

Este trabaliho aborda alguns aspectos que estão sendo alterados no estudo das deformaçós que ocorrem no concreto e no aço. Com base na analise de resultados, são feitas algumas consideraçổes que podem contribuir para as modificaçốes da NB-1, ora em desenvolvimento, e para futuros trabalhos sobre os temas abordados. Palayras-chave: concreto armado; deformações; flechas 
FERNADES, S.A. Concrete strains and beams under single flexion behavior analysis. Săo Carlos, 1995. 142p. Dissertação (Mestrado) - Escola de Engenharia de São Carlos, Universidade de Săo Paulo.

Since it appears, in France, the reinforced concrete has been developing, with changes in its component materials, in its doses and in its constructive process. This evolution has as result a change of its behavior. So, it makes necessary to bring the standards that are responsible for its specifications up to date. Based on the concrete evolution, the standards, as the EC-2/B9, CEB/9O and the NB-1. have been essentially brought up to date based on new tests.

This essay broaches some points of view that are being changed in the steel. Based on the result analysis, I do some considerations that can contribute for the modernization of the NB-1, for the time in developemente, and for future essays about the topics broached.

keywords: Reinforced concrete; strains; deflections. 


\section{1 - INTRODUCAOO}

\section{1 - gENERALIDADES}

- concreto armado surgiu na França em meados do século $X I X$, tendo como primeira peca o barco de Lambot. Por apresentar un custo relativamente baixo e ser de facil moldagem, tornou-se indispensável na construça civil. Sua principal caracteristica e a elevada resistencia a compressão, o que não ocorre quanto a resistencia a traçăo, que em geral e considerada desprezivel. Para suprir tal deficiencia, utiliza-se o aço, que apresenta uma alta resistencia a traça. A utilizaçăo dos dois materiais, concreto e aço, trabalhando solidariamente constitui o que chamamos de concreto armado.

- concreto e obtido atraves de uma mistura, convenientemente proporcionada, constitulda por agregados, graúdos e miúdos, um aglomerante hidráulico, o cimento, e água. Por ser constituido de uma mistura, apresenta uma estrutura interna que sofre alteraços no seu volume, devidas às diversas reaçós quimicas que ocorrem entre seus componentes. A estas deformaçoses denominam-se retração ou expansão, caso ocorra diminuiçăo ou aumento de volume, respectivamente. As deformaços que ocorrem no concreto também podem ser provocadas por forças externas. Atraves de corpos-de-prova e possivel determinar as deformaçós provocadas tanto por forcas 
internas e reaçóes químicas como por forças externas.

Os aços comercializados para o concreto armado encontram-se divididos em duas classes: classe $A$ e classe B. Ambos diferem-se pelo processo de fabricação, sendo o primeiro laminado a quente e o outro encruado a frio. Os aços da classe $A$ apresentam como principais caracteristicas o limite de escoamento e o patamar de escoamento no diagrama tensăo $x$ deformaçăo bem definidos, - que năo ocorre com os aços da classe B. Para os aços da classe $B$, o limite de escoamento é convencional, definido atraves de uma deformação residual de $0,2 \%$. As deformaç̧es no aço são determinadas através de ensaios em corpos-de-prova.

Sendo os dois materiais capazes de se deformarem quando solicitados por carregamento externo, cabe observar tais deformaçós quando ambos trabalham solidariamente. Tal procedimento pode ser feito através de ensaios realizados em vigas de concreto armado. As vigas são submetidas à flexão simples, ou seja, podem ser aplicadas duas forcas concentradas equidistantes dos apoios. 0 carregamento es aplicado gradualmente ate que ocorra a ruina da viga. Para cada incremento de carga, são registradas suas respectivas deformaçơs. Estas deformaçöes que ocorrem no concreto e no aço 5 ăo registradas atraves de extensómetros eletricos. Durante o carregamento ocorrem deslocamentos, medidos através de transdutores de deslocamentos instalados em pontos especificos. Tais deformaçós e deslocamentos să teoricamente calculados atraves de varios métodos de calculo. Estes metodos diferem-se pelos parâmetros empregados mas buscam o mesmo objetivo: adequar de melhor maneira seus resultados aos valores encontrados experimentalmente. Esta verificaçăo, de qual melhor se adapta à realidade, feita atraves de uma análise comparativa entre os resultados. Estes, obtidos pelos metodos teoricos, apresentam comportamentos diferentes 
quando há variação na taxa de armadura. Portanto, uma melhor análise dos parâmetros considerados nos cálculos permitem um melhor ajuste nos resultados.

\title{
1.2 - oBJETIVOS
}

\begin{abstract}
Sabe-se que o concreto armado é constituido basicamente por dois materiais, concreto simples e aço, e que ambos se deformam quando solicitados por carregamento externo. E possivel conhecer estas deformaçōes atraves da aplicaçăo de fórmulas empiricas. Processos diferentes de cálculo são utilizados e em cada um existem vários parămetros que interferem na determinaçăo das deformaçós. O objetivo de todos os processos de cálculo é apresentar, teoricamente, as deformaçóes que ocorrem na realidade, fornecendo valores próximos ou superiores. A verificação de qual processo de cálculo melhor se adapta e feita através de uma análise comparativa entre os valores obtidos teoricamente e os experimentais.

Entre os objetivos do trabalio encontra-se a elaboraçăo de texto dedicado a iniciantes no estudo das estruturas de concreto, abrangendo a deformabilidade por retração e por fluência, as caracteristicas mecânicas do concreto e dos aços para armadura e os fundamentos do cálculo, principalmente em serviço.

Tem-se também como objetivo uma analise comparativa entre resultados teoricos e experimentais, aproveitando resultados disponiveis no Laboratorio de Estruturas da Escola de Engenharia de São Carlos. Para vigas com carregamento crescente até a ruina, serão analisadas as diversas etapas do carregamento, considerando as deformaçzes no concreto e nas armaduras e as flechas obtidas.
\end{abstract}




\section{3 - ETAPAS DO TRABALHO}

A estrutura interna do concreto, os parâmetros considerados no calculo e os fatores que influem na retraçăo e na fluência, a expansão, as deformaçōes provocadas por forças externas e as deformaçöes termicas estão abordadas no estudo da deformabilidade do concreto, capitulo 2 .

No capitulo 3, trata-se do estudo das caracteristicas mecânicas do concreto: resistencia à compressão, resistência à traçăo, resistência no estado múltiplo de tensठ̃es e os fatores que influem na resistencia do concreto.

0 estudo dos aços, capitulo 4, trata, de maneira sucinta, desde os processos de fabricaça a á a classificação dos aços.

No capitulo 5, tem-se os fundamentos de calculo: estados limites, açaes, os metodos para verificação da segurança e os tipos de solicitaçóes.

0 estudo do método classico, analisando as tensores e as deformações no concreto e no aço quando solicitados por um carregamento externo, encontra-se no capitulo 6.

No capitulo 7 encontram-se: a descriça do ensaio realizado, os dados iniciais, o dimensiomamento do modelo, os cálculos dos momentos de ruina e de fissuração, das tensöes, das deformaçôes e das flechas, segundo a NBR 7197/89 e o CEB/90. Encontram-se tambem os valores, determinados teoricamente e experimentalmente, das deformaçớes $e$ dos deslocamentos com seus respectivos diagramas.

As análises dos resultados bem como as conclusöes estão dispostas no capitulo 8 . 


\section{2 - DEFORMABILIDADE DO CONCRETO}

0 concreto é constituido pela mistura de cimento, agregados graúdo e miúdo e agua. Durante a processo de amassamento, o cimento reage com a agua formando um gel de cimento, que envolve o agregado.

a concreto e um material de consistencia mais ou menos plastica, que permite fácil trabalhabilidade. Ao longo do tempo, o concreto endurece formando uma rocha artificial, que apresenta como principal caracteristica a resistencia à compressåo.

\section{1 - ESTRUTURA INTERNA DO CONCRETO}

A estrutura imterna exerce grande influencia nas propriedades do concreto, tal como na resistencia e na deformabilidade.

Atraves da figura 2.1 , e possivel observar os principais aspectos da estrutura interna do concreto. Esta estrutura e formada basicamente pelos agregados graúdo e miúdo, pela pasta de cimento com seus poros cheios de ar e pela rede capilar.

A água necessária para dar trabalhabilidade ao concreto e da orden do dobro da agua necessária para a hidrataçăo do cimento. Esta água pode ser decomposta em tres parcelas bem distintas: 
- áqua consumida nas reações químicas, chamada água não evaporável; esta sofre uma contraçăo de volume de cerca de $25 \%$ do seu volume inicial. Esta retraçăo provoca o aparecimento de poros cheios de ar com um volume de 7,5\% do volume total da pasta endurecida.
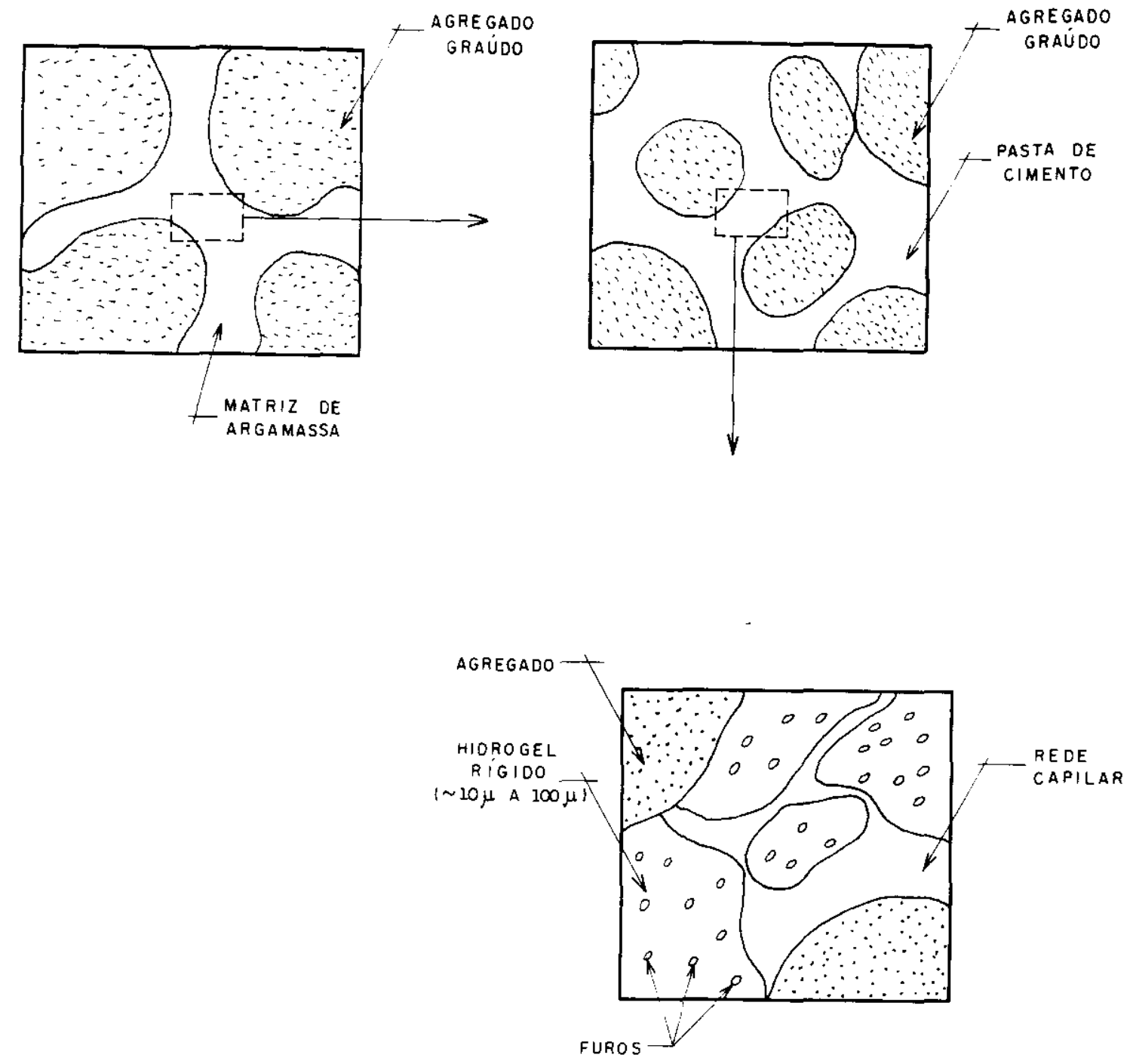

FIG. 2.1 - ESTRUTURA INTERNA DO CONGRETO 
- aqua adsorvida ao gel, chamada aqua evaporavel podendo ser removida em estufa a una temperatura de $105^{\mathrm{C}} \mathrm{C}$

- água capilar, que pode evaporar a temperatura ambiente, formando uma rede capilar; esta evaporação provoca forças capilares, equivalentes a uma compressăo isotrópica da massa de concreto, que vai aumentando à medida que os meniscos camintam para capilares de diâmetros menores (ver fig. 2.2).
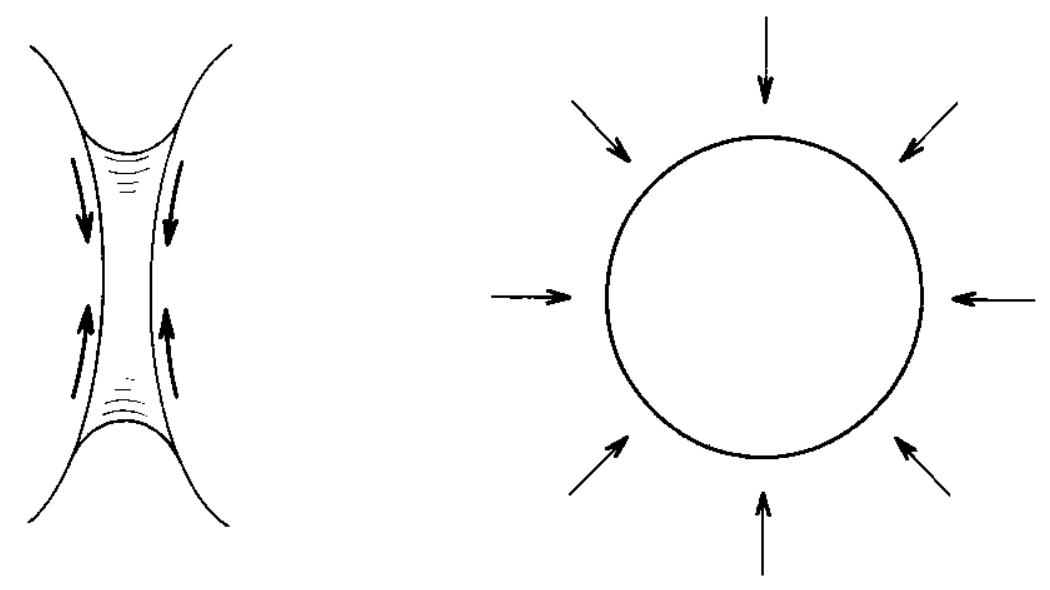

FIG. 2.2 - TENSAOO CAPILAR

Logo, a concreto é um material poroso constituido por uma parte solida, que engloba os cristais de gel e os agregados, por uma parte ilquida, constituida pela água capilar, e por uma parte gasosa, que é constituida pelo ar. 


\section{2 - RETRACTO E EXPANSAO}

A retração é uma redução espontânea de volume, que ocorre no concreto, na ausência de tensões externas e de variaçốs de temperatura. Ao fenômeno inverso denomina-se expansão.

A figura 2.3 mostra a variaçăo da retraçăo e da expansão com a idade. E possivel observar que a evoluçăo da retraçăo é mais acentuada no inicio, tendendo assintoticamente a um valor final. Quanto à expansăo, no inicio ocorre retraçăo até que as tensŏes causadas pelo fluxo de agua no sentido oposto superem as tenszes de retraçăo.

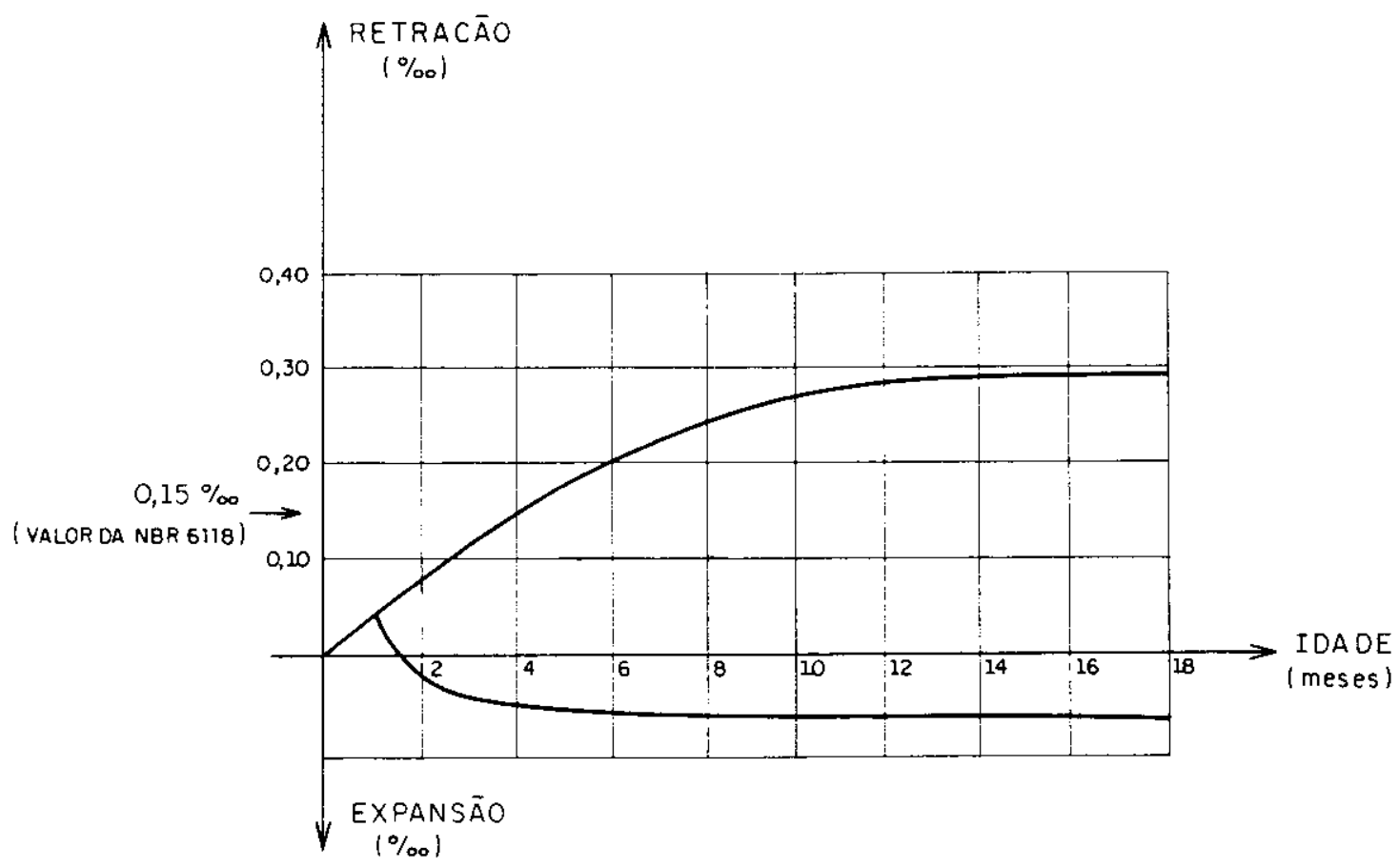

FIG. 2.3 - RETRAGĂO E EXPANSÄO DO CONCRETO 
Săo três as causas da retraçăo em peças de concreto armado curadas ao ar livre:

a) retração quimica - dumante o processo de endurecimento da pasta, a água não evaporável combina com - cimento provocando uma contração;

b) retração por tensões capilares - as tensões capilares são desenvolvidas quando ocorre evaporação parcial da água capilar; é a principal causa;

c) retração por carbonatação dos produtos decorrentes da hidrataçăo do cimento, que também es uma retraçăo química.

A NB-116 admite como hipoteses que a curva de retraçăo en função do tempo varia com a espessura ficticia da peça e que o valor final da retração depende da umidade relativa do ar, da consistencia do concreto e da espessura ficticia da peça.

\section{3 - DEFORMAÇESS PROVOCADAS POR FORCGAS EXTERNAS}

Deformaçóses provocadas pela presença de forças externas se apresentam sob duas formas. Uma, definida como deformaçăo imediata, $\varepsilon_{c i}$, ocorrendo no instante em que e aplicada a carga. A outra, definida como deformaçă lenta ou fluencia, $\varepsilon_{c c}$, ocorrendo quando a tensăo ao longo do tempo, $\sigma$, émantida constante.

A figura 2.4 , mostra o comportamento de uma peça de concreto comprimida submetida a uma tensáo constante a partir de um instante $t_{o}$, sendo:

to - instante de aplicação da carga;

$\varepsilon_{e i}$ - deformação imediata; ocorre acomodaçăo dos cristais que formam o material, provocando a deformaça 
cristais que formam o material, provocando a deformaçăo instantànea;

$\varepsilon_{c c}$ - fluência: com $\sigma_{c}$ constante e com o passar do tempo, ocorre diminuição dos capilares, provocando um aumento na tensão superficial que, por sua vez, aumenta a evaporação e, consequentemente, provoca a fluência do concreto;

$\varepsilon_{c c, \alpha}$ - fluência final;

$\varepsilon_{c t}$ - deformaçăo específica total:

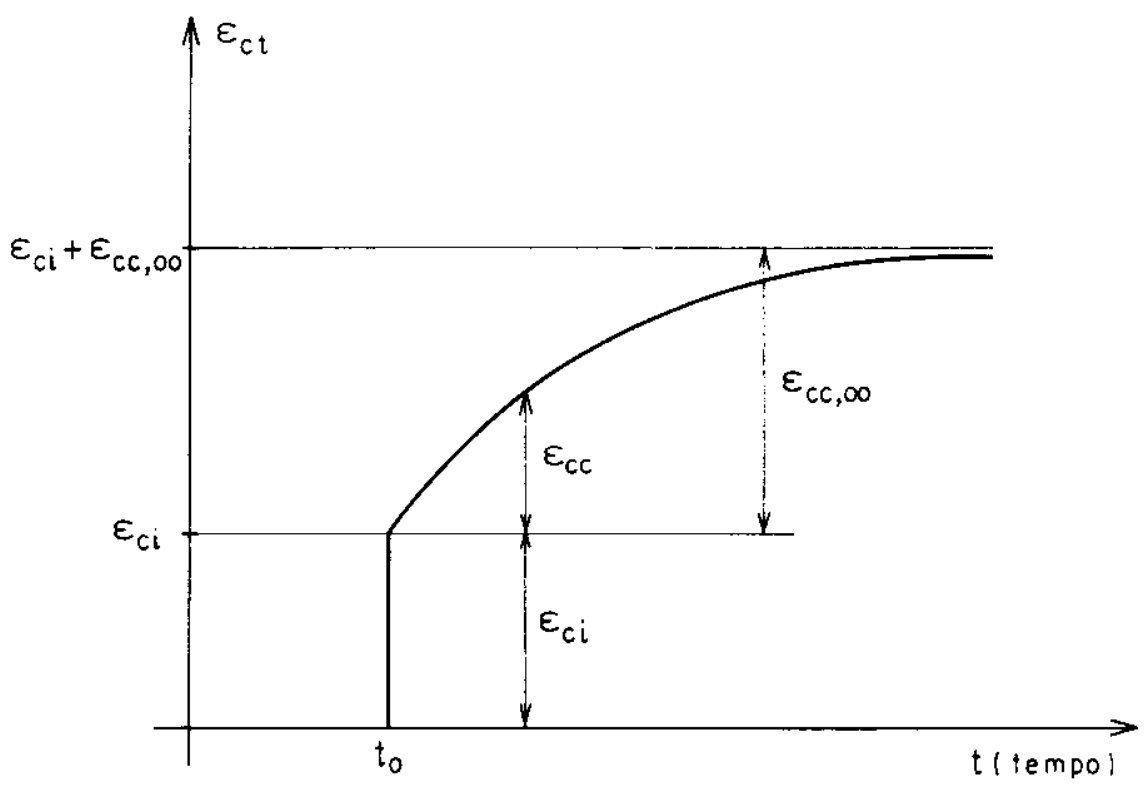

FIG. 2. - EVOLUÇ̃̃ DA DEFORMAÇÁ TOTAL COM O TEMPO 
Para açöes de longa duraçăo, deve ser considerado um outro fenomeno que édenominado relaxaçăo. A relaxaçăo é dada pela diminuição da tensão com o tempo, estando o material submetido a um estado de deformação constante. Este fenómeno aumenta com velocidade decrescente em função do tempo, tendendo a tensão residual para o valor $\gamma_{c, t=x}$, como mostra a figura 2.5 .

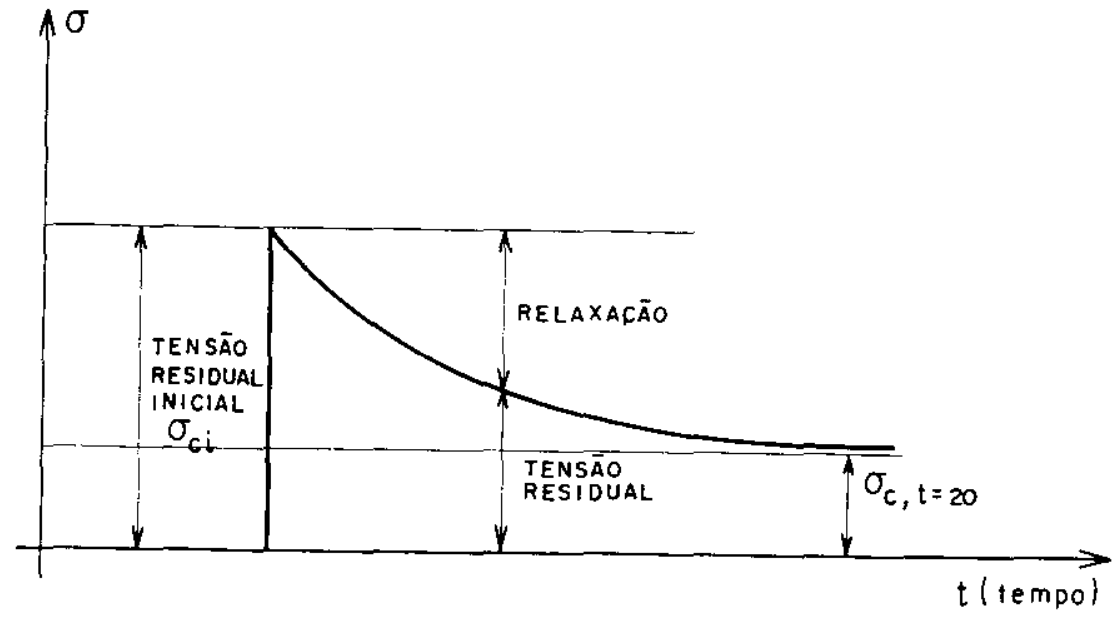

FIG. 2.5 - RELAXAÇĂO

A figura 2.6 ilustra o comportamento de uma pefa submetida a uma tensa constante, o, num intervalo de tempo (t, ti), sendo: 
$\varepsilon_{c e}{ }^{i t, t}{ }_{0}^{\prime}-$ deformação devida à fluência:

$\varepsilon_{\text {- }}$ - recuperação elástica instantanea:

$\varepsilon_{d}$ - deformação elástica recuperável;

$\varepsilon_{f}$ - deformação lenta permanente.

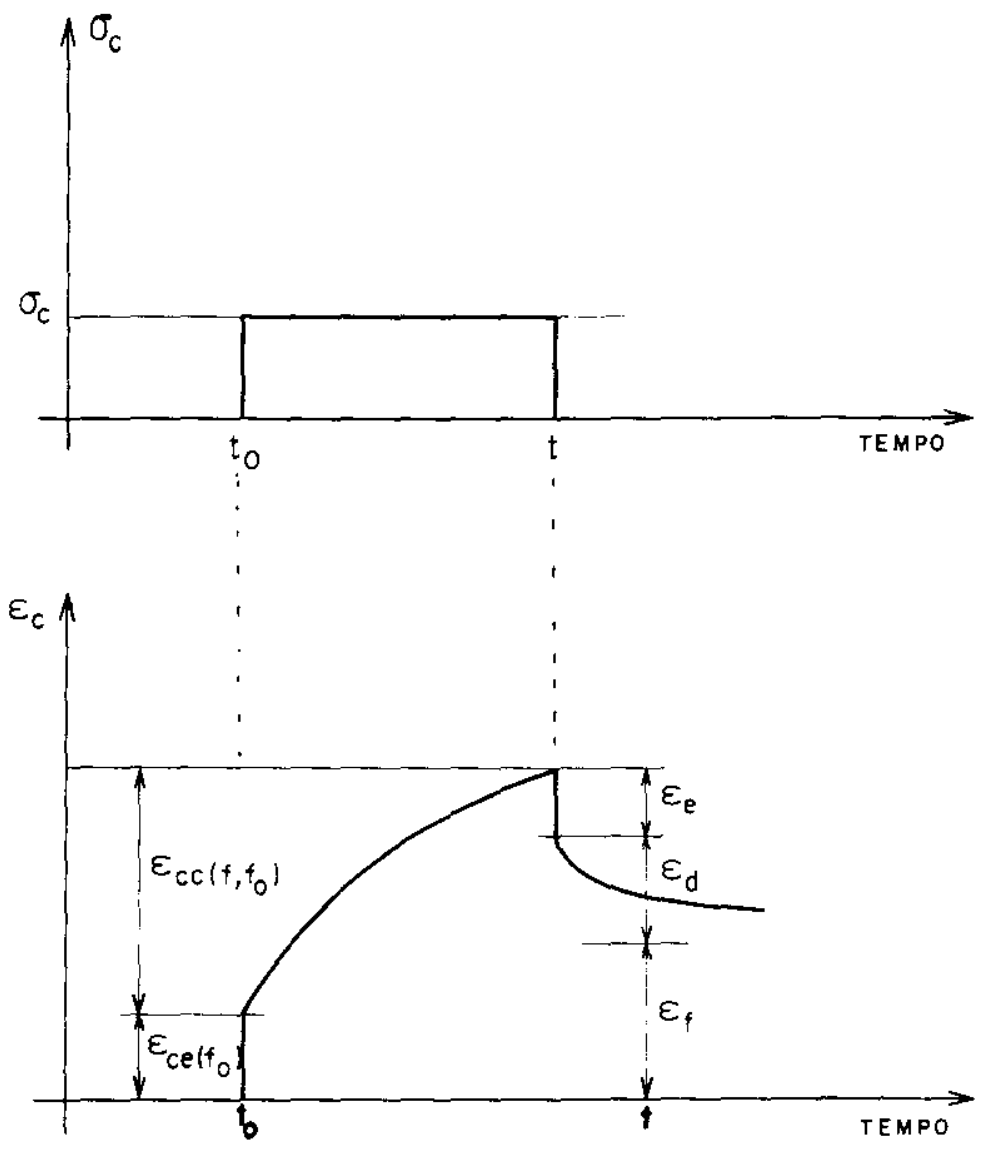

FIG. 2. O - DEFORMAĢOES RECUPERÁVEIS E DEFORMAÇOES RESIDUAIS

Tanto a deformaçăo elastica quanto a filiencia podem ser determinadas conforme item 2.9 . deste trabaiho. 


\section{4 - DEFORMACCES TERMICAS}

A variação da temperatura ambiente acarreta no concreto uma deformação especifica, dada por:

$$
\varepsilon_{c t}=\alpha \cdot \Delta T
$$

0 valor de $\alpha$, coeficiente de dilatação térnica, recomendado pela $\mathrm{NB}-1 / 78$ e $10^{-5}{ }^{\circ} \mathrm{C}^{-1}$ para 0 concreto armado.

De acordo com a NBR 6118: "Supơe-se, para o cálculo, que as variaçós de temperatura sejam uniformes na estrutura, salvo quando a desigualdade dessas variaçóes, entre partes diferentes da estrutura seja acentuada. Nă e necessaria a consideraçăo da variaçăo de temperatura em peças permanentemente envolvidas por terra ou água e em edificios interrompidos por juntas de dilatação a cada 3om, no máximo. Para peças maciças ou ocas, com os espaços vazios inteiramente fechados (seçăo caixăo), cuja menor dimensão seja inferior a $50 \mathrm{~cm}, \Delta T$ varia entre $\left( \pm 10^{\circ} \mathrm{C}\right)$ e $\left( \pm 15^{\circ} \mathrm{C}\right)$. Guando a menor dimensao for superior a $70 \mathrm{~cm}, \Delta T$ varia entre $\left({ }^{+} 5^{\circ} \mathrm{C}\right)$ e $\left( \pm 10^{\circ} \mathrm{C}\right)$. Quando a menor dimensăo estiver compreendida entre 50 e $70 c m$, faz-se interpolação linear entre os valores recomendados anteriormente."

\section{5 - FATORES QUE INFLUEM NA RETRAÇXO E NA FLUENCIA}

Os principais fatores que influem na retraçăo e na fluência eståo enumerados a seguir:

- a quantidade de cimento empregada no concreto 
esta diretamente ligada ao aumento da retraçăo. Isto se deve, fundamentalmente, a retraçăo quimica;

- os cimentos de endurecimento rápido e os de alta resistencia têm como consequência o aumento da retraçăo;

- o aumento na relação agua/cimento resulta no aumento de capilares e, consequentemente, aumento na retração;

- quanto maior a finura dos grãos, maior será a quantidade de água necessária para dar trabalhabilidade ao concreto e mais finos serão os capilares. Isto resulta no aumento da tensăo superficial, que proporcionara aumento na retraça;

- quanto maior a umidade do ar, menor será a retraç̃̃ ;

- a retração diminui com a diminuição da superficie especifica em contato com o ambiente;

- o aumento da temperatura favorece a evaporação, aumentando a retração;

- a retraçăo varia inversamente com a idade do concreto;

- a armadura é uma das soluçōes empregadas no controle da retraçăo.

\section{6 - PARAMETROS CONSIDERADOS NO CALCULO}

A retração pode ser calculada se forem conhecidos os parâmetros: idade ficticia do concreto, espessura ficticia e abatimento.

a) Idade ficticia

A temperatura influi na maturidade do concreto para 
temperaturas diferentes de $20^{\circ} \mathrm{C}$, que é tomada como padrão.

De acordo com o CEB-90, item 2.1.8.2, a idade ficticia pode ser calculada através da expressão:

$$
t_{T}=\Sigma \Delta T_{i} \exp -\left(\frac{4000}{273+T\left(\Delta T_{i}\right)}-13,63\right)
$$

sendo:

$$
\begin{aligned}
& T\left(\Delta T_{i}\right) \text { - temperatura }\left({ }^{\circ} \mathrm{C}\right) \text { durante o periodo } \Delta T_{i} ; \\
& \Delta T_{i} \text { - número de dias com dada temperatura } T .
\end{aligned}
$$

Segundo O CEB-9O, a idade também influencia na resistencia à compressão, item 2.1 .6 .1 , e no módulo de elasticidade, item 2.1.6.3.

\section{b) Espessura ficticia}

De acordo com o item 2.1.6.4 do CEB-90, a espessura ficticia pode ser determinada atraves da expressão:

$$
H_{0}=\frac{2 A c}{u}
$$

sendo:

$$
\begin{aligned}
& A_{c} \text { - area da secão transversal de concreto; } \\
& u^{-} \text {- perimetro da seçăo em contato com o ambiente. }
\end{aligned}
$$

\section{c) Abatimento}

A consistencia do concreto e um parâmetro que considera vários fatores que interferem na retraçăo. Segundo a NBR 7223 - Determinaça da consistencia do concreto - e possivel determinar a plasticidade $e$ a coesão do concreto através do ensaio de abatimento do 
tronco de cone. Os principais fatores considerados pelo abatimento săo: teor de água/mistura seca, granulometria e forma do grão do agregado, tempo e temperatura.

\section{6 - MODULO DE ELASTICIDADE}

A natureza dos agregados, o traço do concreto, o fator aqua/cimento e a idade săo fatores que influem no módulo de elasticidade.

- diagrama tensăo-deformação para qualquer tipo de concreto e, geralmente, de forma curva, não apresentando um limite de proporcionalidade bem definido como no caso do aço classe A, conforme mostra a figura 2.7 .

A partir deste diagrama, pode-se definir o módulo de elasticidade na origem, $E_{0}$, e modulo de elasticidade secante, $E_{c}$. O primeiro e definido como sendo a derivada da funçăo tensăo-deformação na origem, dado por:

$E_{0}=t g \phi_{0}=\left.\frac{d a_{c}}{d \varepsilon}\right|_{\varepsilon=0}$

o segundo, definido num ponto genérico M considerado, e dado por:

$$
E_{c}=\operatorname{tg} \phi_{s}=\left.\frac{\sigma_{c}}{\varepsilon}\right|_{\varepsilon=\varepsilon_{m}}
$$




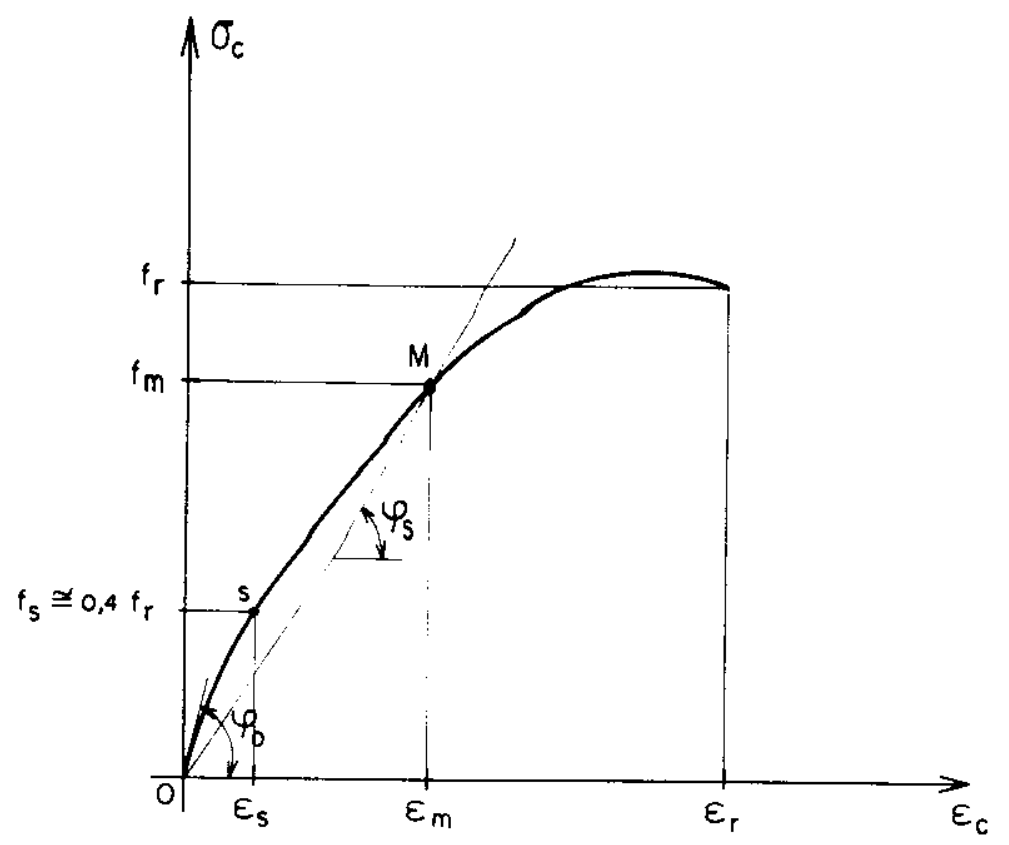

FIG. 2. ? - DIAGRAMA TENSĂO-DEFORMAÇĂO DO CONCRETO

O valor na origem do módulo de elasticidade tangente do concreto é de grande importancia, pois os coeficientes de segurança que săo aplicados fazem com que, em serviço, - concreto trabalhe com uma tensăo o inferior a $40 \%$ da tensăo de ruptura. Nesta faixa de trabalino, trecho os da figura 2.7, $\square$ modulo de elasticidade sofre pouca variaçăo. Portanto, o modulo de elasticidade ao longo do trectio os é pouco menor do que o na origem.

A NB-1/78 recomenda que, no calculo de deformaçóes para cargas em servico, deve-se considerar, para o concreto. o seu modulo de elasticidade secante. 
adotando-se, para ele, $90 \%$ do valor do módulo tangente na origem.

A partir de varios ensaios realizados, o valor do módulo de elasticidade tangente na origem pode ser determinado, considerando a resistencia média à compressão.

a) Segundo a $N B-1 / 78$

$E_{0}=6600\left(f_{c j}\right)^{1 / 2} \quad(M P a)$
$E_{c}=0,9 E_{0}$
$f_{c j}=f_{c k}+3,5 \mathrm{MPa}$
$f_{c j}-$ resistência média aos jdias de idade

b) Segundo o CEB-90

$E_{0, j}=a_{e}\left(f_{c j} / 10\right)^{1 / 3}(M P a)$

$f_{c j}=f_{c k}+8 \mathrm{MPa}$

$E_{s}=0,85 E_{0, j}$

$a_{e}=21500 \mathrm{MPa}$

2. 8 - COEFICIENTE DE POISSON

0 coeficiente de Poisson é definido como sendo a relação entre a deformação transversal e a deformação longitudinal e e representado pela letra 
0 coeficiente de deformaçăo transversal, coeficiente de Poisson, varia, com a resistencia à compressăo do concreto, de 0,15 a 0,25 . A NB-1/78 recomenda a adoção de 0,20 .

\section{9 - ESTUDO COMPARATIYO DO CALCULO DA RETRACAOO E DA FLUENCI A}

A seguir apresenta-se uma análise da proposta apresentada no texto base da NB-1/93 em elaboraçăo, para - cálculo da retração e da fluencia do concreto.

Um exemplo foi preparado $e$ os resultados foram comparados com aqueles relativos a Norma Europeia EUROCODE 2, ao Código Modelo CEB-90 e a Norma Brasileira NBR-7197.

\subsection{1 - INTRODUÇAOO}

A mistura en proporção adequada de cimento, agregados e agua dá origem, após endurecimento, ao concreto simples. Para permitir a necessaria trabalhabilidade, tanto durante a propria mistura quanto durante o transporte $a$ o lançamento nas fôrmas, a quantidade de agua necessária é maior que aquela consumida nas reaços químicas de hidrataçăo do cimento. A agua excedente faz com que o concreto resulte em un material poroso.

Verifica-se que ao longo do tempo, mesmo na ausência de açöes externas, o concreto apresenta diminuicão de volume. Este fenomeno e denominado retracão. 
Uma parte da retraçăo é decorrente do fato das reações de hidrataçăo do cimento ocorrerem com diminuição de volume, parcela esta que se denomina retraçăo química. Componentes secundarios do cimento, como por exemplo o hidróxido de cálcio, podem reagir com o gás carbônico resultando carbonatos. Essas reaçōes tambem ocorrem com reduçăo de volume e constituem a retraçăo por carbonatação. Esta parcela da retraçăo é de importância secundaria e pode, inclusive, ser considerada como fazendo parte da retração química. Pela sua natureza, a retraçăo química se restringe basicamente ao período de cura do concreto.

Dutra parcela da retraçăo, que e a principal, decorre das tensbes superficiais da áqua com as paredes dos poros capilares. Dependendo do equilibrio higrometrico com o meio ambiente, parte desta água capilar caminha para fora da massa de concreto, processo no qual se manifestam tenszes superficiais, que atuam em todas as direçós e provocam uma diminuiçăo do volume da peça. Essa parcela é denominada retraça por tensão superficial ou retraçăo capilar. Em peças submersas, o fluxo de agua de fora para dentro da peça, em direção aos poros decorrentes da retraçăo quimica, pode fazer com que ocorra expansão.

Ao ser solicitado por tenszes de compressão, o concreto apresenta uma deformação elástica instantânea, denominada deformaço imediata, decorrente basicamente da acomodaça dos cristais que constituem a parte sólida do concreto.

Verifica-se que, se as tenszes de compressão permanecerem, as deformaçäes aumentam mesmo sem acrescimo das tenszes. Essa deformaçăo, que se desenvolve ao longo do tempo, recebe o nome de fluência e tambén é causada por tenszes capilares, as quais são ampliadas pela atuação da força externa. A acomodação dos cristais diminui o diâmetro dos capilares e comprime a aqua capilar. Quanto menor o diametro do capilar, maior e a 
tensăo superficial. A pressão na agua capilar força seu fluxo para fora da peça, intensificando tambem as tenszes sapilares.

\subsection{2 - FATORES QUE INFLUEM NA DEFORMABILIDADE}

Os fatores que influem na deformabilidade do concreto podem ser classificados conforme: as caracteristicas dos materiais utilizados, D amadurecimento do concreto e o equilíbrio higrométrico com o meio ambiente.

\section{a) Caracteristicas dos Materiais}

0 tipo e a quantidade de cimento influem principalmente na retraçăo química. Os cimentos de endurecimento rápido e os de alta resistencia inicial produzem maior retração. Maior quantidade de cimento acarreta maior deformabilidade.

Maior relação água-cimento aumenta a porosidade e, consequentemente, aumenta a deformabilidade decorrente de tensöes capilares.

A granulometria do cimento e dos agregados influi na porosidade e na escolita da relaçăo água-cimento. A distribuiçăo granulometrica deve ser adequada para evitar porosidade. Excesso de grãos finos corresponden a maior superficie especifica dos agregados, exigindo mais água para dar a adequada trabalhabilidade; os capilares resultam mais finos e mais numerosos. Portanto, a granulometria influi principalmente na retraçăo capilar. 


\section{b) Amadureci mento}

O amadurecimento e influenciado pelo tipo de cimento, pela idade e pela temperatura da peça.

A resistencia aumenta com a idade, o que faz com que a deformabilidade diminua.

A temperatura da peça acelera o amadurecimento do concreto. Portanto, uma peça submetida a uma temperatura maior apresentará menores deformaçठes por retração e por fluencia. As deformaçöes termicas são consideradas de forma independente e năo serăo analisadas neste trabalho.

\section{c) Equilibrio Higrometrico}

\footnotetext{
A deformabilidade é também muito influenciada pela superficie especifica em contato com $\square$ meio ambiente, através da qual é feita a troca de umidade. Se essa superficie for grande, certamente havera grandes deformaçaes decorrentes das tensaes capilares.

Se nouver equilibrio higrometrico, so havera retraça quimica, diminuindo portanto a deformabilidade do concreto.
}

2.9.3 - PARAMETROS PARA CALCULO

- cálculo das deformaçôes no concreto depende, entre outros, dos seguintes fatores: resistencia à compressăo, espessura equivalente, idade ficticia do concreto, tipo de cimento e módulo de elasticidade. 


\section{a) Resistência à compressão}

A resistência à compressão e considerada atraves da resistência media aos 28 dias, em MPa, dada pela expresร สัo:

$$
f_{c m}=f_{c k}+7 \mathrm{MPa}
$$

\section{b) Espessura equivalente}

A espessura equivalente $h_{0}$ é um parămetro de calculo definido pela expressão $(2.2)$.

\section{c) Idade ficticia}

A temperatura influi no amadurecimento do concreto, sendo a idade ficticia obtida através da expressão (2.1).

\section{d) Influesncia do tipo de cimento no valor da fluência}

No calculo da fluencia, o tipo de cimento é considerado corrigindo a idade do concreto no instante do carregamento $t_{o}$, atraves da expressão

$t_{\text {of }}=t_{\text {oT }}\left[\frac{9}{2+\left[t_{\text {oT }}\right]^{0,5}}+1\right]^{\alpha} \geq 0,50$ ias

onde:

$t_{\text {ot }}$ - obtido pela equaçăo (2.1); 


$$
\alpha= \begin{cases}-1 & \text { CIMENTO DE ENDURECIMENTO LENTO } \\ & \text { (AF, POZ, MRS, ARS) } \\ 0 & \text { CIMENTO PORTLAND COMUM (CP) } \\ 1 & \text { CIMENTO DE ALTA RESISTENCIA INICIAL (ARI) }\end{cases}
$$

e) Módulo de elasticidade

O módulo de elasticidade do concreto aos 28 dias, em MPa, ed dado por:

$$
E_{C}(2 B)=\left(f_{c m}\right)^{1 / 3} \cdot 10^{4}
$$

sendo $f_{\mathrm{cm}}$ dado pela expressão (2.11).

\section{9. 4- CALCULO DA RETRAÇXo}

A retração do concreto $\varepsilon_{c s}$, entre os instantes $t_{s} e t$, e calculada pela expressão:

$$
\varepsilon_{c s}\left(t, t_{s}\right)=\varepsilon_{c s o} \cdot \beta_{s}\left(t, t_{s}\right)
$$

sendo:

$t$ - idade real no instante em que se calculam as deformaçชes;

$t_{s}$ - idade real no instante a partir do qual a retraçă começa a se desenvolver;

$\varepsilon_{\text {cso }}$ - valor de referencia da retração; 
$\beta_{s}\left(t, t_{s}\right)$ - mede o desenvolvimento da retração com 0 tempo.

a) Valor de referência da retração

0 valor $\varepsilon_{\text {cso }}$ depende da resistencia do concreto, do tipo de cimento e da umidade relativa, sendo dado por:

$\varepsilon_{\mathrm{CSO}}=\left[160+\beta_{\mathrm{SC}}\left(90-\mathrm{f}_{\mathrm{cm}}\right)\right] \cdot 10^{-6} \cdot \beta_{\mathrm{UR}}$

onde:

$\beta_{S C}= \begin{cases}4 & \text { CIMENTO DE ENDURECIMENTO LENTO } \\ 5 \text { CAF, POZ, MRS, ARS) } \\ \text { GIMENTO PORTLAND GOMUM (CP) } \\ \text { CIMENTO DE ALTA RESISTENCIA INICIAL (ART) }\end{cases}$

$\beta_{U R}=\left\{\begin{array}{lc}-1,55\left[1-[\mathrm{UR} / 100]^{3}\right] & \text { UO\% } \leq \mathrm{UR}<0 \% \% \\ +0,25 & \mathrm{UR} \geq 00 \%\end{array}\right.$

Nos valores de $\beta_{u R}$, o sinal megativo corresponde a diminuição de volume, enquanto que o simal positivo é relativo à expansão da peça.

b) Desenvol vimento da retraçao com o tempo

o desenvolvimento da retraçăo depende do intervalo de tempo e da espessura equivalente, sendo dado pela expresรสัด: 


$$
\beta_{s}\left(t, t_{s}\right)=\left[\frac{t-t_{s}}{3,5 \cdot h_{0}^{2}+t-t_{s}}\right]^{0,5}
$$

na qual:

$h_{0}$ - dado pela equaçăo (2.2);

$\left(t-t_{s}\right)$ - $e$ a duração real da retração en dias, não corrigida.

\subsection{5 - DEFORMAÇAO IMEDIATA}

Ao ser submetido em um instante $t_{0} a$ uma tensão $\sigma_{c}\left(t_{o}\right)$, o concreto sofre uma deformação imediata, dada por:

$$
\varepsilon_{c i}=\frac{\sigma_{c}\left(t_{o}\right)}{E_{c}\left(t_{o}\right)}
$$

- módulo de elasticidade do concreto no instante to depende do correspondente módulo aos 28 dias, do tipo de cimento e da idade ficticia do concreto ajustada por temperatura $t_{\text {ox }}$. Seu valor é dado por:

$$
E_{c(t)}=E_{c}(28) \cdot\left\{\exp \left[s \cdot\left(1-\left(\frac{28}{t_{o T}}\right)^{0,5}\right]\right\}^{1 / 2}\right.
$$

sendo: 


$$
5= \begin{cases}0,39 & \begin{array}{l}
\text { CIMENTO DE ENDURECIMENTO LENTO } \\
\text { AF, POZ, MRS, ARS ) }
\end{array} \\
0,25 & \text { CIMENTO PORTLAND COMUM (CP) } \\
0,20 & \text { CIMENTO DE ALTA RESISTENCIA INICIAL (ARI); }\end{cases}
$$

\subsection{6- VALOR DA FLUENCIA}

Se a tensão $o\left(t_{0}\right)$ aplicada no instante $t_{0}$ permanecer, a deformaçăo imediata e a retraçăo deverá ser adicionada a parcela relativa a fluencia do concreto, dada por:

$$
\varepsilon_{c c}\left(t, t_{0}\right)=\frac{\varepsilon_{c}\left(t_{0}\right)}{E_{c}(28)} \cdot \phi\left(t, t_{0}\right)
$$

sendo, $\phi\left(t, t_{0}\right)$ a coeficiente de fluencia en $t$ para o carregamento aplicado em $t_{0}$.

o coeficiente de fluência é dado por:

$$
\phi\left(t, t_{0}\right)=\phi_{0} \cdot \beta_{c}\left(t, t_{0}\right)
$$

onde:

$$
\phi_{0} \text { - o valor de referencia do coeficiente de }
$$
fluência na idade $t_{0}$;

- tempo.

$$
\beta_{c}\left(t, t_{0}\right) \text { - mede o desenvolvimento da fluéncia com }
$$


a) Valor de referéncia do coeficiente de fluência

- valor de $\phi_{0}$ depende da umidade relativa, da espessura equivalente, da resistência do concreto, do instante de aplicaçăo do carregamento e do tipo de cimento, sendo dado pela expressão:

$$
\begin{aligned}
& \phi_{0}=\left[1+\frac{\left(1-\frac{U R}{100}\right)}{0,215\left(h_{0}\right)^{1 / 3}}\right] \cdot \frac{16,8}{\left(f_{c m}\right)^{0,5}} \cdot \frac{1}{0,1+\left(t_{\text {of }}\right)^{0,2}} \\
& \text { UR - umidade relativa em } \%
\end{aligned}
$$

b) Desenvol vimento da fluencia

- desenvolvimento da fluencia depende do intervalo de tempo, da umidade relativa e da espessura equivalente, sendo estes dois últimos aspectos considerados atraves de :

$$
\begin{aligned}
& \beta_{H}=15 \cdot\left[1+\left(1,2 \cdot \frac{U R}{100}\right)^{18}\right] \cdot h_{0}+250 \leq 1500 \\
& \text { A evolução da fluência é dada por: } \\
& \beta_{c}\left(t, t_{0}\right)=\left(\frac{t-t_{0}}{\beta_{H}+t-t_{0}}\right)^{0,3}
\end{aligned}
$$




\subsection{7 - DADOS DO EXEMPLO}

Considera-se uma peça de concreto armado com seção transversal $20 \mathrm{~cm} \times 60 \mathrm{~cm}$, cimento CP normal, concreto Classe C25, abatimento de 3 a $5 \mathrm{~cm}$, exposta a uma temperatura media de $20^{\circ} \mathrm{C}$ e umidade relativa de $70 \%$.

Com as recomendaçŏes do texto base da NB-1 (1993), EUROCODE 2 (1989), CEB (1990) e NBR-7197 (1989), foram calculadas as deformaçóes indicadas na tabela 2.1 .

\section{a) Retração}

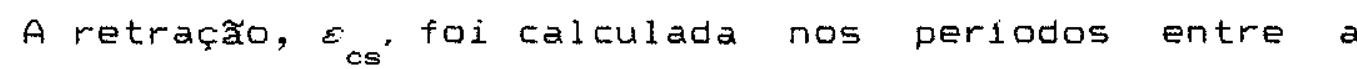
concretagem e as seguintes idades:

$t=3,7,28,90,365 \in \infty$

b) Deformação imediata

A deformaçăo imediata, $\varepsilon_{i}$, foi calculada para $\sigma_{c}=$ $12,8 \mathrm{MPa}$, aplicada nos instantes:

$t=7,28,90$ e 365

c) Fi uência

Admitindo que a tensão indicada no item anterior foi mantida constante, foi calculada a fluência, $\varepsilon_{c c}$ para as seguintes idades:

$$
t=365 \text { e } \infty
$$


TABELA 2.1 - ANÁLISE DAS DEFORMAÇOES (mm/m\}

\begin{tabular}{|c|c|c|c|c|c|c|}
\hline$\varepsilon$ & \multicolumn{2}{|c|}{$\begin{array}{l}\text { tou to } \\
\text { (dias) }\end{array}$} & $N B-1 / 93$ & $E C$ & CEB $/ 90$ & $\begin{array}{l}\text { NER } \\
7198\end{array}$ \\
\hline \multirow{6}{*}{$\varepsilon_{c s}$} & \multicolumn{2}{|l|}{3} & 0,0279 & 0,0279 & 0,0279 & 0,0114 \\
\hline & \multicolumn{2}{|l|}{7} & 0,0430 & 0,0425 & 0,0475 & 0,0199 \\
\hline & \multicolumn{2}{|l|}{28} & 0,0849 & 0,0839 & 0,0839 & 0,0511 \\
\hline & \multicolumn{2}{|l|}{90} & 0,1467 & 0,1450 & 0,1450 & 0,1022 \\
\hline & \multicolumn{2}{|l|}{365} & 0,2577 & 0,2550 & 0,2550 & 0,1818 \\
\hline & \multicolumn{2}{|l|}{$\infty$} & 0,4580 & 0,4530 & 0,4530 & 0,2840 \\
\hline \multirow{4}{*}{$\varepsilon_{i}$} & \multicolumn{2}{|l|}{7} & 0,4570 & 0,4760 & 0,4530 & - \\
\hline & \multicolumn{2}{|l|}{28} & 0,4030 & 0,4200 & 0,4000 & 0,4040 \\
\hline & \multicolumn{2}{|l|}{90} & 0,3810 & 0,3970 & 0,3780 & - \\
\hline & \multicolumn{2}{|l|}{365} & 0,3680 & 0,3840 & 0,3650 & - \\
\hline \multirow{7}{*}{$\varepsilon_{c c}$} & \multirow{3}{*}{$t=305$} & 7 & 0,9200 & 0,7510 & 0,6830 & 0,9970 \\
\hline & & 28 & 0,7010 & 0,5720 & 0,6830 & 0,7110 \\
\hline & & 90 & 0,5400 & 0,4410 & 0,4010 & 0,4260 \\
\hline & \multirow{4}{*}{$t=\infty$} & 7 & 1,1900 & 0,9710 & 0,8840 & 1,3470 \\
\hline & & 28 & 0,9160 & 0,7470 & 0,6800 & 1,0610 \\
\hline & & 90 & 0,7330 & 0,5980 & 0,5440 & 0,7800 \\
\hline & & 365 & 0,5590 & 0,4560 & 0,4150 & 0,5120 \\
\hline
\end{tabular}

2.9.8 - ANALISE DOS RESULtADOS

Para a retraçăo, nota-se que os resultados da NBR-1/93 săo muito próximos dos obtidos com a CEB e com o Eurocode. Porem, diferem muito das relativos à NBR-7197. Para a deformação imediata, os resultados das quatro normas são muito próximos.

Com relaçăo à fluência, os valores obtidos com a NB-1/93 são maiores que os do Eurocode (23\%) e os do CEB (35\%). Quando comparados com os resultados da NBR-7197, ficam ora abaixo ora acima, dependendo das idades em que se aplica a carga e em que se considera a fluência. 


\section{3 - CARACTERISTICAS MECANI CAS DO CONCRETO}

\section{1 - GENERALIDADES}

A resistencia, as condiçases de aderencia e a impermeabilidade săo algumas das caracteristicas mecanicas do concreto simples, sendo a resistência a mais importante. Entre outros fatores, esta resistência b influenciada pela qualidade e granulometria dos agregados, pelo tipo e quantidade de cimento e pela relação aqua/cimento e é medida atraves de ensaios em corpos-de-prova padronizados. Estes ensaios dependem fundamentalmente dos fatores: forma $e$ dimensăes dos corpos-de-prova e duração da solicitaçăo. A idade do concreto e também um fator muito importante, que influi no valor da resistência.

De acordo com a NBR 5738 - Confeção e cura de corpos-de-prova de concreto cilindricos ou prismaticos, são padronizados a moldagem e o preparo para o ensaio. A NBR 5739 - Ensaio de compressão de corpos-de-prova cilindricos de concreto - Metodo de ensaio, normaliza o ensaio.

Us corpos-de-prova com forma e dimensöes padronizadas têm como objetivo reproduzir, em laboratorio, as condiçớs de funcionamento real da estrutura. Assim, as normas brasileiras, bem como a maioria das normas internacionais, recomendam peças cilindricas, com $15 \mathrm{~cm}$ de 
diâmetro e 30cm de altura. Em alguns paises, são utilizadas peças cúbicas, com $20 \mathrm{~cm}$ de aresta, para as quais os resultados obtidos săo superiores aos relativos às peças cilindricas.

Como não é possivel considerar, em ensaios, todos os aspectos que influem no concreto, a determinaçăo da resistencia se faz através de ensaios de carga rápida e os demais fatores são considerados atraves de outros procedimentos.

\section{2 - RESISTENCIA A COMPRESSAO}

\footnotetext{
A resistência à compressăo $\&$ a principal caracteristica mecánica do concreto e é determinada atraves de ensaios de curta duraça en corpos-de-prova com idade, normalmente, de 28 dias.

A determinação numerica da resistência caracteristica do concreto decorre de um tratamento estatistico dos resultados, em um número suficiente de corpos-de-prova, que obedecem a uma curva de distribuiçăo de frequencias denominada curva de Gauss.

Esta resistencia caracteristica, $f_{c k}$ definida como - valor que corresponde a $95 \%$ de probabilidade de ocorrencia, ou seja, 5\% de probabilidade de não ser atingido (fig. 3.1 ).
}

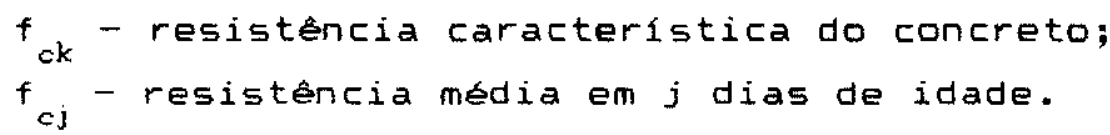

Dos valores estastiticos relativos curva de Gauss, ten-se: 


$$
\begin{aligned}
& f_{c k}=f_{c j}-1,6455 \\
& f_{c j}=\frac{1}{n} \sum_{i}^{n} f_{c j, i} \\
& 5=\left[\frac{\sum_{1}^{n}\left(f_{c j, i}-f_{c j}\right.}{n-1}\right]^{1 / 2}
\end{aligned}
$$

Nestas expressðes:

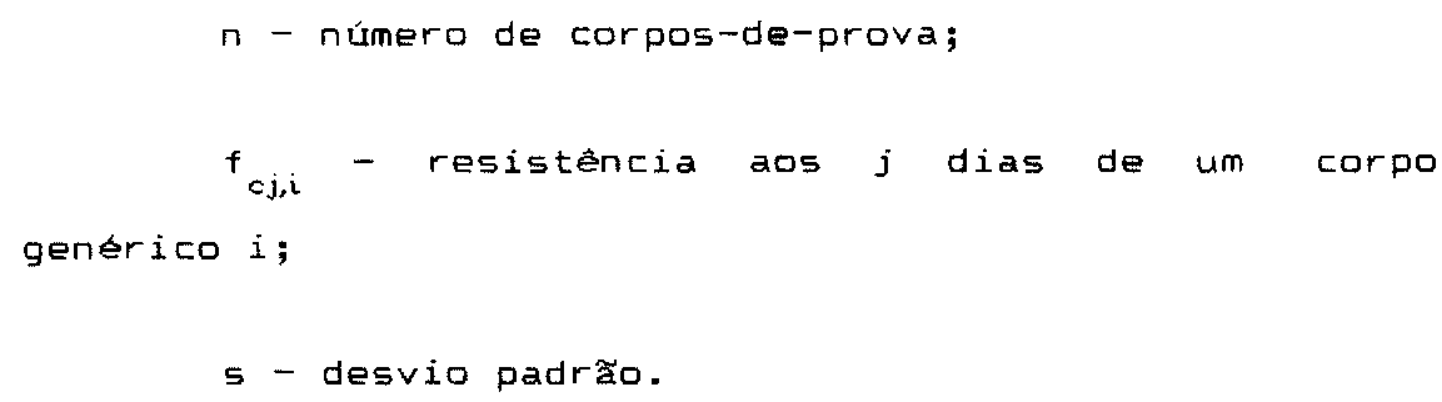

Segundo o item 5.2 da norma citada, os concretos destinados a outros fins, cuja resistencia caracteristica seja definida por um quantil diferente de $5 \%$ ou idade diferente de 28 dias, devem ser identificados pela letra $B$, seguida da resistência em MPa. Portanto, E necessário especificar o quantil e a idade do concreto.

0 controle da resistencia, segundo a NBR 6118 , pode ser feito de dois modos: controle sistemáticoe controle assistemático.

o controle sistematico e recomendavel sempre que for adotado concreto com classe acima de $\mathrm{C} 16$ ou se o coeficiente de ponderaçăo da resistencia do concreto, $\gamma_{c}$, 
for menor que 1,4. Em caso contrário, pode ser usado controle assistemático.

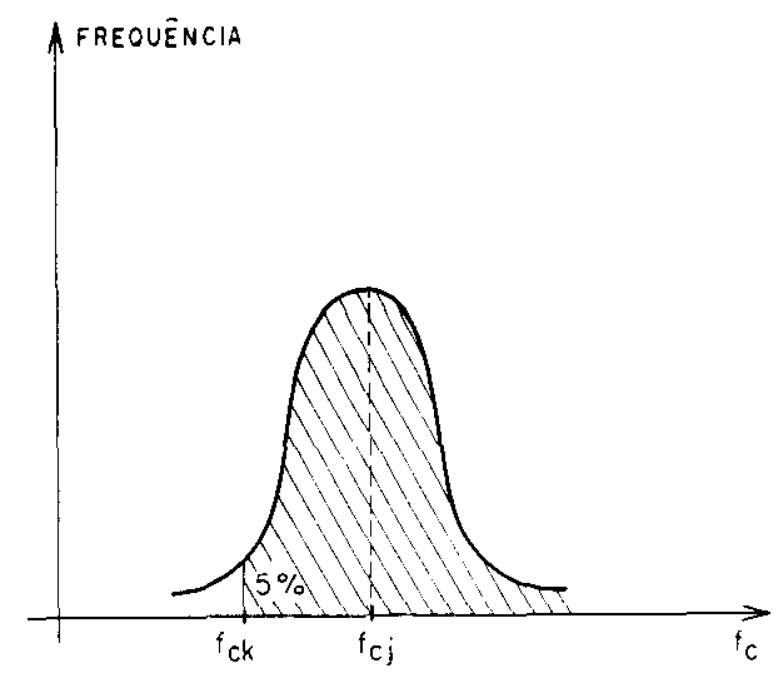

FIG. 3. 1 - CURVA DE DISTRIBUIÇẮ NORMAL

\section{3 - RESISTENCIA A TRACAO}

Săo varios os fatores que influem na resistencia à traçăo. o principal é a aderência entre os grăos dos agregados e a argamassa de cimento.

A resistencia caracteristica do concreto a traçăo, $f_{i, k}$ e o valor que tem $5 \%$ de probabilidade de năo ser atingido pelos elementos de um lote. Esta resistencia pode ser verificada por meio de tres metodos diferentes: traçăo axial, traça por fendilhamento icompressăo diametrall e tracăo na flexulo. 


\section{a) Tração axial}

A determinação da resistência consiste na aplicação de tensŏes de tração axiais e uniformemente distribuidas em corpos-de-prova de concreto simples, com dimensbes conforme mostra a figura 3.2, atraves de placas de aço.

Com a descoberta de resinas de alta aderencia, e possivel fazer a colagem das placas de aço nas extremidades do corpo-de-prova, permitindo a realização dos ensaios sem influências pertubadoras.

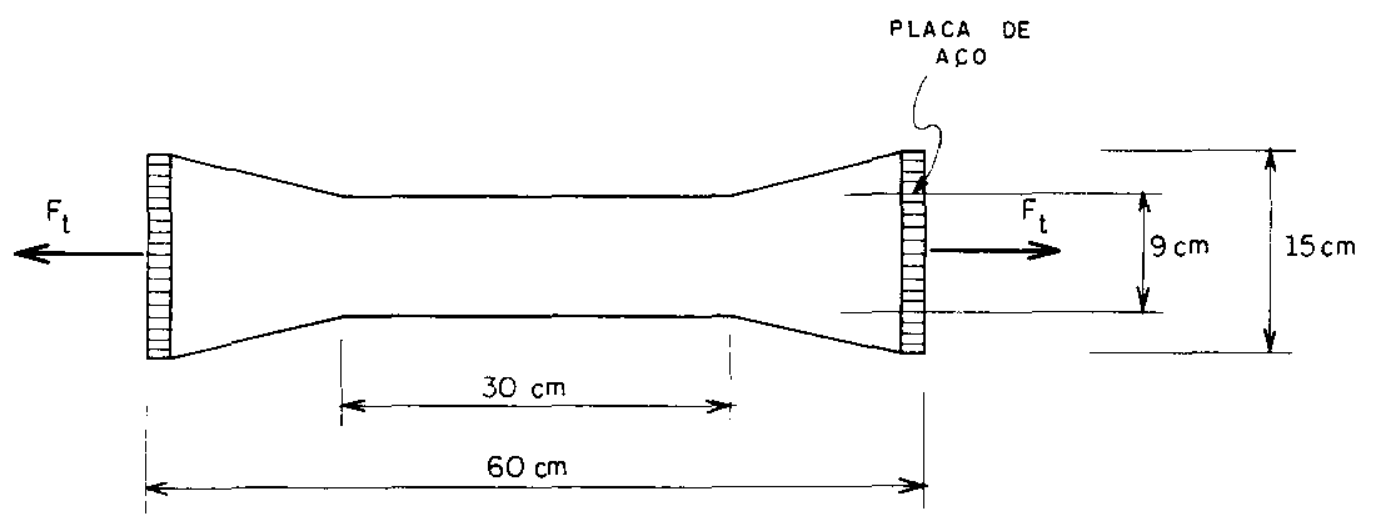

FIG. 3. 2 - DETERMINAÇẤ DA RESISTENCIA À TRAÇÃ̆o AXIAL

A resistencia e determinada pela expressão:

$f_{t l}=\frac{F_{2}}{A_{c}}$

$$
\text { A - irea da sefăo transversal de concreto }
$$




\section{b) Resistência à traçăo por fendilhamento}

É determinada através de ensaios em corpos-de-prova cilindricos de $15 \mathrm{~cm}$ de diametro e zocm de altura e normalmente executados aos 28 dias.
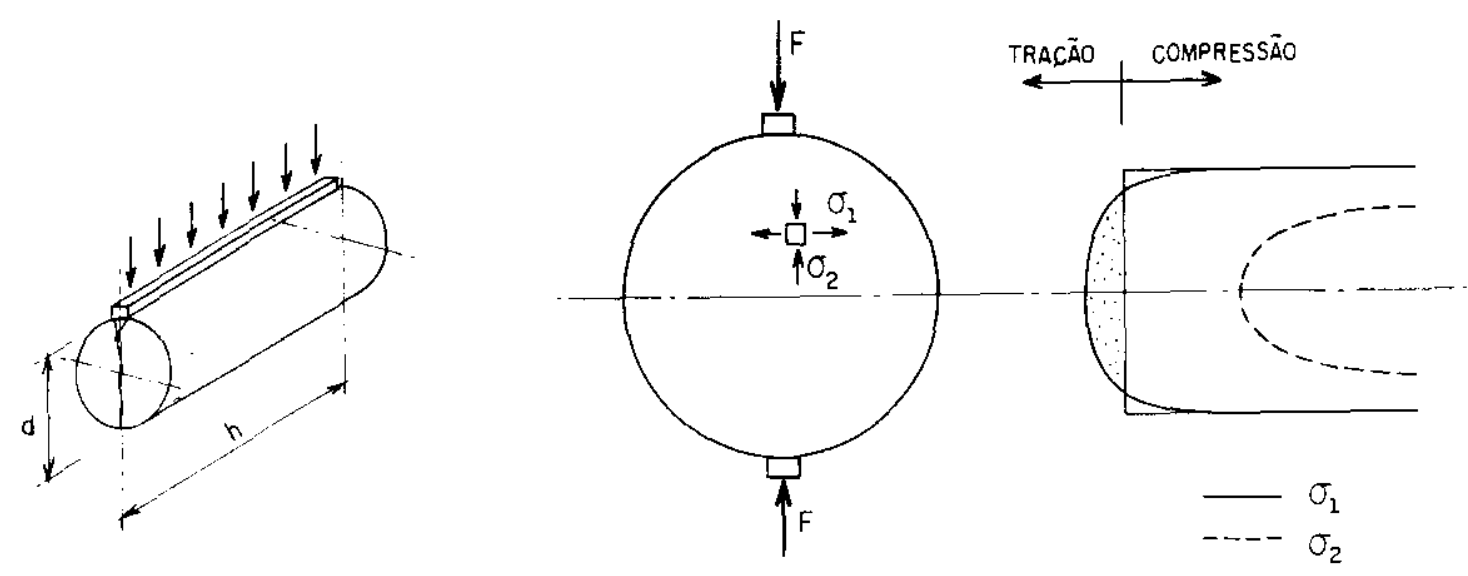

FIG. 3. 3 - DETERMINAÇÃO DA RESISTENCIA A TRAÇÄO POR FENDILHAMENTO

Estes ensaios consistem na aplicação de uma compressão diametral, conforme mostra a figura 3.3 , que é aumentada gradualmente ate que ocorra a ruptura do cilindra. Durante o carregamento, surgem tensỏes de traçăo na direçăo perpendicular aquela de aplicaçăo, rompendo-se o corpo-de-prova por fendilhamento, quando atingida a resistencia $\Rightarrow$ traço.

A resistencia a traça do concreto e calculada pela expressăo: 


$$
f_{t i}=\frac{2 F_{i}}{\pi d h} \cdot 0,86
$$

onde:

$$
\begin{aligned}
& \text { d - diàmetro da base; } \\
& \text { h - altura do corpo-de-prova; } \\
& \text { F - carga maxima. }
\end{aligned}
$$

\section{c) Resistência à tração na flexão}

Este ensaio consiste em submeter uma viga de concreto simples a flexăo, através da aplicação de duas forças equidistantes dos apoios (fig. 3.4). O resultado depende do ponto de aplicação das forfas e das dimensöes dos corpos-de-prova.
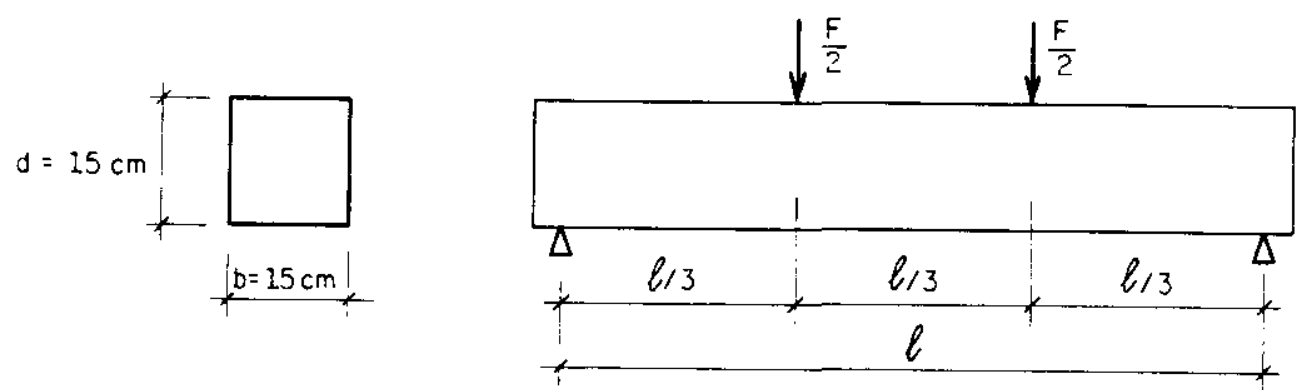

FIG. 3. * - DETERMINACAO DA RESISTENCIA À TRAÇẮ NA FLEXÄO 
Supondo distribuição linear de tensŏes ao longo da seçăo transversal, a resistëncia a tração é calculada da seguinte forma:

$f_{t i}=\frac{F q}{b h^{2}}$

3.4 - RESISTENCIA NO ESTADO MULTIPLO DE TENSOES

Carregar biaxialmente una peca de concreto significa aplicar tensós, simultaneamente, em duas direçoses perpendiculares, estando a terceira livre de tensbes e de impedimento de deformaģes.

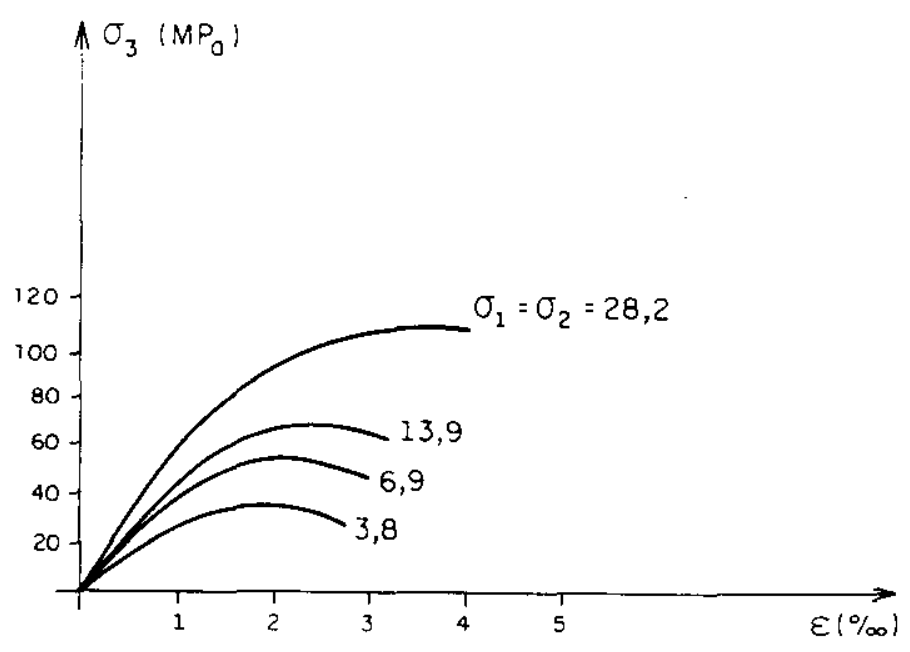

FIG. 3.5 - ENSAIO TRIAXIAL DE COMPRESSÄO 
A figura 3.5, apresentada por CHEN (1982) mostra o comportamento do concreto submetido ao ensaio triaxial de compressão. Nesta figura, é possivel observar o notavel aumento da tensão $\sigma_{3}$ en função do aumento de $\sigma_{1}$ e $\sigma_{2}$.

Quando um corpo-de-prova é submetido a um estado biaxial de compressão, a tensão de compressão máxima aumenta de aproximadamente $25 \%$ para a relação $\alpha_{2} / \alpha_{1}=0,5$ e de $16 \%$ para $a_{2} / \alpha_{1}=1,0$. A resistencia à compressăo decresce linearmente com o aumento linear da tensão de tração quando $\sigma_{1}$ e $\sigma_{2}$ forem tensăes de tração $e$ compressăo respectivamente. A resistència do concreto, no caso de traçăo biaxial, é praticamente a mesma que na trą̧̊o pura (CHEN, 1982 ).

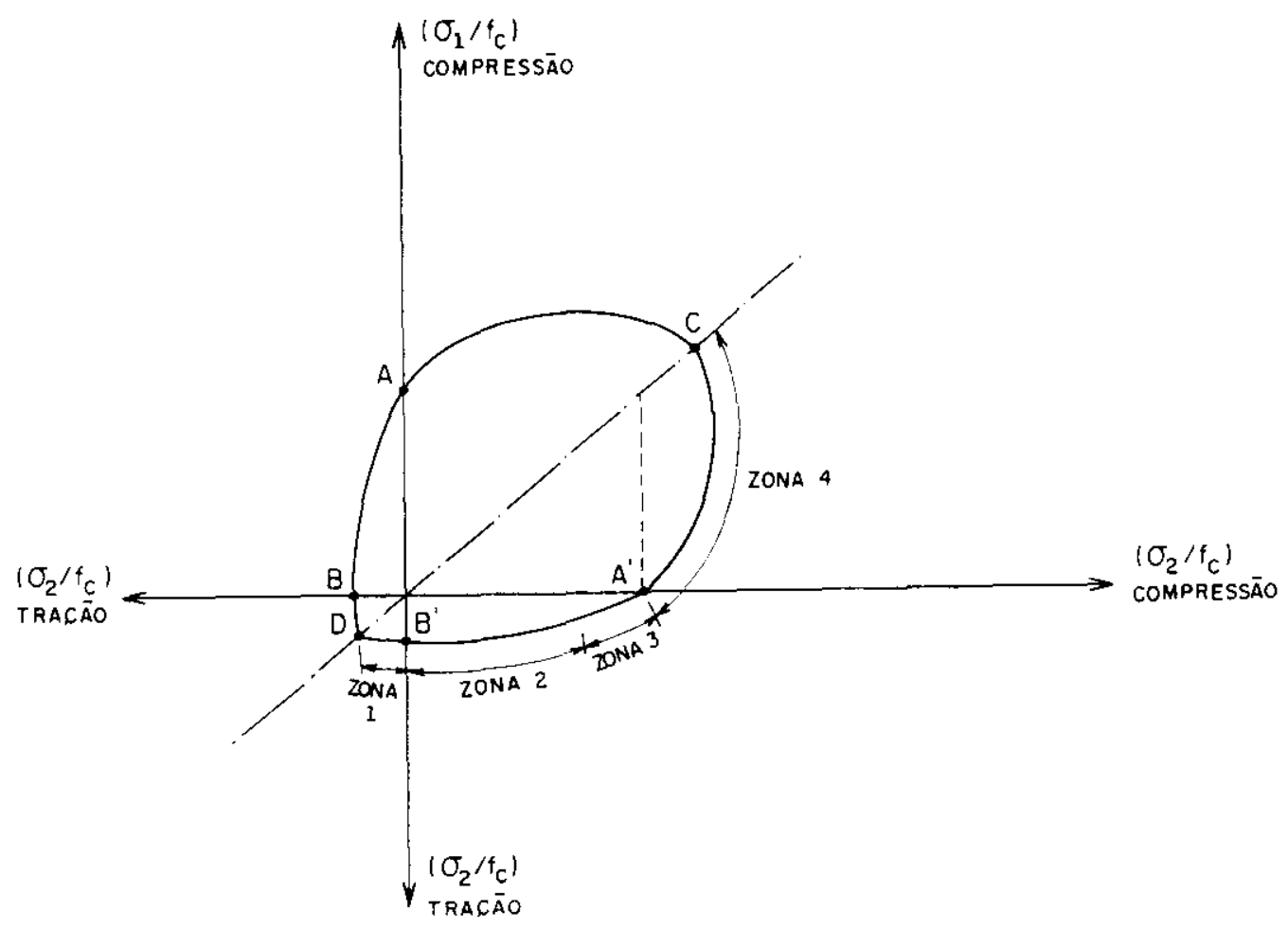

FIG 9. 0 - CONCRETO SUBMETIDO A TENSĂO BIAXIAL 
A figura 3.6, en forma de pera, representa os resultados obtidos por RÜSCH (1975). A linha passa pela resistência à compressão uniaxial, $f_{c}$, em $A$ e $A^{\prime}$ e pela resistencia à tração uniaxial, $f_{c}$, em $B$ e $\theta^{\prime}$, sendo que:

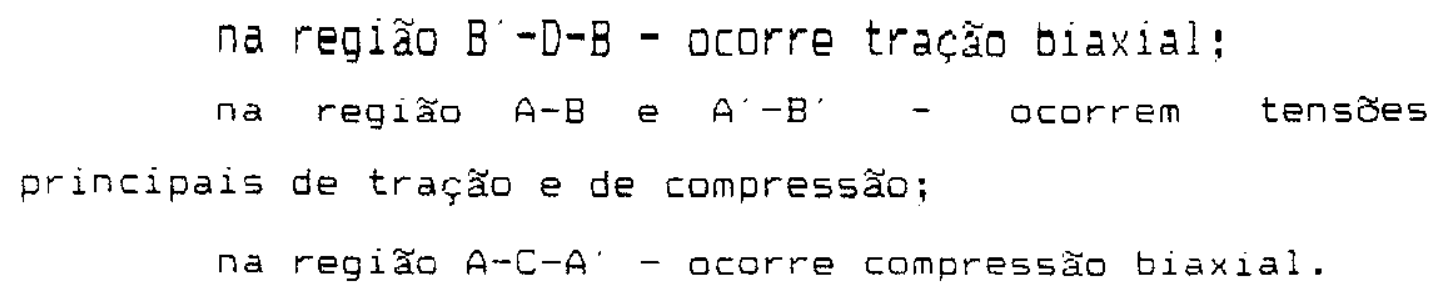

$\mathrm{Na}$ compressão biaxial, no ponto $C$, a resistencia equivale aproximadamente a $107 \%$ de $f_{c}$, conforme mostra a fig. 3.6 (MACGREGOR, 1988).

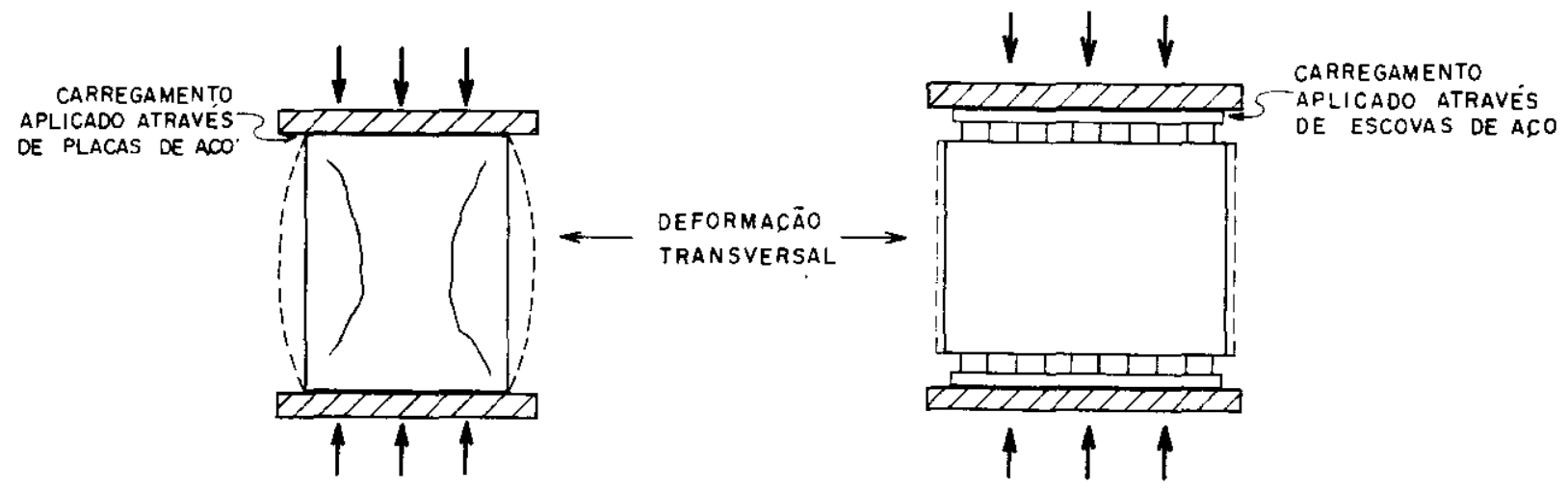

FIG. 3.? - DETERMINAÇÃO DA RESISTENCIA -

TENSBES MULTIAXIAIS

\footnotetext{
Este ensaio foi realizado em corpos-de-prova cubicos com 20cm de lado, submetidos a um estado miltiplo de tensöes. I carregamento foi aplicado atraves de escovas
} 
de aço (figura 3.7), situadas entre o corpo-de-prova e as placas de aço da máquina. Estas escovas têm a finalidade de neutralizar o impedimento à deformaçăo transversal.

\section{5 - FATORES QUE INFLUEM}

Varios săo os fatores que influem na resistência do concreto, sendo alguns enumerados a seguir:

- idade do concreto;

- forma dos agregados;

- relação água/cimento;

- qualidade dos materiais e de execuçă

- forma e dimensôes dos corpos-de-prova;

- duração do carregamento.

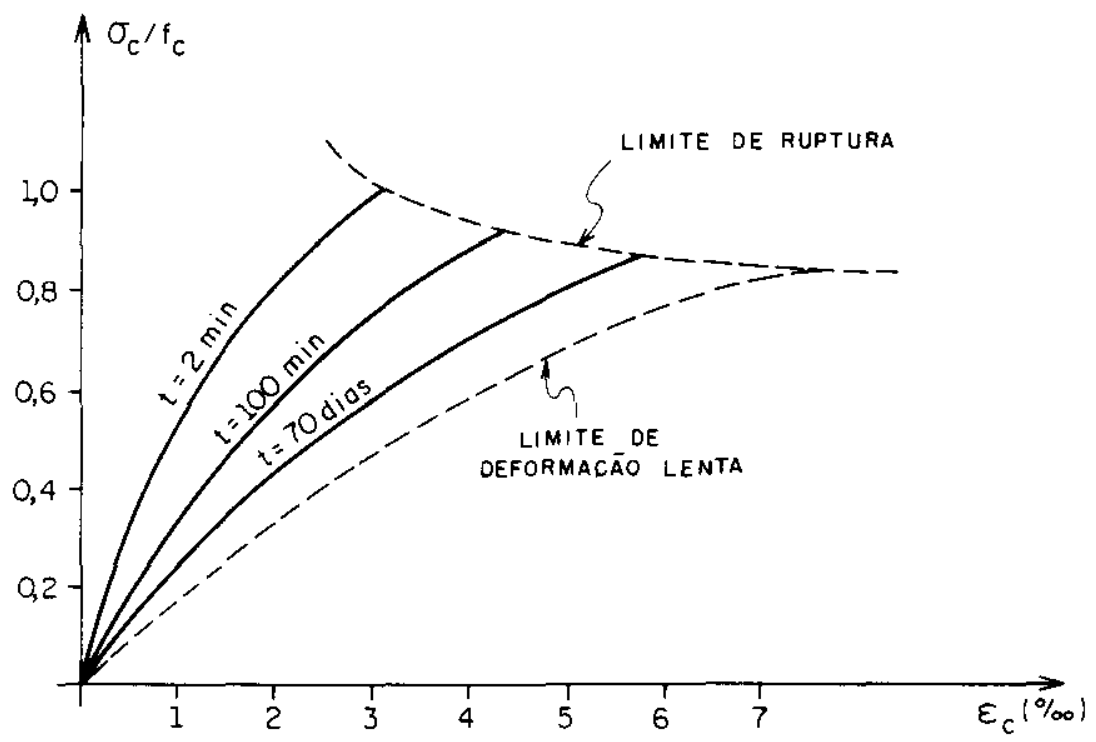

FIG. 3. 9 - DIAGRAMA TENSĂO-DEFORMAÇÃO CARREGAMENTO DE LONGA DURAÇĂO 
Como mostra a figura 3.8, quanto maior for a duração do carregamento, menor será a resistência obtida. Estes resultados, obtidos por RÜSCH (1975), mostram que em ensaios de longa duração o concreto apresenta resistência $20 \%$ menor que aquela obtida em ensaios de curta duraçăo. 


\section{4 - ACOS PARA ARMADURA}

\section{1 - OBTENÇAO DOS AÇOS}

0 mercado oferece alguns tipos de aço, sendo cada um caracterizado pela forma e dimensões da seção transversal e pelo processo de fabricaçăo.

- processo de fabricação inicia-se ao se colocar a mistura minerio de ferro, coque e cal sob elevadas temperaturas nos altos fornos. O calor e o monóxido de carbono liberados reduzem o óxido de ferro a ferro liquefeito, com alto teor de carbono e impurezas, resultando o ferro gusa. Para o ferro gusa ser laminavel e forjável, é necessário reduzir o teor de impurezas; esta purificação ou refino e obtida atraves de uma oxidaçăo em fornos especiais.

- produto siderúrgico apresenta granulaçăo grosseira, sendo quebradiço de baixa resistência. Para aplicaçós estruturais, necessita sofrer algumas modificaçases, que poden ser feitas por dois processos: tratamento a quente e tratamento a frio.

o tratamento a quente é realizado em temperaturas acima de $720^{\circ} \mathrm{C}$, enquanto que o tratamento a frio ou encruamento é realizado atraves de tratamento mecanico a frio, podendo ser a tração, compressão ou torção. 


\section{2 - CLASSIFICACXO}

A NBR 7480 (1978) classifica os aços para armadura em barras e fios, considerando a bitola e o processo de fabricaçăo.
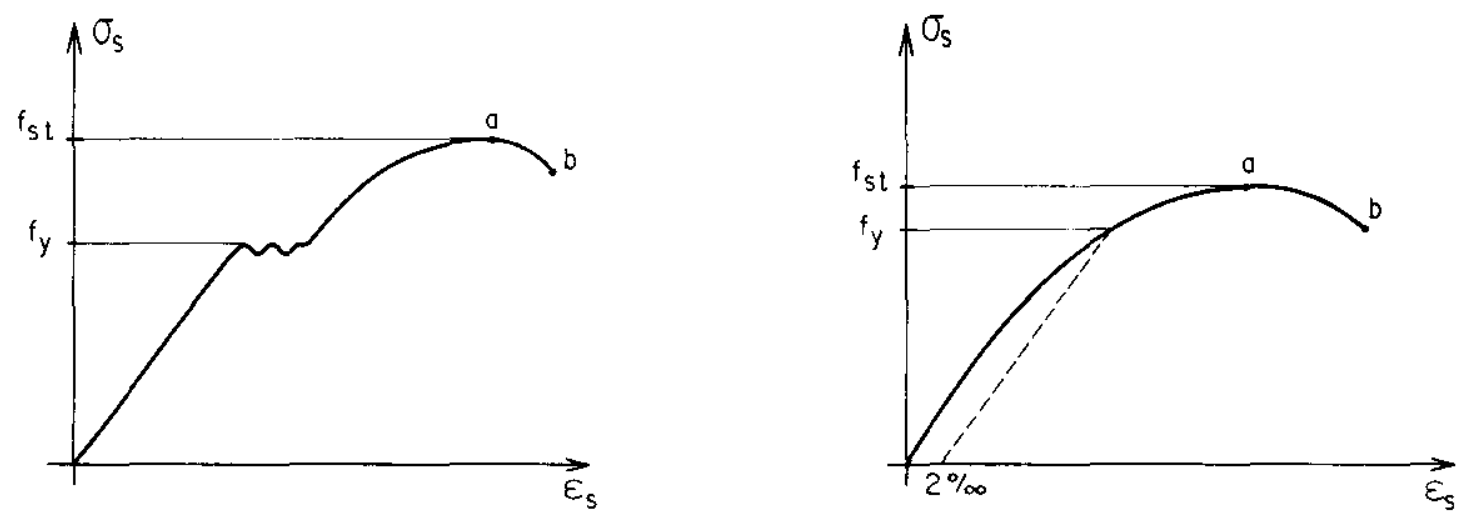

A) CLASSE A

B) CLASSE B

FIG. 4.1 - DIAGRAMAS TENSÄO-DEFORMAÇÄ́

Barras de aço classe A săo obtidas por laminaçăo a quente, sem necessidade de posterior deformaçăo a frio, con escoamento definido, caracterizado por patamar no diagrama tensăo-deformaçăo (ver fig. 4.1a)

Barras e fios de aço B săo obtidos por deformaço a frio e năo apresentam patamar no diagrama tensăo-deformação, conforme a fig. 4.1b. As propriedades mecanicas devem atender aos valores exigidos na tabela 4.: .

Na figura 4.1, o ponto a corresponde a resistencia 
convencional de ruptura, sendo que o ponto $b$ corresponde à resistencia aparente a ruptura.

As barras de aço são classificadas, de acordo com a resistencia caracteristica de escoamento, en CA-25, $C A-32, C A-40, C A-50$ e CA-60. As letras CA referem-5e a aços destinados a concreto armado $e$ os números que as seguem representam a resistencia caracteristica de escoamento em $\mathrm{kN} / \mathrm{cm}^{2}$. Estes aços são classificados em duas categorias: aços de dureza natural e aços encruados a frio. Ha também os aços "patenting", usados em concreto protendido.

\section{a) Aços classe A}

Os aços de dureza natural, aços classe $A$, săo obtidos através da laminação a quente e resfriamento ao ar livre. Suas propriedades baseiam-se em sua composição química e limite de escoamento bem definido.

Os aços classe $A$ são classificados, segundo a NBR 7480, em: $C A-25, C A-32, C A-40 A, C A-50 A$ e CA-60A.

A figura 4.2 mostra os diagramas $o \times E$ caracteristico e de cálculo.

Recomendado pela NBR 6118 (1978), o diagrama simplificado e tipico de um material elastoplástico, limitado pelos alongamentos especificos de $1 \%$ e encurtamentos especificos de $0,35 \%$, sendo este último valor devido ao concreto. Este diagrama é obtido do diagrama caracteristico, dividindo-se os valores de $\sigma_{s}$ por $\gamma_{s}$ em geral igual a 1,15 , onde $\varepsilon_{y d} \Leftrightarrow$ a deformação especifica no inicio do escoamento do diagrama de cálculo. 


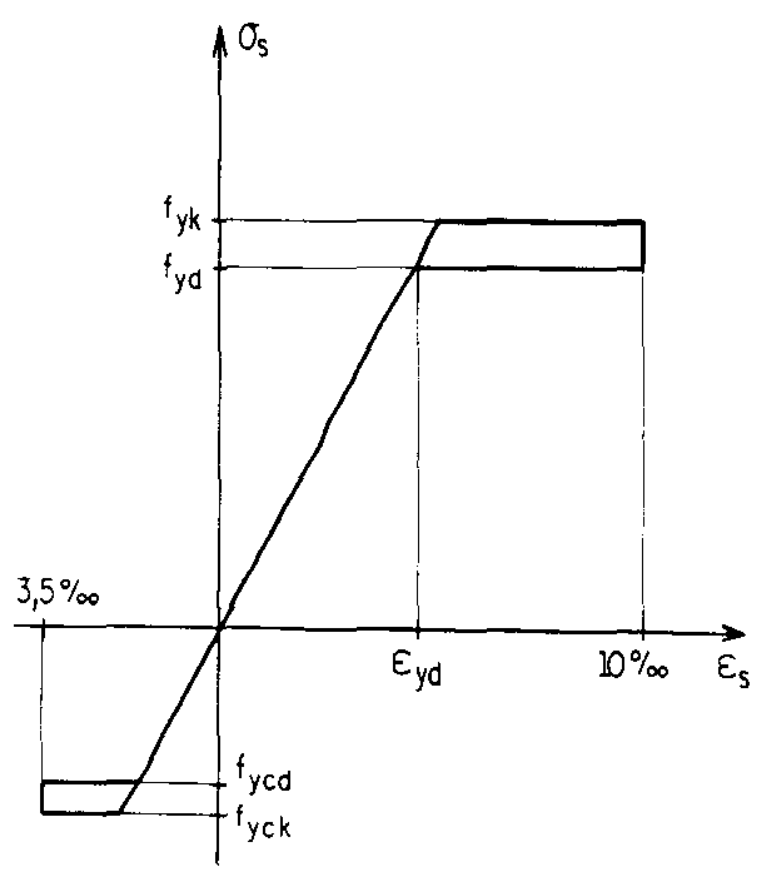

(A) DIAGRAMA

CARACTERISTICO

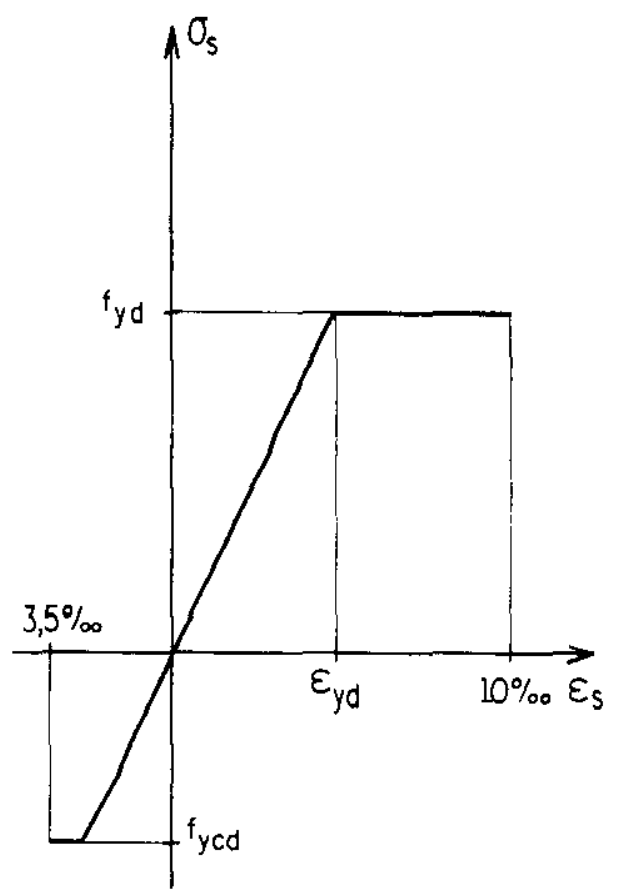

(B) DYAGRAMA

DE CÁLCULO

FIG. 4. 2 - DIAGRAMAS TENSÃo-DEForMAÇÃo - AÇo ClASSE A

\footnotetext{
As resistencias de calculo săo dadas por:$$
f_{y d}=\frac{f_{y k}}{1,15} \quad f_{y c d}=\frac{f_{y c k}}{1,15}
$$

Quando $f_{y k}$ e $f_{y c k}$ não foren determinados en ensaios, adota-se $f_{y k}=f_{y c k}$ Da analise da figura $4.2 b$, sendo a deformaçăo de cálculo, $\varepsilon_{\text {al }}$, e a tensăo de cálculo, os, tem-se :
} 

$0<\varepsilon_{s} \leq \varepsilon_{y}$
$\sigma_{S}=E_{S} \cdot \varepsilon_{S}$
$\varepsilon_{y d}<\varepsilon_{s} \leq 10 \%$
$\theta_{s}=f_{y d}$
$(4.3)$

b) Aços classe B
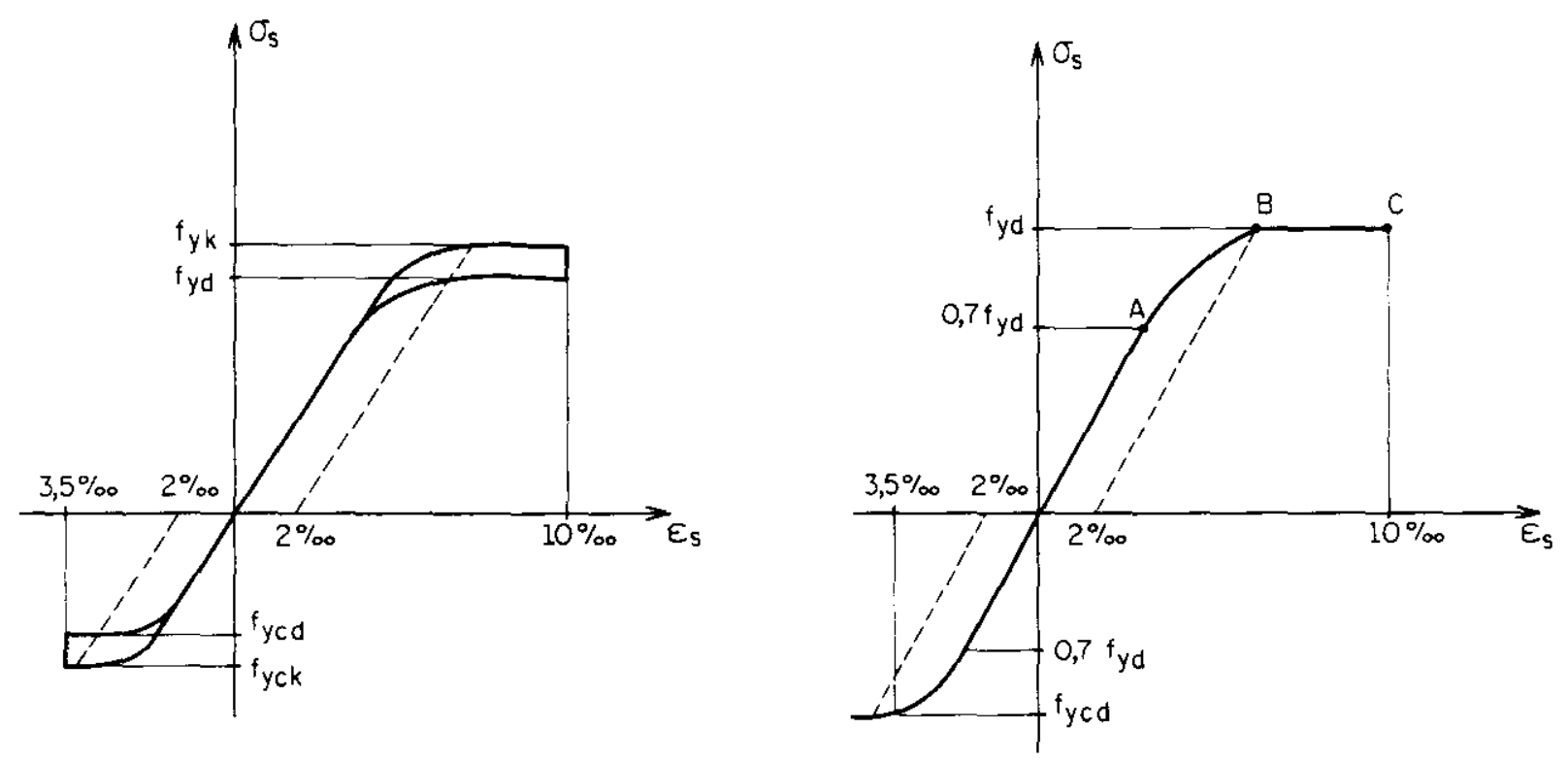

(A) DIAGRAMA

(B) DIAGRAMA

CARACTERTSTICO

DE CALCULO

FIG. 4. 3 - DIAGRAMAS TENSĂO-DEFORMAÇÄO - AÇOS CLASSE 
Os aços classe B são obtidos a partir de aços classe $A$ de resistência inferior, atraves de deformação a frio por tração, estiramento ou torção. Estes aços são caracterizados por não apresentarem um limite de escoamento bem definido, sendo classificados de acordo com o alongamento $0,2 \%$, ver $f i g .4 .3$.

- diagrama de cálculo, figura 4.3b, é obtido dividindo-se as ordenadas do diagrama caracteristico por $\gamma_{s}=1,15$. Segundo a NBR 6118 (1978), este diagrama é composto por tress trechos:

- trecho linear, partindo da origem até o ponto A;

- trecho curvo, entre o ponto $A$ e o correspondente à resistencia de escoamento convencional (Eyd, fyd ${ }_{\text {yd }}$. Esta curva, de acordo com a NBR 6118, é uma parábola de segundo grau;

- trecho reto, paralelo ao eixo $\varepsilon_{s}$, a partir do ponto $B$ até o ponto $C$, cuja deformação limite e $1 \%$.

A resistencia de escoamento de calculo, fyd" para os aços classe $\mathrm{B}$, é valor convencional correspondente à deformação residual $0,2 \%$. No ponto de início de escoamento, o valor da deformaçăo, Eyd, dado por:

$\varepsilon_{y d}=\frac{f_{y d}}{E_{s}}+0,2 \%$

As deformações a as tensões de cálculo são relacionadas pelas equaçóes dadas a seguir:

$$
\begin{aligned}
& 0<\sigma_{s} \leq 0,7 f_{y d} \longrightarrow \varepsilon_{s}=\frac{\sigma_{s}}{E_{s}} \\
& 0,7 f_{y d}<\sigma_{s}<f_{y d} \longrightarrow \varepsilon_{s}=\frac{\sigma_{s}}{E_{s}}+\frac{1}{45}\left[\frac{\sigma_{s}}{f_{y d}}-0,7\right)^{2} \\
& \sigma_{s}=f_{y d} \longrightarrow \varepsilon_{y d} \leq \varepsilon_{s} \leq 1 \%
\end{aligned}
$$


Analogamente, as tensões de calculo são dadas por:

$$
\begin{aligned}
& 0<\varepsilon_{s d} \leq \frac{0,7 f y d}{E_{s}} \longrightarrow \quad \sigma_{s d}=E_{s} \cdot \varepsilon_{s} \\
& \frac{0,7 f_{y d}}{E_{s}}<\varepsilon_{s}<\frac{f_{y d}}{E_{s}} \longrightarrow \sigma_{s}^{2}+\left[\frac{45^{f}{ }^{2}}{E_{s}}-\right. \\
& \left.1,4 f_{y d}\right) \sigma_{s}+\left(0,49-45 \varepsilon_{s d}\right) f_{y d}^{2}=0 \\
& \frac{f y d}{E_{s}} \leq \varepsilon_{s} \leq 1 \% \quad \longrightarrow \quad \sigma_{s}=f_{y d}
\end{aligned}
$$

- módulo de deformação longitudinal, $E_{s}$, para as barras de aço, desde o CA-25 até o CA-60, Classe $A$ ou B, pode ser tomado como igual a $210000 \mathrm{MPa}$.

Segundo a NBR 6118, os aços classe B sao classificados em $C A-4 O B, C A-5 O B$ e $C A-6 O B$.

\section{c) Aços "PATENTING"}

Săo barras de aço de até 8mm de diămetro, utilizadas em concreto protendido, apresentando resisténcia mecânica mais elevada do que as barras utilizadas em concreto armado. Estes aços são encontrados no mercado em três categorias:

- aços trefilados patenteados, que são inicialmente patenteados e em seguida trefilados;

- aços aliviados de tensoes, obtidos através do tratamento de alivio de tenşres, aplicado aos aços 
trefilados patenteados, mediante um reaquecimento entre $250^{\circ}$ e $500^{\circ} \mathrm{C}$, em banho de chumbo derretido;

- aços estabilizados, os quais possuem propriedades de "relaxação", ou perda de tensão com o tempo; os aços para concreto protendido são designados pelas letras CP, seguidas dos núneros que representam a tensão de ruptura. Săo encontrados no mercado fios das categorias $\mathrm{CP}-150, \mathrm{CP}-160$ e $\mathrm{CP}-170$.

\section{3 - DIAMETROS ESPECIFICADOS PELA NBR 7480}

Segundo a NBR 7480 (1978) são classificadas as bitolas relacionadas a seguir:

Barras : $5 ; 6,3 ; 8 ; 10 ; 12,5 ; 16 ; 20 ; 25 ; 32$ e 40

Fios: 3,$2 ; 4 ; 5 ; 6,3 ; 8 ; 10$ e 12,5

A referida norma exige que as barras de qualquer categoria, de bitola igual ou superior a $10 \mathrm{~mm}$, com mossas ou saliências, deverão apresentar marcas de laminaçăo, em relevo, que identifiquem o fabricante e a categoria do material. Em caso contrário, deverá ser feita a identificaçăo atraves de pintura no topo, pelo menos em uma das extremidades, com as cores indicadas na tabela 4.1. 
TABELA 4.1 - PROPRIEdAdES MECANIGAS dOS AĢOS - NBR 7480

\begin{tabular}{|c|c|c|c|c|c|c|c|}
\hline \multirow{3}{*}{$\begin{array}{l}\text { C } \\
\mathbf{A} \\
\mathbf{T} \\
\mathbf{E} \\
\mathbf{G} \\
\mathrm{O} \\
\mathbf{R} \\
\mathbf{I} \\
\mathbf{A}\end{array}$} & \multicolumn{3}{|c|}{$\begin{array}{l}\text { ENSAIO DE TRAÇÃO } \\
\text { (valores minimos) }\end{array}$} & \multicolumn{2}{|c|}{$\begin{array}{l}\text { ENSAIO DE } \\
\text { DOBRAMENTO } \\
\text { A } 180^{\circ}\end{array}$} & \multirow{3}{*}{$\begin{array}{l}\text { ADERENCYA } \\
\\
\eta_{b} \\
\text { PARA } \\
\Phi \geq 10\end{array}$} & \multirow{3}{*}{$\begin{array}{l}\text { DESTIN } \\
\text { TIVO } \\
\text { DA COR } \\
\\
\text { C } \\
0 \\
\text { R }\end{array}$} \\
\hline & \multirow{2}{*}{$\begin{array}{c}f y k \\
(M P a)\end{array}$} & \multicolumn{2}{|c|}{$\begin{array}{l}\text { ALONGAMEN - } \\
\text { TO EM } 10 \Phi \\
(\mathrm{mm})\end{array}$} & \multicolumn{2}{|c|}{$\begin{array}{l}\text { DIAMETRO DO } \\
\text { PINO (mm) }\end{array}$} & & \\
\hline & & $\begin{array}{l}\text { PARA } \\
\text { AÇO } \\
\text { A }\end{array}$ & $\begin{array}{l}\text { PARA } \\
\text { AÇO } \\
\text { B }\end{array}$ & $\Phi<20$ & $\Phi \geq 20$ & & \\
\hline CA-25 & 250 & $10 \%$ & - & $2 \phi$ & $4 \phi$ & 1,0 & amarela \\
\hline CA-92 & 920 & $14 \%$ & - & $\mathbf{2} \phi$ & $4 \phi$ & 1,0 & verde \\
\hline $\mathrm{CA}-40$ & 400 & $10 \%$ & $\theta \%$ & $3 \phi$ & $5 \phi$ & 1,2 & $v e r m e l h a$ \\
\hline CA-5o & 500 & $8 \%$ & $\sigma \%$ & $4 \phi$ & $\phi \phi$ & 1.5 & branca \\
\hline $\mathrm{CA}-\infty$ & 600 & - & $5 \%$ & $5 \phi$ & - & 1,5 & azul \\
\hline
\end{tabular}

\section{4 - INFLUENCIA DA TEMPERATURA NOS AÇOS}

Para temperaturas elevadas, o decréscimo da resistencia observado pelos aços deformados a frio é aproximadamente igual aqueles dos acos de dureza natural. Os aços deformados a frio sofrem, tambem, alteraçros estruturais em certas temperaturas, de modo a existir o perigo de ruptura fragil, efeito devido a aquecimento e rápido esfriamento (LEONHARDT, 1982).

A formação de fissuras por aquecimento e a queda de resistencia nos aços deformados a frio săo alguns dos fenómenos desfavoráveis a que estão sujeitos os aços quando submetidos à solda. 


\section{5 - ADERENCIA}

Para que o concreto e as barras de aço trabalhem conjuntamente, e necessário que haja uma perfeita união entre os dois materiais. Esta solidariedade entre eles é assegurada pela aderencia, que pode ser dividida em: aderência por adesão, aderência por atrito e aderência mecánica.

A aderencia por adesãa resulta das ligaçóes físico-químicas que se estabelecem entre o aço e o concreto durante as reaçres de pega. Este efeito de colagem depende também da rugosidade e da limpeza das barras, sendo vencido quando ocorrem pequenos deslocamentos. A aderencia por atrito é uma força que se opze ao escorregamento entre os dois materiais. Esta força de atrito depende do coeficiente de atrito entre os materiais, sendo uma função da rugosidade superficial da barra. Já a aderencia mecânica é decorrente da existencia de mossas ou saliencias na superficie da barra. Também se aplica barras lisas, em razao das irregularidades próprias, oriundas do processo de fabricação.

Segundo a NBR 7480 (1978), item 4.1.4:

a) as barras de bitola iqual ou superior a 10 devem apresentar coeficientes de conformação superficial pelo menos igual ao fixado na tabela 4.1. As barras de categoria CA-50 são obrigatoriamente providas de saliencias transversais ou mossas;

b) os fios de diámetro igual ou superior a 10 , das categorias CA-50 e CA-60, devem ter obrigatoriamente saliencias transversais ou mossas. 


\section{5 - FUNDAMENTOS DO CALCULO}

\section{1 - ESTADOS LIMITES}

o calculo de estruturas en concreto tem como objetivos garantir uma segurança adequada contra a ruina e contra determinadas condiç̧es de serviço. As bases do dimensionamento consistem en assegurar a obra estabilidade, conforto e durabilidade. Quando estes objetivos não săo atingidos, a estrutura atinge uma situaçăo de "estado limite", definido como estado limite último ou estado limite de utilização.

\subsection{1 - ESTADOS LIMITES ULTIMOS}

Os estados limites últimos são caracterizados pela maxima capacidade portante da estrutura ou de uma parte dela. Destacam-se como principais:

- perda de estabilidade como corpo rigido;

- ruptura de seçós criticas;

- transformação em mecanismo;

- flambagem;

- fadiga. 


\section{1 .2 - ESTADOS LIMITES DE UTILIZACX̃O}

Săo caracterizados pela impossibilidade de emprego da estrutura, por năo oferecer as condiçŏes necessárias de estética, conforto, desempenho e durabilidade, mesmo não se tendo esgotado a capacidade portante da estrutura. As principais causas são enumeradas a seguir:

- fissuração excessiva;

- deformações excessivas;

- vibraçz̃es excessivas;

- corrosão.

\section{2 - ACOES}

De acordo com a NBR 8681 (1984) - AçÖes e segurança nas estruturas, as açőes são as causas que provocam esforços ou deformaçơses nas estruturas. Do ponto de vista pratico, estas forças e deformaçós impostas pelas açôes são consideradas como se fossem as próprias açöes, sendo que as deformaçőes impostas são, por vezes, designadas por açôes indiretas e as forças por açôes diretas.

\subsection{1 - CLASSIFICACXO}

De acordo com a variabilidade no tempo, as açơes săo classificadas em 3 categorias: permanentes, variáveis e excepcionais. 


\section{a) Açס̃es permanentes}

Săo aquelas que ocorrem ao longo do tempo, com valores constantes ou com pequenas variações. Podem ser classificadas como diretas (ex.: peso próprio) ou indiretas (ex.: retração).

\section{b) Açőes variáveis}

São aquelas que, ao longo do tempo, apresentam variaçzes significativas. Săo consideradas como açăes variáveis: cargas de uso das estruturas, forças de frenação, de impacto e centrífugas, efeitos do vento, das variaçốes de temperatura, etc.

Dependendo da probabilidade de ocorréncia, as açб̌es variaveis szo classificadas em:

- açốes variáveis normais - são aquelas que têm grande probabilidade de ocorrencia, sendo obrigatoriamente consideradas em projeto;

- aç⿸厃s variáveis especiais - são ações especiais como sismicas ou cargas de uso de natureza ou de intensidades especiais.

\section{c) Ações excepcionais}

Så aquelas com baixa probabilidade de ocorrencia e curta duração, mas que devem ser consideradas em determinadas estruturas. Tais açőes săo decorrentes de explosöes, choques de velculos, incendios, enchentes, etc. 
5. 2. 2 - VALORES REPRESENTATIVOS PARA ESTADO LIMITE ULTIMO

Segundo a NBR 8681, as açס̋es são classificadas por seus valores representativos em: valores caracteristicos, valores caracteristicos nominais, valores reduzidos de combinação e valores convencionais excepcionais.

\section{a) Valores caracteristicos}

Estes valores são definidos, em funçăo da variabilidade de suas intensidades, em açбes permanentes e em açốs variáveis.

Para as açós permanentes, os valores característicos correspondem a variabilidade existente num conjunto de estruturas análogas. Quando estas aç̧̄es produzen efeitos desfavoraveis na estrutura, o valor caracteristico corresponde ao quantil de $95 \%$ da respectiva distribuiça de probabilidade (valor caracteristico superior). Quando produzem efeitos favoráveis nas estruturas, o valor caracteristico corresponde ao quantil de $5 \%$ de suas distribuiçoses (valor caracteristico inferior), figura 5.1 .

Se as açóes variáveis produzirem efeitos favoraveis, estas não serão consideradas como atuantes na estrutura.

A adoçăo de un único periodo convencional de referencia de 50 anos, para a definiç̃o do valor caracteristico das açöes variáveis, e uma necessidade de ordem prática. A distribuição de probabilidade de ocorrência de uma dada ação depende do período de tempo considerado, sendo que o valor desta ação tem probabilidades de ocorrencia diferentes conforme 0 periodo considerado. Portanto, a definição de um valor caracteristico único para cada ação independente do tipo 
de construçăo considerada, exige que tal definiçăo se refira a um periodo único de tempo.

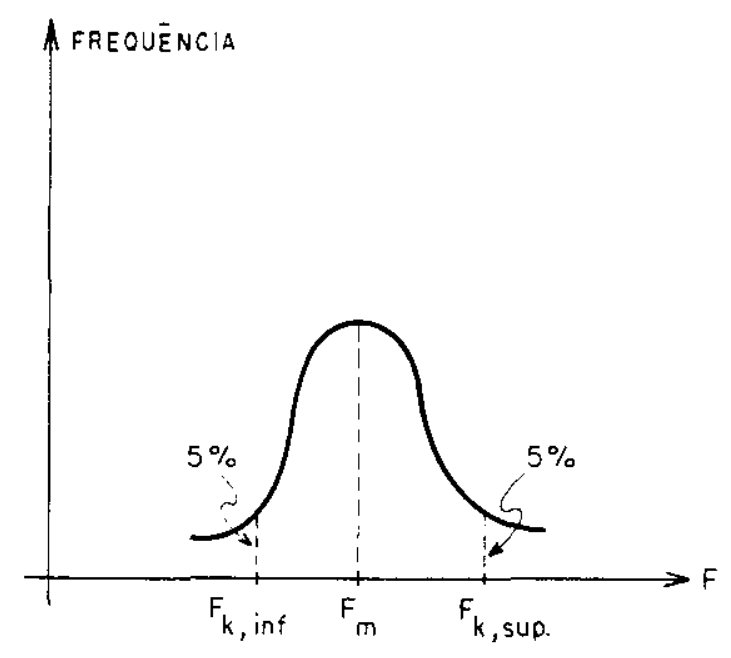

FIG. 5.1 - CURVA DE DISTRIBUIÇÃO

Os valores caracteristicos das açoses varibueis
correspodem a valores que tem de $25 \%$ a $35 \%$ de
probabilidade de serem ultrapassados no sentido
desfavoravel, durante o periodo de 50 anos. Uma forma
alternativa para obter a probabilidade de ocorrencia dos
valores caracteristicos adotados consiste em se estudar o
seu periodo medio de retorno. A aços cujos valores
caracteristicos tem probabilidade da ordem de $25 \%$ a $35 \%$
de serem ultrapassados em 50 anos, correspondem


aproximadamente a periodos médios de 200 a 150 anos, respectivamente.

\section{b) Valores caracteristicos nominais}

Para as açỡes que não tenham sua variabilidade adequadamente expressa por distribuiçōes de probabilidade, os valores característicos são substituidos por valores nominais convenientemente escolnidos. Quando apresentarem baixa variabilidade, diferindo pouco entre si os valores caracteriticos superior e inferior, adotam-se como caracteriticos os valores medios das respectivas distribuiçzes.

c) Valores reduzidos de combinaçăo

Estes valores săo determinados a partir dos valores caracteristicos atraves da expressão $\psi_{0} \cdot F_{k}$, sendo $\psi_{0} 0$ coeficiente de combinaçăo. A probabilidade de ocorrencia simultânea dos valores caracteristicos de duas ou mais variaveis de naturezas diferentes e muito baixa. Por

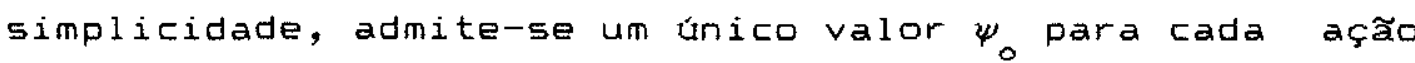
a ser considerada no projeto. Segundo a NBR 8681, quando certas combinaçőes $\left(F_{i}, F_{j}\right)$ exigem tratamento particular, os valores de $\psi_{0}$ săo desdobrados en varios casos.

d) Valores convencionais excepcionais

Estes valores são arbitrados para as açช̋s excepcionais e deven ser estabelecidos por consenso entre - proprietário da construção e as autoridades governamentais que nela tenham interesse. 


\subsection{3 - VALORES REPRESENTATIVOS PARA ESTADOS LIMITES DE UTILIZAÇAO}

Ds valores representativos das açōes para os estados limites de utilizaçăo săo os valores reduzidos e os valores raros, indicados a seguir.

a) Valores reduzidos de utilização

\footnotetext{
Os valores reduzidos de utilização săo determinados, a partir dos valores caracteristicos, pelas expressós $\psi_{k} F_{k}$ e $\psi_{2} F_{k}$, sendo os valores $\psi_{1} F_{K}$ designados por valores frequentes $e$ os valores $\psi_{2} F_{k}$ por valores quase permanentes das ações variáveis.

Nas estruturas de concreto, os valores $\psi_{1} F_{k}$ são empregados na verificação da segurança em relaçăo aos estados limites de fissuraça $e$ os valores $\psi_{2} F_{k}$ em relação ao estados limites de deformaçŏes excessivas.
}

b) Valores raros de utilizaçăo

Estes valores quantificam as açäes que podem acarretar estados limites de utilizaçăo, mesmo que atuem com duração muito curta sobre a estrutura.

5. 2. 4 - VALORES DE CALCULO DAS AÇOES

Os valores de calculo das aç̋̈es, $F_{d}$, são obtidos a partir dos valores representativos, multiplicando-os pelos respectivos coeficientes de ponderaçăo $\gamma_{f}$. Este 
coeficiente pode ser considerado como sendo um produto de $\gamma_{f 1}, \gamma_{f 2}$ e $\gamma_{f 3}$, onde $\gamma_{f 2}$ a próprio coeficiente $\psi_{0}$ de combinação.

Considerando estados limites ultimos, o coeficiente $\gamma_{f}$ pode ser dado pelo produto de $\gamma_{f 1} \times \gamma_{f \ni}$, onde $\gamma_{f 1}$ leva em conta a variabilidade das ações e $\gamma_{\text {fg }}$ considera os possiveis erros de avaliaçăo do efeito. Geralmente o coeficiente de ponderação para os estados limites últimos é tomado como $\gamma_{\mathrm{f}}=1,4$.

Quando se consideram estados limites de utilização, o coeficiente de ponderação das açöes tomado como $\gamma_{f}=$ 1,0, salvo exigência em contrário, expressa em norma especial.

\section{3 - SEGURANÇA}

Uma estrutura oferece segurança quando ela possui condiçoses de suportar todas as açâs, com intensidades e combinaçós mais desfavoráveis, durante toda a sua vida útil, sem atingir um estado limite.

Uma segurança exagerada acarreta em alto custo financeiro.

Qs metodos para verificação da segurança podem ser classificados em: metodos deterministicos, metodos probabilisticos e metodo dos coeficientes parciais.

\subsection{1 - METODOS DETERMINISTICOS}

Os métodos deterministicos são aqueles que consideram fixos os parametros que servem de base para cálculo. 
Dentre estes, encontram-se o método das tensóes admissiveis e a metodo do coeficiente de segurança externo.

a) Método das tensø̃es admissiveis

Este método foi empregado até aproximadamente 1930. Baseava-se nas hipóteses de calcula nos estádios I e II.

A segurança das estruturas e garantida pela limitação das máximas tensỏes atuantes em serviço. A máxima tensão em serviço não ultrapassa a tensão admissivel. Esta tensão admissivel é definida como sendo a razão entre a tensão de ruptura do material e o coeficiente de segurança interno.

$\sigma_{a d m}=\frac{\sigma_{\mathbf{R}}}{\gamma_{i}}$ ou $\sigma_{a d m}=\frac{\sigma_{0}}{\gamma_{i}}$

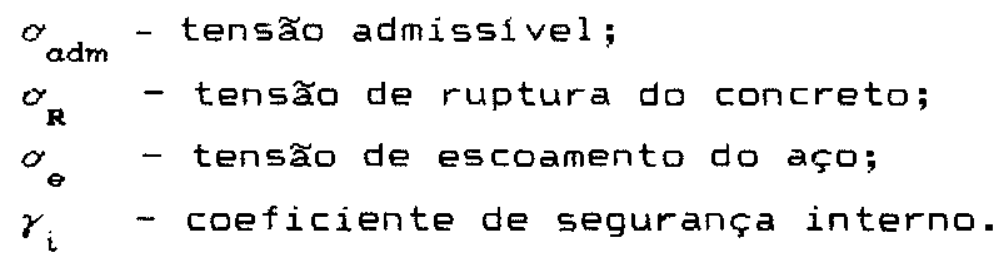

A figura 5.2 apresenta de maneira esquenática a idéa básica do metodo. 


$\left\{\begin{array}{r}\gamma_{i} \text {-coeficientede } \\ \text { segurarça interno } \\ \left(\sigma_{\max }=\sigma_{\text {adm }}\right)\end{array}\right.$

FIa. 5.2 - METODO DAS TENSÖES ADMISSTVEIS

A seguir são enumeradas algumas criticas em relação ao método, segundo SANTOS (1977):

- supōe que a tensão no concreto se mantem proporcional à deformação até a ruptura, o que não acontece;

- o coeficiente interno $\gamma_{i}$ năo permite considerar diferentemente as diversas combinaçôes das açöes;

- D metodo admite $\alpha_{\theta}=\frac{E_{s}}{E_{c}}$ constante, quando na realidade não

b) Metodo do coeficiente de segurança externo

Este método baseia-se nas hipoteses de calculo no estádio III, considerando a acomodaça plástica do material por ocasião da ruptura do concreto. Por não haver proporcionalidade entre tensöes e açőss, e melhor usar carga admissivel em vez de tensão admissivel, quando se pretender quantificar a segurança.

Este metodo consiste em majorar a carga de serviço, $F$, pelo coeficiente externo, $\gamma_{\theta}$. Isto faz com que a peça 
perca a estabilidade ou que a tensão em um de seus pontos atinja o valor de ruptura ou de escoamento. A figura 5.3 mostra a idéia básica do método.

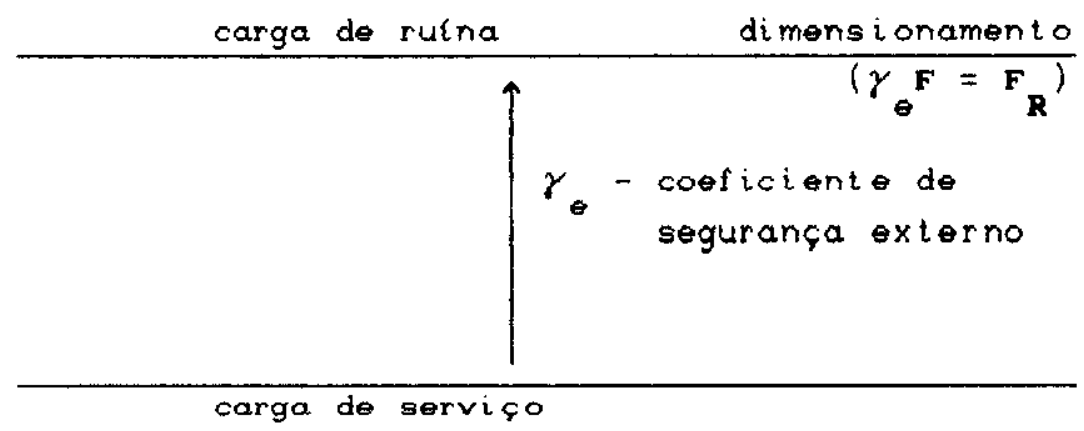

FIG. 5.3 - METODO DO COEFICIENTE DE SEGURANÇA EXTERNo

Algumas criticas do metodo, segundo SANTOS (1977):

- trabalha com esforços solicitantes majorados e năo com açठ̌es; no caso de năo proporcionalidade entre cargas e esforços solicitantes, o metodo leva a uma quantificação errada da segurança;

- a tensão de ruptura não é um valor deterministico e sim uma variavel aleatoria;

- não leva em conta a combinação prevista das ações; $0 \gamma_{\theta}$ também não $e$ bom para quantificar a segurança.

Este metodo foi abandonado pela NB-1/78.

\subsection{2 - METODOS PROBABILISTICOS}

A idéia básica do método é substituir o conceito de coeficiente de segurança por probabilidade de ruina. 


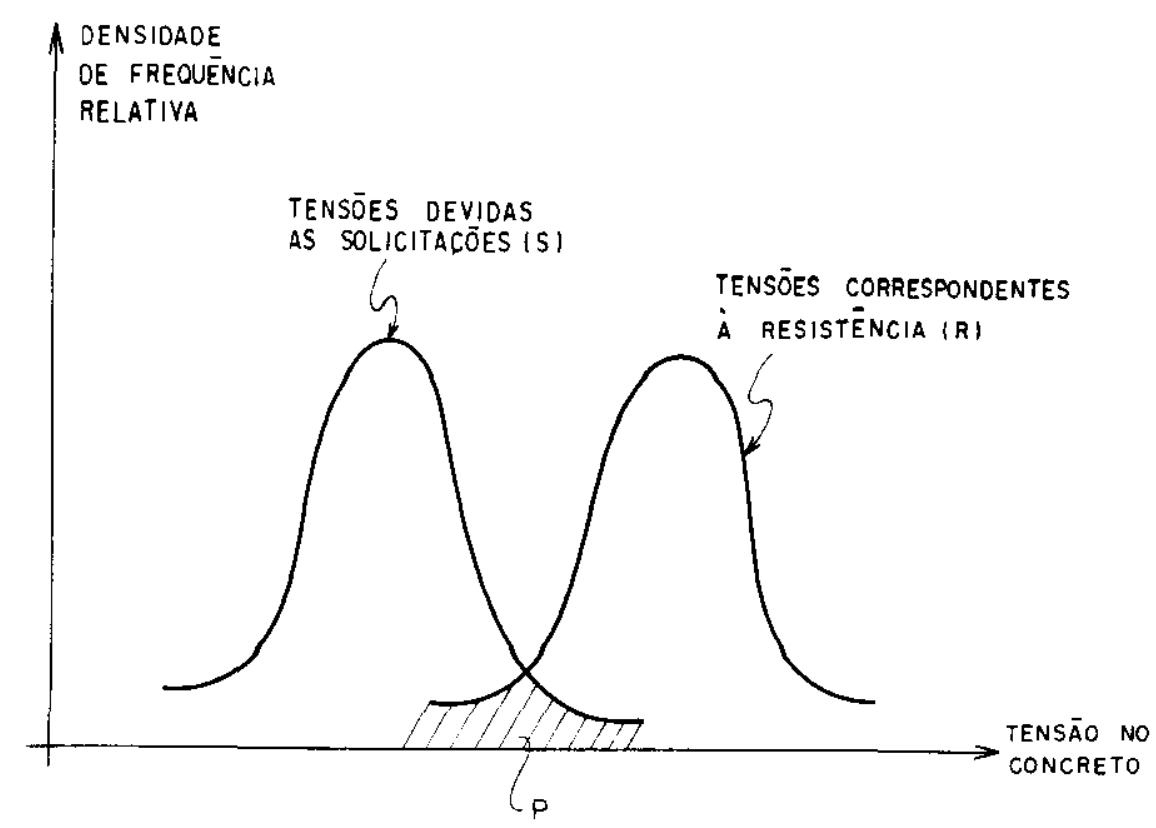

FIG. 5.4 - PROBABILIDADE DE RUINA

Sejam $R$ e $S$ as grandezas escolhidas, respectivamente, para representar a resistencia e a salicitacăo. Supondo-se que tanto as resistencias como as solicitaçäes possam ser colocadas em funçăo de un mesmo parămetro e sobre um mesmo sistema de eixos, a probabilidade de rusma, $p$, édeterminada quando $R$ e alcançado por 5 . A solicitaçăo é maior do que a resistencia da peça, conforme mostra a figura 5.4 .

Năo o possivel obter seguranga absoluta ( $p=0$ ), ponto de encontro das curvas. A parte hachurada representa a probabilidade de ruina.

săo dois os tipos de metodos probablilsticos: condicionado e puro. 


\section{a) Método probabilistico condicionado}

Neste método as açôes, as solicitaçöes, as resistências e a geometria da estrutura são aleatórias. Apenas a propria teoria que formece a configuraçăo de ruina da estrutura continua deterministica.

A fixaça deterministica da configuraçăo de ruina tambem não corresponde à realidade.

b) Método probabilistico puro

Este metodo considera as configuraçóses de ruína possiveis pela aleatoriedade das propriedades mecánicas e dos parametros geometricos. Por não se conhecer o comportamento estrutural num grau de perfeição suficiente, o método probabilistico puro não é aplicado.

\subsection{3 - METODO DOS COEFICIENTES PARCIAIS}

E um método semi-probabilistico, no qual se adotam valores deterministicos e, na medida do possivel, dados estatisticos e conceitos probabilisticos.

A figura 5.5 mostra, de maneira esquematica, a idéia básica deste método:

- majoram-se as açôes e as solicitaçâes; obtém-se valores de cálculo, de modo que seja pequena a probabilidade destes valores serem ultrapassados;

- reduzem-se os valores das resisténcias, obtendo-se resistencias de cálculo, de modo que a probabilidade dos valores reais descerem ate este ponto seja pequena;

- equaciona-se a situação de ruina considerando 
que a solicitação de cálculo, $S_{d}$, encontrou a resistência de cálculo, $\mathrm{R}_{d}$.

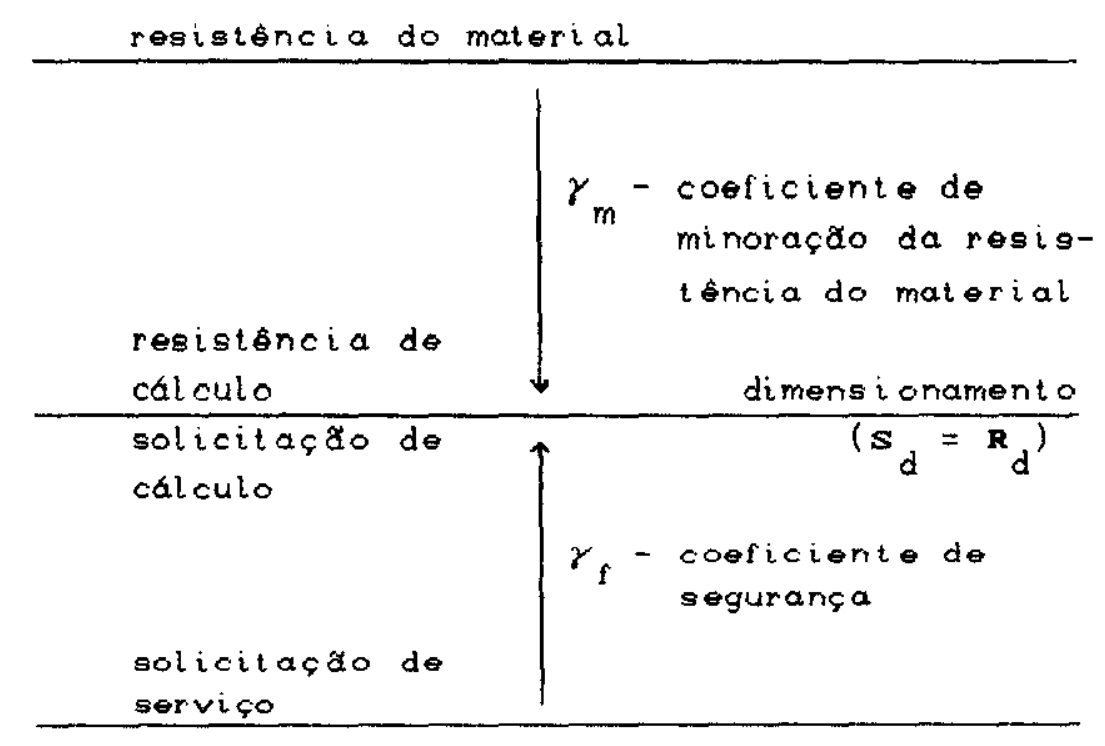

FIG. 5.5 - METODO DOS COEFICIENTES PARCIAIS

\section{4 - TIPOS DE SOLICITAÇOES}

As solicitações podem ser classificadas quanto aos esforços solicitantes, quanto ao plano de ação do momento fletor e quanto a direção dos esforços.

\section{4.1 - QUANTO AOS ESFORÇOS SOLICITANTES}

\section{a) Compressão simples e traçăo simples}

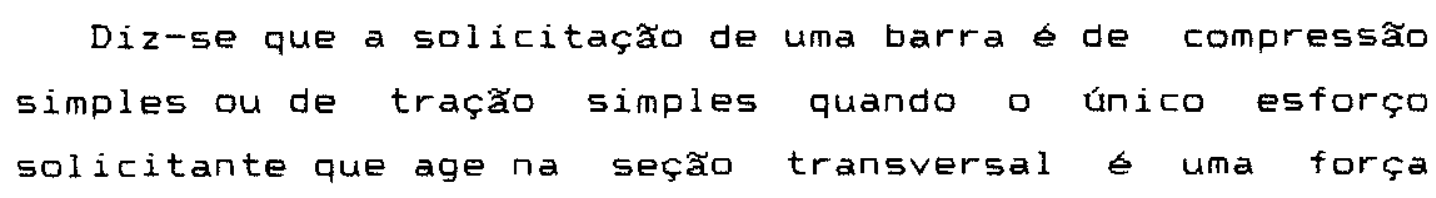


normal, $N$, respectivamente, de compressăo ou de tração.

\title{
b) Compressão excêntrica e tração excêntrica
}

\begin{abstract}
Diz-se que compressão excêntrica, ou tração excêntrica, é o estado de uma barra em que os esforços solicitantes são só momentos fletores e forças normais de compressão ou de traçăo, respectivamente. Na prática é considerada como um caso particular da flexăo composta, com força cortante nula.
\end{abstract}

c) Flexão simples e flexão pura

\begin{abstract}
Diz-se que flexão simples é o estado de uma barra em que os esforços solicitantes săo momentos fletores e forças cortantes. A flexăo pura considerada como um caso particular da flexăo simples com força cortante nula, tendo como esforços solicitantes somente os momentos fletores.
\end{abstract}

d) Fl exão composta

Diz-se que flexão composta e o estado de uma barra em que os esforços solicitantes săo momentos fletores, forças cortantes e forças normais. 


\section{4. 2 - QUANTO AO PLANO DE AÇAO DO MOMENTO FLETOR}

a) Flexão normal

Define-se como flexão normal a flexăo pura, simples ou composta, em que o plano de ação do momento fletor contém um dos eixos centrais de inercia da seção transversal.

\section{b) Flexåo obliqua}

Define-se como flexăo obliqua a flexăo pura, simples ou composta, em que o plano de ação do momento fletor não contem nentum dos eixos centrais de inercia da seção transversal.

\subsection{3 - QUANTO A DIRECAO DOS ESFORCOS}

a) Solicitaçós normais

Solicitaçăes normais săo aquelas que introduzem
tensöes normais na seção; atuam momentos fletores e
forças normais.

b) Solicitações tangenciais

Solicitaçōes tangenciais săo aquelas que introduzem tensర̋es tangenciais na seça; atuam momentos de torçăo e forcas cortantes. 


\subsection{4 - TIPOS DE CALCULO}

\section{a) Dimensionamento}

Com as solicitaçőes atuantes e a capacidade resistente dos materiais conhecidas, determinam-se as dimensôs da seção transversal de concreto e as areas das armaduras.

\section{b) Verificaçăo}

Contiecida a seção transversal, as armaduras e o momento atuante, determinam-se as tensöes máximas no concreto e nas armaduras. Quando dadas as tenszes admissiveis, calcula-se a maxima solicitaçăo que pode ser aplicada.

\section{4.5 - DEFORMAÇOES DE RUPTURA DO CONCRETO}

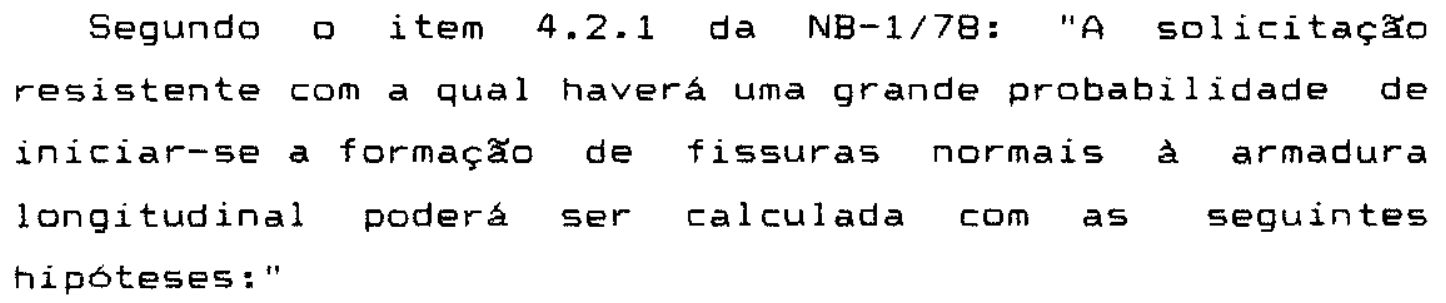

a) $\mathrm{Na}$ compressăo

- compressão simples: $\varepsilon_{\text {cu }}=2 \%$

- flexaัo: $\varepsilon_{c u}=3,5 \%$. 
b) $\mathrm{Na}$ tração

- tração simples: $\varepsilon_{t u}=2,7 \mathrm{f}_{t k} / E_{c}$

- flexaัด: $\varepsilon_{t u}=4,05 f_{t k} / E_{c}$

\section{5 - COMPRESSATO SIMPLES E TRAÇAO SIMPLES}

Seja uma secão retangular com armadura simetrica submetida a uma forfa normal $N$ de compressão (fig. 5.S).
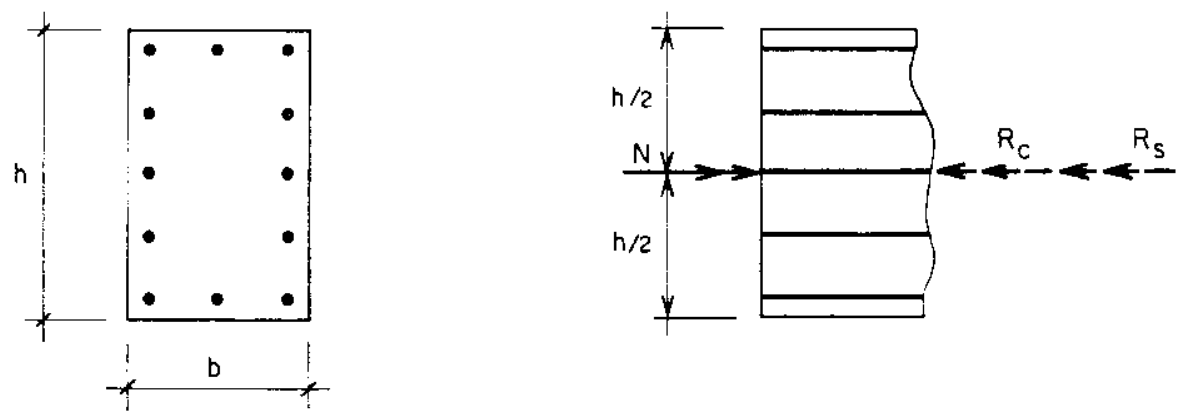

FIO. 5. - - SEÇĂo RETANGULAR SUBMETIDA A FORÇA NORMAL 
Equação de equilibrio:

$$
\begin{aligned}
N=R_{c} & +R_{s}=A_{c} \sigma_{c}+A_{s} \sigma_{s} \\
& -R_{c}-\text { resultante no concreto; } \\
& -R_{s}-\text { resultante no aço; } \\
& -A_{c}-\text { area de concreto }\left(A_{c}=b h\right) ; \\
& -A_{s}-\text { area de aço. }
\end{aligned}
$$

Portanto,

$$
N=b h \cdot \sigma_{c}+A_{s} \sigma_{s}
$$

A equação 5.3 e válida tanto na compressão quanto na tração.

\subsection{1 - COMPRESSAO SIMPLES}

Serão considerados as seçoes de concreto simples e de concreto armado, submetidas à compressão simples.

\section{a) Concreto simples}

Para uma seção retangular de concreto simples submetida a uma força normal $N$ de compressăo é válida a equaçăo 5.3, considerando-se $A_{s}=0$.

\section{Na ruina:}

$$
\sigma_{c d}=0,85 \cdot f_{c d}
$$


Portanto:

$N=b \cdot h \cdot \sigma_{c d}=0,85 \cdot b \cdot h \cdot f_{c d}$

b) Concreto armado

Para seçŏes retangulares de concreto armado:

$N=0,85 \cdot b \cdot h \cdot f_{c d}+A_{s} \cdot \sigma_{s}$

o valor de o é obtido do diagrama do aço para uma deformaçăo de ruptura $2 \%$.

\subsection{2 - TRACXXO SIMPLES}

Serão consideradas seçశ̄es sem e com armadura.

\section{a) Seçăo sem armadura}

Para uma seção de concreto simples submetida a uma força normal de traçăo, $N$, válida a equação (5.3) desde que seja satisfeita a condição: $A_{s}=0$

b) Concreto armado na iminência de fissuraçáo

E válida a equação (5.3) para seções de concreto armado na iminência de fissuração. 


\section{c) Seção fissurada}

No instante en que ocorre a primeira fissura, o concreto deixa de resistir a tração, a qual e totalmente absorvida pela armadura. Entretanto, évalida a equação (5.3) desde que satisfeita a condiçăo: $A_{c}=b . h=0$

\section{6 - FLEXAO PURA}

Uma seção sujeita a flexão pura reage com tensð̋es de compressăo de um lado da seçăo e com tensßes de traçăo do outro lado, ambas normais ao plano da seçăo transversal. $\mathrm{Na}$ flexăo pura atua apenas momento fletor.

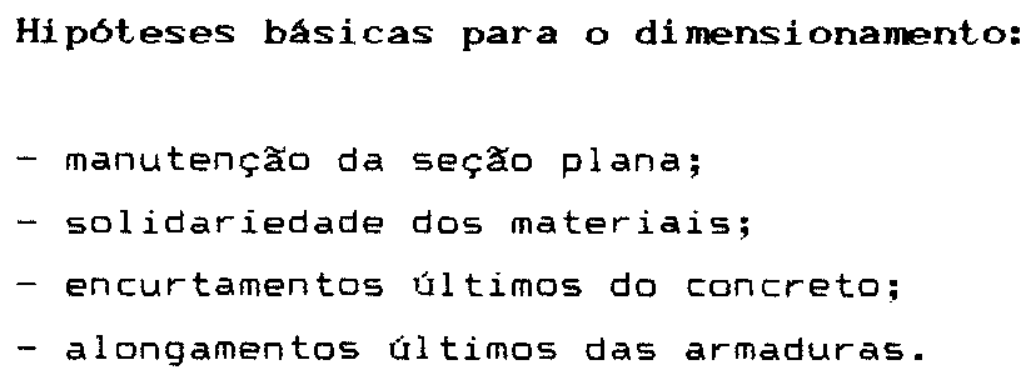

\subsection{1 - DI AGRAMA DE TENSOES}

Atraves de um ensaio com cargas crescentes a partir de um valor pequeno, verifica-se que, para momentos ainda reduzidos, sendo as tensơes tambem reduzidas, o concreto resiste às tensoes de traçăo. A figura 5.7 descreve como se comporta uma viga de concreto armado, simplesmente apoiada, sob a ação de um carregamento crescente ate provocar a ruptura da viga. Nesta figura tem-se: 

a) seção transversal da viga;
b) estadio Ia - concreto resiste a tração com diagrama triangular
c) estadio Ib - iminència de fissuraçăo;
d) estádio Ii - seçăo fissurada;
e) estadio III - plastificaçăo do concreto na compressão.

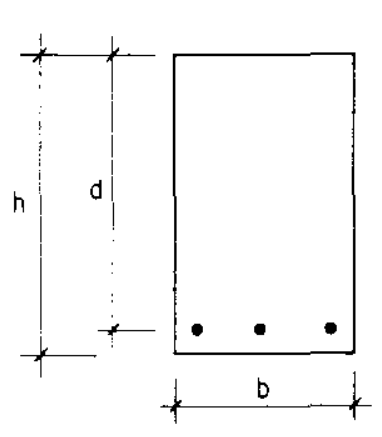

(a)

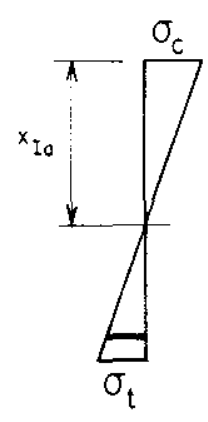

(b)

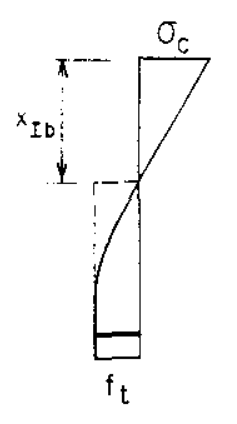

(c)

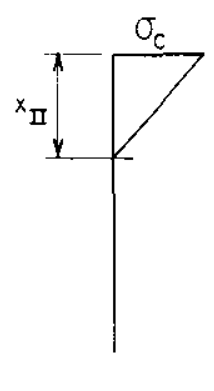

(d)

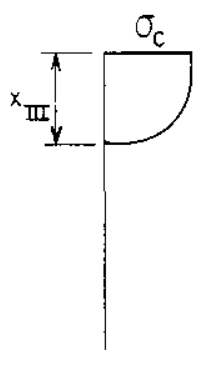

(e)

FIO. 5.7 - FASES DE COMPORTAMENTO DE UMA SEÇĂO SUBMETIDA A FLEXÃO PURA 


\subsection{2 - DEFINIÇÃO DOS ESTADIOS}

o estádio Ia ocorre quando o carregamento é de pequena intensidade. A viga se deforma pouco e as tensठes normais que surgen nas seçz̄es transversais mais solicitadas são pequenas. E admitida a linearidade das tensz̃es ao longo de toda a seção transversal.

0 dimensionamento neste estadio exige dimenszres muito exageradas para as peças, pois leva em conta a resistencia à tração do concreto, que é muito pequena, figura 5.7b.

Aumentando o carregamento, as tensöes de tração nas fibras mais afastadas da linha neutra deixam de ser proporcionais as deformaçóes. Admite-se linearidade das tensర̃es apenas na zona comprimida. Na borda inferior da viga, a tensão e a deformaçăo atingem os valores correspondentes a ruptura. 0 diagrama do estadio Ib, figura 5.7c, mostra a fase correspondente do estadio I que precede o estádio II; o concreto na zona tracionada está plastificado.

Continuando com o aumento no carregamento, a concreto tracionado rompe. No estádio II, o diagrama de tensöes varia linearmente, crescendo do valor zero, na linha neutra, para um valor maximo na borda comprimida, figura 5.7d.

Aumentando ainda mais o carregamento, as fissuras caminham em direção à borda superior da viga. A linha neutra sobe e a tensão na armadura cresce, podendo atingir, em determinado instante, o limite de escoamento. o estádio III é definido como sendo a fase em que o concreto comprimido está na iminência da ruptura, ou seja, estado limite último da ruptura do concreto por compressão, figura 5.7e. 


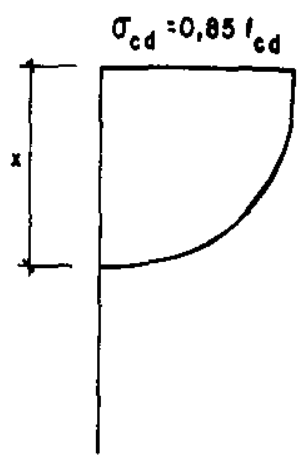

(0)

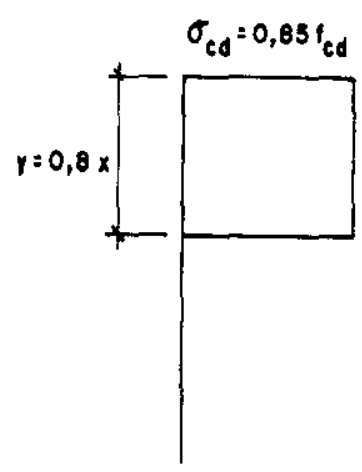

(b)

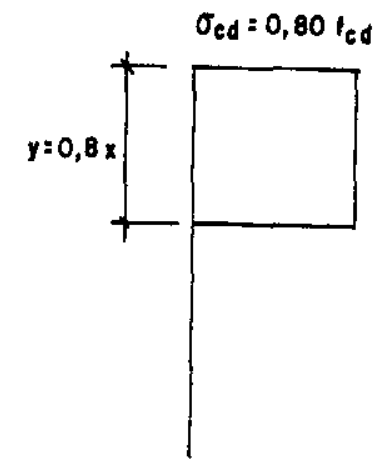

(c)

FIG. 5.8 - DIAGRAMAS DE TENSGES

Conforme mostra a figura 5.8, no estádio III admite-se que as tensöes de compressão na seça transversal das peças tenham uma distribuiçăo de acordo com o diagrama parabola-retângulo ou de acordo com o diagrama retanguiar.

\section{a) Diagrama parábola-retángulo}

Este diagrama é formado por:

- un trectio retangular para deformação de compressăo de $2 \%$ ate o encurtamento convencional de ruptura de $3,5 \%$, no qual a tensão de compressão constante e igual a $0,85 \mathrm{f}$ cd

- um trecho no qual a tensão de compressão varia segundo uma parabola de segundo grau, saindo do ponto de deformação igual a zero, $(\varepsilon=0)$, ate o ponto de 
deformaçăo igual a $2 \%\left(\varepsilon_{c}=2 \%\right.$. ).

\section{b) Diagrama retangular}

Podem ser considerados com:

- altura $y=0,8 x$ e $\sigma_{c d}=0,85 f_{c d}$ - este é utilizado para seções de concreto constantes ou crescentes no sentido das fibras mais comprimidas;

- altura $y=0,8 x$ e $\sigma_{c d}=0,80 f_{c d}$ - este é utilizado para seções de concreto de largura decrescente no sentido das fibras mais comprimidas.

5.6. 3 - EQUAÇOES GERAIS DE EQUILIBRIO

A figura 5.9 mostra uma seçăo de concreto armado submetido ao momento $M$.

Equaçöes de equilibrio:

$\Sigma F=0 \longrightarrow R_{e}+R_{s}^{\prime}-R_{s}-R_{t}=0$

$M_{e x t}=M_{\text {int }} \longrightarrow M_{\text {ext }}=R_{c} \cdot z_{c}+R_{s}(x-d)+R_{t} \cdot z_{t}+R_{s}(d-x)$ 


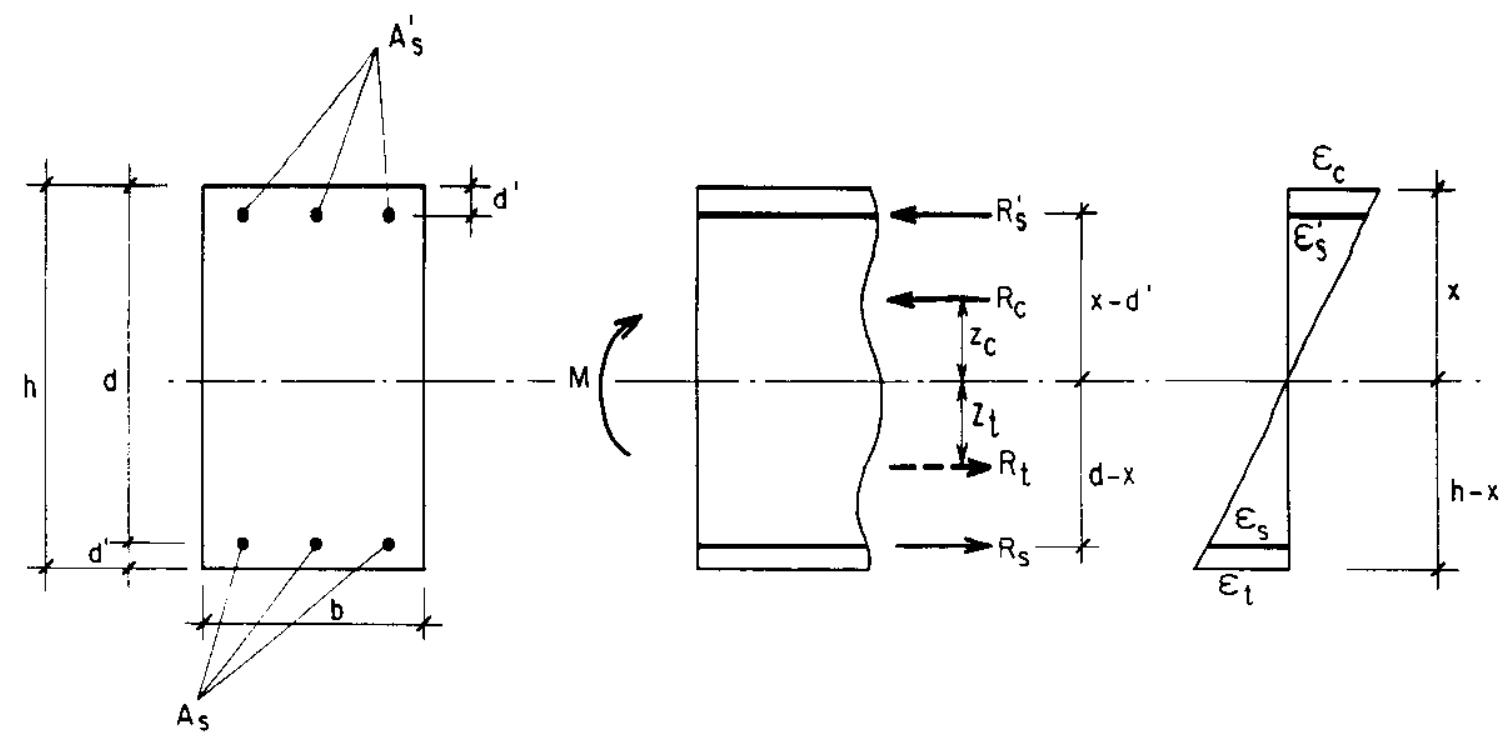

FIG. 5.) - SEÇẮ RETANGULAR DE CONCRETO COM ARMAdURA DUPLA

a) Concreto simples

Só e possivel nos estadios Ia e Ib. Săo válidas as equaçöes $(5.7)$ e $(5.8)$, desde que satisfeita as seguintes condiçชes:

$$
\begin{aligned}
& R_{S}=0 \\
& R_{S}^{\prime}=0
\end{aligned}
$$




\section{b) Armadura simples}

Em seçơs de concreto com armadura simples, nos estádios II e III, săo válidas as equações (5.7) e (5.8), desde que satisfeita as condiçớs:

$$
\begin{aligned}
& R_{t}=0 \\
& R_{s}^{\prime}=0
\end{aligned}
$$

En seçöes de concreto com armadura simples no estadio I, a condição de ser satisfeita e:

$$
R_{s}^{\prime}=0
$$

c) Armadura dupla nos estádtos II e III

Nos estádios I I $e$ I I despreza-se a colaboração do concreto tracionado:

$$
R_{t}=0
$$

5.6. 4 - EQUAÇOES DE COMPATIBILIDADE DE DEFORMACOES

Do diagrama de deformaçoes, figura 5.9, são obtidas as equaçöes de compatibilidade de deformaçoses:

$$
\frac{\varepsilon_{c}}{x}=\frac{\varepsilon_{s}^{\prime}}{x-d^{\prime}}=\frac{\varepsilon_{s}}{d-x}=\frac{\varepsilon_{t}}{h-x}
$$


$\varepsilon_{c}$ - máxima deformação especifica do concreto a compressao;

$\varepsilon^{\prime}$ - deformação especifica do aço à compressão;

$\varepsilon_{t}$ - deformaçăo especifica do concreto à tração;

$\varepsilon_{s}$ - deformaçăo especifica do aço à tração.

\section{6 .5 - EQUAÇOES CONSTITUTIYAS}

As equaçóes constitutivas relacionam deformaçães com tensóes. Para os aços, dados pela NBR 6118, tem-se os diagramas tensరes-deformaçðes dos aços classe $A$ e B. Para - concreto, estas equaçóes constitutivas depedem de estádio en que se encontra a peça de concreto. 


\section{6 - METODO CLASSI CO}

0 metodo clássico decorre da adaptaçăo das hipoteses que regem a teoria classica da resistencia dos materiais as peças de concreto. Para que se apliquem ao concreto estas hipoteses, é necessario que se transforme a seção heterogênea, composta de concreto e de aço, em uma seção homogênea.

\section{1 - HOMOGENEIZAÇXO DA SEÇAO}

Nas peças de concreto armado, toma-se o concreto como material de referência, ou seja, a área de armadura é substituida por uma área de concreto que resista ao mesmo esforço (fig. 6.1).

De acordo com a figura 6.1 a admitindo-se a aplicabilidade da Lei de Hooke, tem-se: 


$$
\begin{aligned}
& \varepsilon_{s}=\frac{\sigma_{s}}{E_{s}}=\frac{\sigma_{c s}}{E_{c}} \\
& \sigma_{s}=\frac{E_{s}}{E_{c}} \cdot \sigma_{c s} \\
& \sigma_{s}=\alpha_{s} \cdot \sigma_{c s} \\
& \sigma_{c s}=\frac{\sigma_{s}}{\alpha_{\theta}}
\end{aligned}
$$

Analogamente,

$$
\sigma_{c g}^{\prime}=\frac{\sigma_{9}^{\prime}}{\alpha_{\theta}}
$$

sendo:

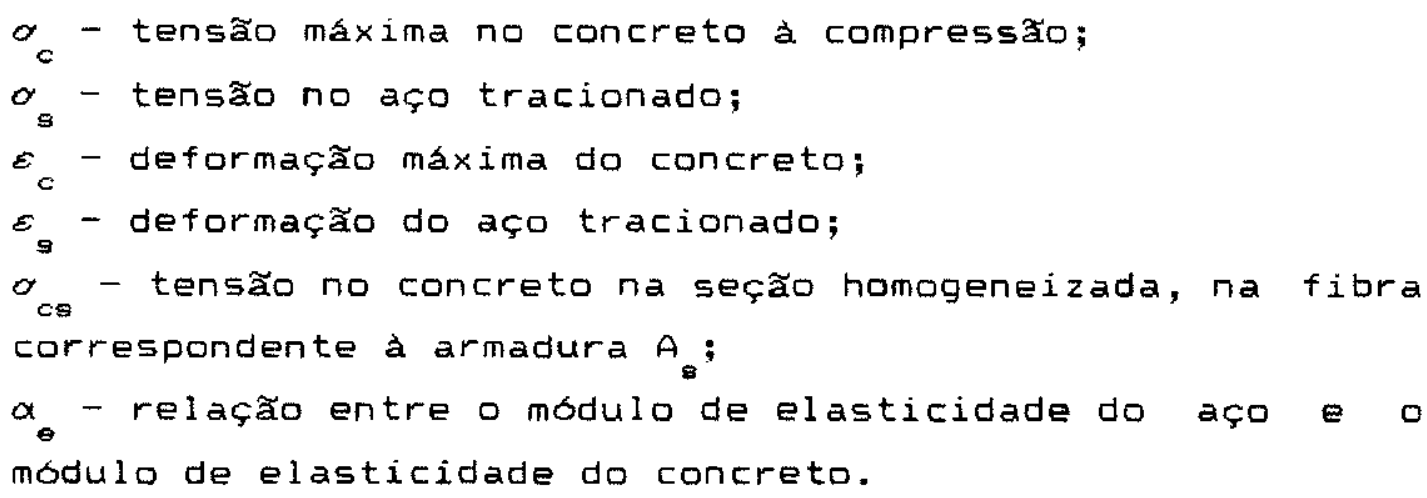

A área equivalente de concreto, que substitui a área de aço, ebtida igualando-se os esforços resistentes:

$$
\sigma_{c s} \cdot A_{c s}=\sigma_{s} \cdot A_{s} \longrightarrow A_{c s}=\frac{\sigma_{s}}{\sigma_{c s}} \cdot A_{s}
$$

Substituindo a equação $(6.4)$ em (6.6), resulta:

$$
A_{c s}=\alpha_{e} \cdot A_{s}
$$


Sendo $E_{c}$ e $E_{s}$ admitidos como tendo o mesmo valor, tanto na compressăo quanto na traçăo, conclui-se que:

$$
\begin{aligned}
& \sigma_{s c}^{\prime}=\frac{\sigma_{s}^{\prime}}{\alpha_{s}} \\
& A_{s c}^{\prime}=\alpha_{g} \cdot A_{s}
\end{aligned}
$$

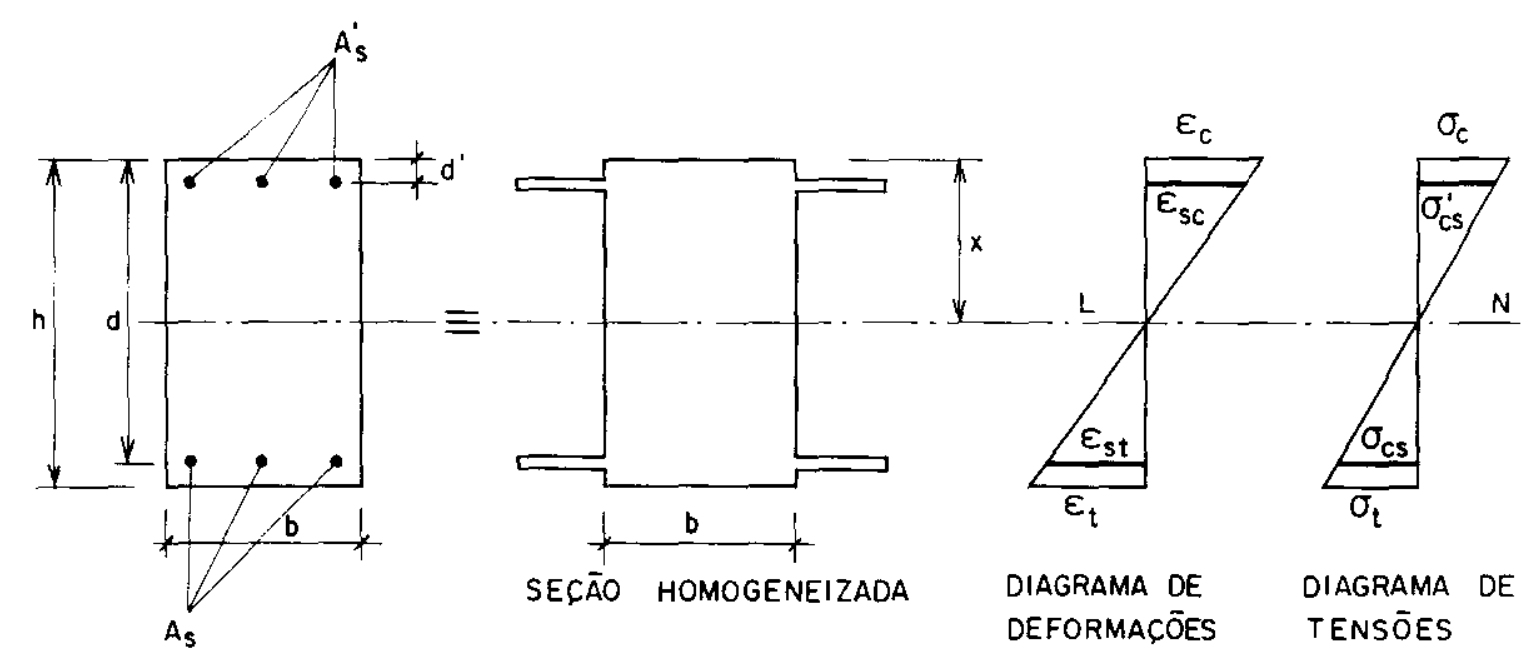

FIG. б. 1 - HOMOGENEIZAÇĂO DA SEĢĂO

\section{2 - COMPATIBILIDADE DAS TENSOES}

Da Iinearidade do diagrama de tensbes, figura (6.1), resulta: 


$$
\frac{\sigma_{c}}{x}=\frac{\sigma_{c s}^{\prime}}{x-d^{\prime}}=\frac{\sigma_{t}}{h-x}=\frac{\sigma_{c s}}{d-x}
$$

Considerando as equaçóes $(6.4)$ e $(6.5)$ em $(6.10)$, resulta:

$$
\frac{\sigma_{c}}{x}=\frac{\sigma^{\prime}}{\alpha_{e}\left(x-d^{\prime}\right)}=\frac{\sigma_{t}}{h-x}=\frac{\sigma_{s}}{\alpha_{e}\left(d^{-x}\right)}
$$

\section{3 - VERIFICAÇZO NO ESTADIO Ia}

Baseia-se na hipotese de Bernoulli (ale a ruptura, as seçôes transversais permanecem planas), Lei de Hooke, Lei de Navier (as tensöes são proporcionais a distancia a linha neutra, para materiais homogeneos), Lei da Homogeneização e no concreto resistindo à traçăo.

\subsection{1 - DETERMINAÇAO DA POSI ÇXO DA LINHA NEUTRA}

A posiça da lintia neutra pode ser determinada em função das caracteristicas geometricas da seç̃o transversal.

Fazendo o momento estático da seção homogeneizada, em relaçăo à linha neutra, igual a zero, figura 6.1 , tem-se:

$$
\text { b. } \frac{x^{2}}{2}+\alpha_{e} \cdot A_{s}^{\prime}\left(x-d^{\prime}\right)-b(h-x) \cdot \frac{h-x}{2}-a_{e} \cdot A_{s}(d-x)=0
$$


$x=\frac{\frac{b h^{2}}{2}+\alpha_{e}\left(A_{s} \cdot d+A_{s}^{\prime} \cdot d^{\prime}\right)}{b h+\alpha_{e}\left[A_{s}+A_{s}^{\prime}\right)}$

\subsection{2 - MOMENTO DE INERCIA}

Conhecendo-se a posiçăo da linha neutra, calcula-se o momento de inércia da seção homogeneizada através da equação:

$I=\frac{b h^{3}}{12}+b h\left(\frac{h}{2}-x\right)^{2}+a_{e} \circ A_{s}^{\prime}(x-d)^{2}+a_{\theta} \circ A_{s}(d-x)^{2}$

6.3.3 - TENSOES

Determinada a posição da linha neutra e o momento de inercia da seçăo transversal em relação a ela, calcula-se a tensão em qualquer ponto da seçã logo:

$\sigma_{c}=\frac{M}{I} \cdot x$

$\sigma_{c t}=\frac{M}{I} \cdot(h-x)$

$\sigma_{s}^{\prime}=\alpha_{\theta} \cdot \frac{M}{I} \cdot\left(x-d^{\prime}\right)$

$\sigma_{s}=\alpha_{e} \cdot \frac{M}{I} \cdot(d-x)$ 


\section{3.4 - DEFORMAÇOES}

Admitindo-se a validade da Lei de Hooke para ambos os materiais, tem-se:

$$
\begin{aligned}
& \varepsilon_{c}=\frac{\sigma_{c}}{E_{c}} \\
& \varepsilon_{c t}=\frac{\sigma_{c t}}{E_{c}} \\
& \varepsilon_{s}^{\prime}=\frac{\sigma_{s}^{\prime}}{E_{s}} \\
& \varepsilon_{s}=\frac{\sigma_{s}}{E_{s}}
\end{aligned}
$$

\section{4 - VERIFICACXO NO ESTADIO II}

Baseia-se na hipótese de Bernoulli, na Lei de Hooke, de Navier e da Homogeneização e na hipotese da resistência de concreto à tração ser nula.

\section{4. 1 - DETERMINAÇAO DA POSI ÇAO DA LINHA NEUTRA}

No estádio II, despreza-se a colaboraçăo do concreto tracionado.

Fazendo o momento estático da seçăo homogeneizada, em relaçăo a linha neutra, igual a zero, obtem-se as equaçơs: 
$b \cdot \frac{x^{2}}{5}+a_{\theta} \cdot A^{\prime}\left(x-d_{\prime}\right)-a_{\theta} \cdot A^{2}(d-x)=0$

$x^{2}+\frac{2^{a} e}{b}\left(A_{s}+A_{s}^{\prime}\right) x-\frac{2^{a_{e}}}{b}\left(A_{s} \cdot d+A_{s}^{\prime} \cdot d^{\prime}\right)=0 \quad(6.22 b)$

\subsection{2 - MOMENTO DE INERCIA}

o momento de inercia da seça homogeneizada em relagão

a Iinha neutra e dado pela equação:

$I=\frac{b x^{3}}{12}+b x\left(\frac{x}{2}\right)^{2}+\alpha_{\theta} \cdot A_{g}^{\prime}\left(x-d^{\prime}\right)^{2}+\alpha_{\theta} \cdot A_{s}(d-x)^{2} \quad(0.23)$

\section{5 - MOMENTO FLETOR DE FISSURACAO}

o momento fletor de fissuração, $M_{r}$, corresponde à primeira fissura da peça.

6.5.1 - CALCULO SEGUNDO A NBR $7197 / 89$

Seu calculo e baseado nas hipoteses do estadio la:

$M_{r}=\frac{f_{c t m}-I}{h-x}$ 
onde:

$f_{\text {ctm }}$ - resistencia do concreto a tração na flexăo;

$f_{c t m}= \begin{cases}1,2 f_{c t k} & \text { para seção } T \text { ou duplo } T \\ 1,5 f_{c t k} & \text { para seção retangular }\end{cases}$

$\alpha_{e}= \begin{cases}15 & \begin{array}{l}\text { para carregamentos freqüentes ou } \\ \text { quase permanentes; }\end{array} \\ 10 & \text { para carregamentos raros; }\end{cases}$

$f_{c t k}= \begin{cases}\frac{f_{c k}}{10} & \text { para } f_{c k} \leq 18 \mathrm{MPa} \\ 0,06 f_{c k}+0,7 \mathrm{MPa} & \text { para } f_{c k}>18 \mathrm{MPa}\end{cases}$

$f_{\text {ctk }}$ - resistencia caracteristica do concreto à tração

6.5.2 - CALCULO SEGUNDO O CEB $/ 90$ O cálculo segundo o CEB/90 também e baseado nas
hipóteses do estádio Ia:

$M_{r}=f_{c i} \circ W_{1}$

$w_{1}=\frac{I}{h-x}$

sendo:

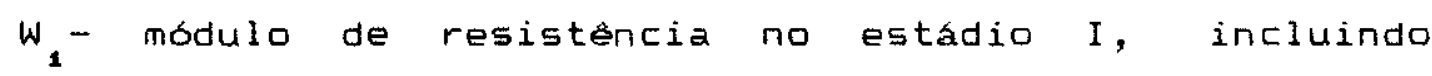
armadura; 


$$
f_{c t}= \begin{cases}0,7 f_{c t m} & \begin{array}{l}
\text { se deformaçóes locais devem ser } \\
\text { consideradas }
\end{array} \\
f_{\text {ctm }} & \text { se os efeitos dos deslocamentos em } \\
& \text { toda a peça devem ser considerados }\end{cases}
$$

$$
f_{c t m}=1,4\left(\frac{f_{c k}}{10}\right)^{2 / 3}(M P a)
$$

$E_{c}=21500\left(\frac{{ }^{f} \mathrm{~cm}}{10}\right)^{1 / 3}$

$$
f_{\mathrm{cm}}=f_{\mathrm{ck}}+8 \mathrm{MPa}
$$

$$
\begin{aligned}
& a_{\theta}=\frac{E_{s}}{E_{c}} \\
& E_{s}=200 \mathrm{GPa}
\end{aligned}
$$




\section{7 - ENSAIOS DE VIGAS}

Os ensaios foram realizados no laboratório do Departamento de Engenharia de Estruturas, com a coordenação do Professor T. Takeya, sendo os resultados aproveitados para a realizaçăo deste trabalho. Consistem en submeter uma viga em concreto armado a flexăo, atraves da aplicação de duas forças eqüidistantes dos apoios. 0 carregamento e aplicado gradualmente ate a viga atingir a ruina. Em cada incremento de carga săo medidas as deformaçōes, na armadura e no concreto, e os deslocamentos ocorridos. As deformaços são medidas atraves de extensómetros eletricos (EE). Para a determinação dos deslocamentos, săo utilizados transdutores de deslocamentos (TD), conforme fig. 7.1 .

As seis vigas ensaiadas apresentavam diferentes armaduras de flexăo $e$ foram divididas em três grupos distintos, conforme o numero de barras: $3 \phi 10,5 \phi 10$ e $7 \phi 10$.

Na determinação da posiçăo da linha neutra e do momento de inercia, foi considerado $\alpha_{\theta}=E_{s} / E_{c} \cdot 0$ carregamento foi de curta duração e aplicado aos 28 dias. Ensaiaram-se duas vigas de cada grupo e por apresentarem resultados muito próximos, adotou-se a media aritmética entre eles. A resistencia do concreto estimada era de 25 MPa mas, nos ensaios realizados em curpos-de-prova, a resistência alcançada foi de 23,93 MPa. Portanto, a resistencia utilizada nos cálculos foi a encontrada experimentalmente. Por se tratar de carregamento de curta duração, foi considerada uma tensão de calculo igual a 
$f_{c}$, em vez de $0,85 f_{c}$. Conforme dito anteriormente, foram colocados extensómetros eletricos em todas as barras de aço, determinando-se assim a deformaçăo ocorrida em cada barra. Com isto, foram obtidos varias curvas forfas $x$ deformaçós para cada viga ensaiada. Neste caso, tambem foi utilizado o critério da média entre as deformaçð̌s. Assim, cada caso considerado apresenta apenas uma curva $F$ $x \varepsilon_{s}$. Para as deformaçóes no concreto, tambem foi utilizado o mesmo critério.

Para as flechas, foram considerados os valores registrados pelo transdutor de deslocamentos localizado no meio do văo, conforme fig. 7.1.

\section{1 - ESQUEMA DO ENSAIO}

o esquema de ensaio encontra-se indicado na figura 7.1 .

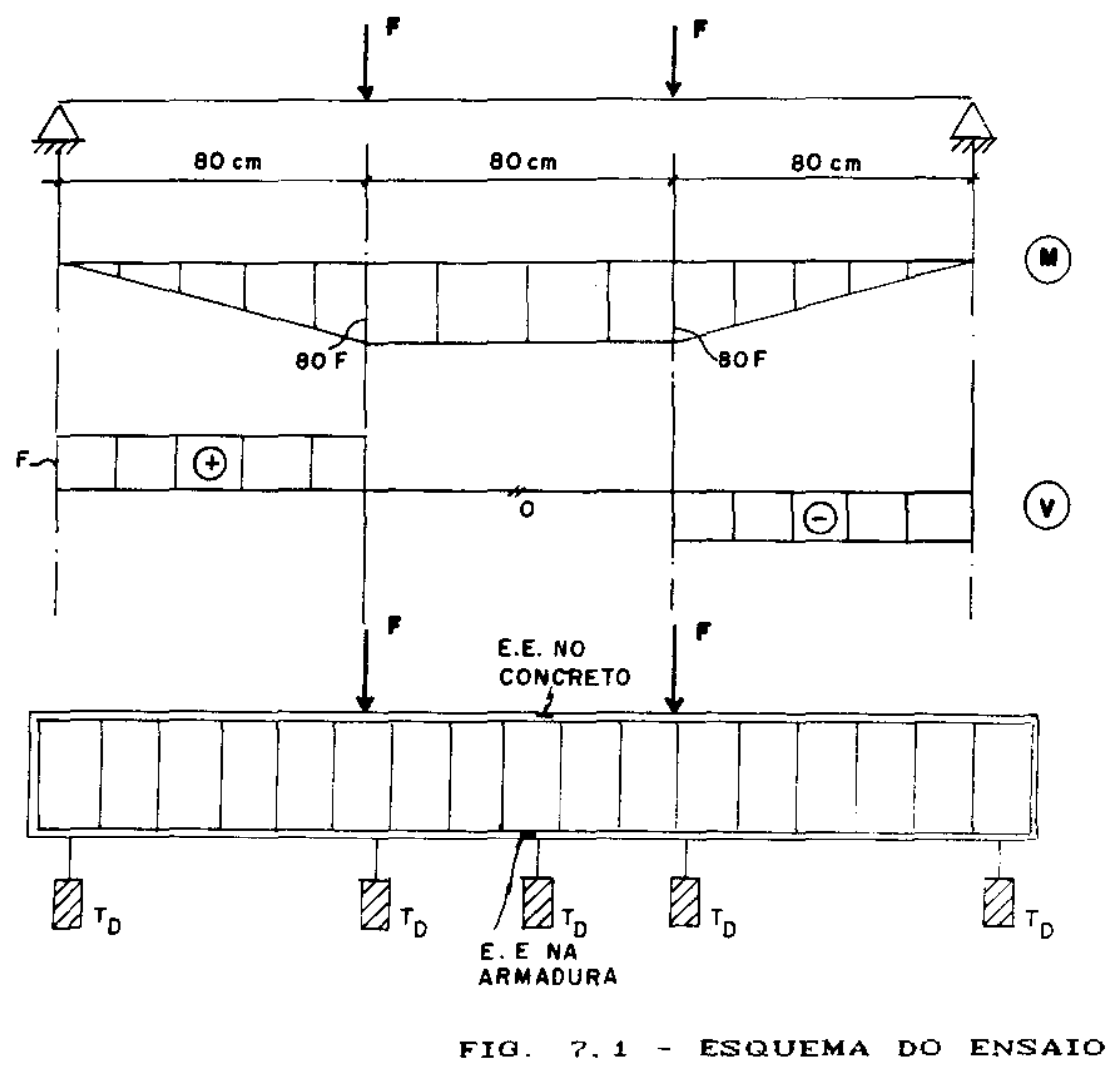

E.E. NO CONCRETO (2)

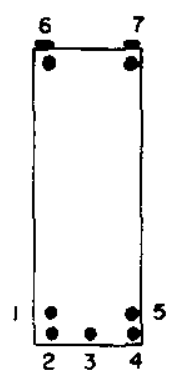

E.E. NA ARMAOURA 15 


\section{2 - DADOS INICIAIS}

Em todas as vigas foram utilizados:

aço $C A-50 A$

concreto: traço em peso 1: 2,42:4,03; aic $=0,50$

consumo de cimento $=310 \mathrm{~kg} / \mathrm{m}^{3}$

$f_{\text {cj,est }}=25 \mathrm{MPa}$

$j=28$ dias
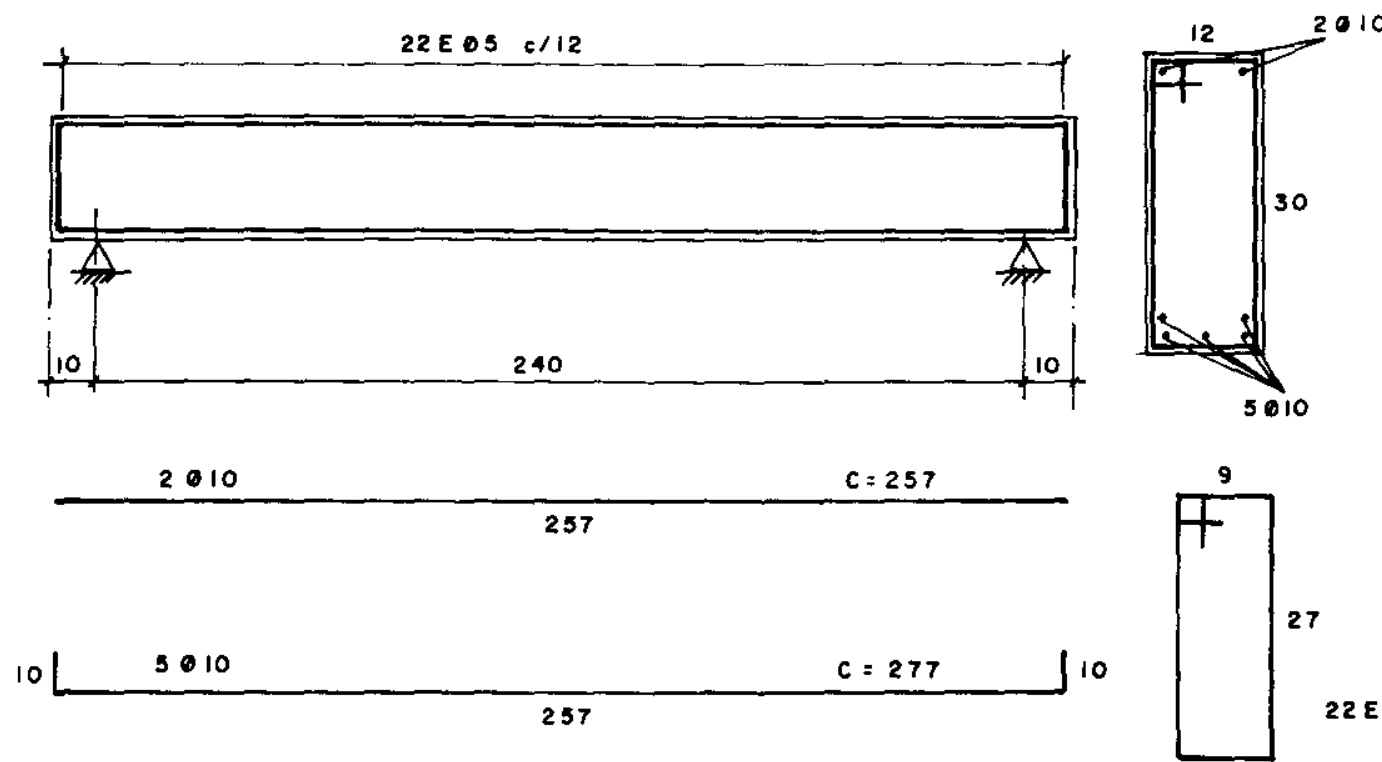

27

$22 \varepsilon \bullet 5 \mathrm{c} / 12$ $c=90$

FIG. ?. 2 - VIGA EM CONCRETO ARMADO

As vigas apresentavam $260 \mathrm{~cm}$ de comprimento com seça transversal de $12 \mathrm{~cm} \times 30 \mathrm{~cm}$, conforme fig. 7.2 . 


\section{3 - DIMENSIONAMENTO DO MODELO}

Aplicando as equaçóses de equilibrio para o dimensionamento do modelo, segundo esquema da figura 7.3 , tem-se:
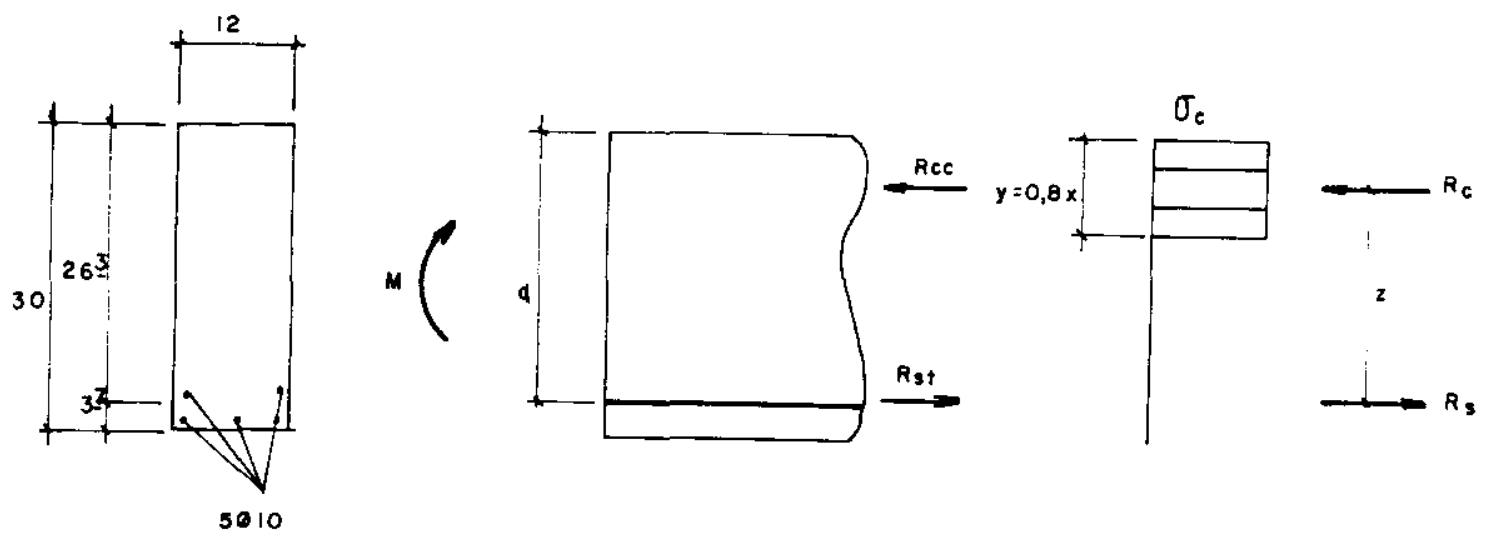

FIG. 7.9 - DIMENSIONAMENTO DO MODELO

$$
\begin{aligned}
& R_{c}=R_{s} \\
& R_{c}=0,8 \cdot x \cdot b \cdot c_{c} \\
& R_{s}=o_{s} \cdot A_{s}
\end{aligned}
$$


Fazendo $\beta_{x}=\frac{x}{d}$, tem-se a resultante do concreto a compresรão:

$R_{c}=0,8 \cdot \beta_{x} \cdot b \cdot d \cdot \sigma_{c}$

A segunda equação de equilibrio fornece:

$$
M=R_{c} \cdot z=R_{s} \cdot z
$$

Substituindo-se na equação $(7.4)$ os valores dados pelas expressces $(7.2)$ e (7.3), obtém-se a expressão para cálculo da área de aço, $A_{s}$ :

$A_{s}=\frac{0,8 \cdot \beta_{x} \cdot b \cdot d \cdot \sigma_{c}}{\alpha_{s}}$

Considerando-se a deformação especifica do concreto igual a $0,35 \%$ e a deformaçăo caracteristica de escoamento do aço iqual a relação entre a resistência caracteristica de escoamento e o módulo de deformação longitudinal, tem-se:

$\varepsilon_{y k}=\frac{f_{y k}}{E_{s}}=\frac{500}{210} \cdot 10^{-3}=2,381 \cdot 10^{-3}$

$\beta_{x}=\frac{\varepsilon_{c}}{\varepsilon_{c}+\varepsilon_{y k}}=0,595$ 
Logo, $\operatorname{com} a_{c}=25 \mathrm{MPa}, f_{y k}=500 \mathrm{MPa}$ e a equaçăo (7.5) determina-se:

$A_{s}=7,51 \mathrm{~cm}^{2}$

Para armaduras menores do que a calculada, tem-se seçăo subarmada, $\square$ que ocorre nos tres casos considerados, em que $A_{s}$ vale respectivamente $2,4 \mathrm{~cm}^{2}, 4,0$ $c m^{2}$ e $5, \dot{c m^{2}}$.

7.4 - CÁLCULO do MOMENTO FLETOR DE RUINAC M $M_{4}$ )

Sera determinado o momento de ruina de una viga em concreto armado com sefão retangular e armada com 5 p 10 (fig. 7.4$)$.
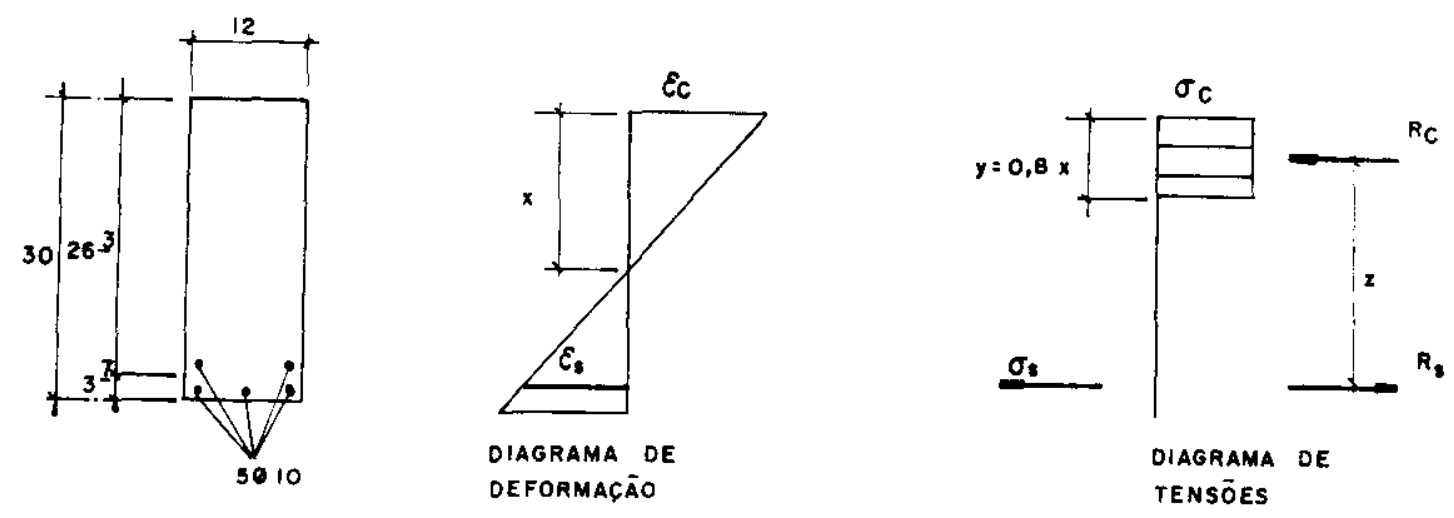

FIG. 7. - CALCULO DO MOMENTO DE RUINA 
A altura útil para a viga considerada é de $26,3 \mathrm{~cm}$ e a distancia da fibra mais tracionada ao centro de gravidade da armadura de $3,7 \mathrm{~cm}$, conforme figura 7.4. Considera-se que a peça está trabalhando no estádio III, domínio III, ou seja, deformaçăo específica no concreto igual a 0,35\% e deformação no aço localizada no patamar de escoamento, $\varepsilon_{y}<\varepsilon_{s}<10 \%$. Considerando a resistência do concreto à compressão igual a $23,93 \mathrm{MPa}$ e a resistencia de escoamento do aço igual a $500 \mathrm{MPa}$, tem-se:

Equações de equilibrio:

$$
\begin{aligned}
& R_{c}=R_{s} \\
& R_{c}=b \cdot y \cdot \sigma_{c} \\
& R_{s}=\sigma_{s} \cdot A_{s}
\end{aligned}
$$

Levando as equaçớs (7.7) e (7.8) en (7.6), obtém-se a altura do diagrama retangular, figura 7.4.

$$
\begin{aligned}
& y=\frac{A_{s} \cdot \sigma_{s}}{b \cdot \sigma_{c}}=6,97 \mathrm{~cm} \\
& \text { o braço de a lavanca, } z, \text { dado por: } \\
& z=d-\frac{y}{2}=22,82 \mathrm{~cm} \\
& \text { Logo, o momento de ruina }\left(M_{u}\right) \text { dado por: } \\
& M_{u}=R_{c} \cdot z=R_{s} \cdot z=4564 \mathrm{kNcm}
\end{aligned}
$$

Portanto:

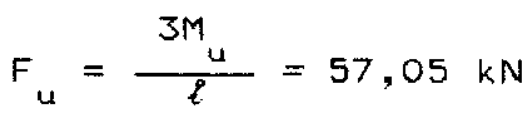

Analogamente, para os outros dois casos considerados, 
$3 \phi 10$ e $7 \phi 10$, determinou-se o momento de ruina, igual a $3049,20 \mathrm{kNcm}$ e $5616,90 \mathrm{kNcm}$, respectivamente.

\section{5 - CALCULO DO MOMENTO FLETOR DE FISSURAÇÃO (M)}

O momento de fissuração, $M_{r}$, corresponde a primeira fissura da peça. Portanto o cálculo é baseado nas hipoteses do estadio la. Logicamente o calculo deste momento obedece criterios especificos de cada norma; ver item 0.5.
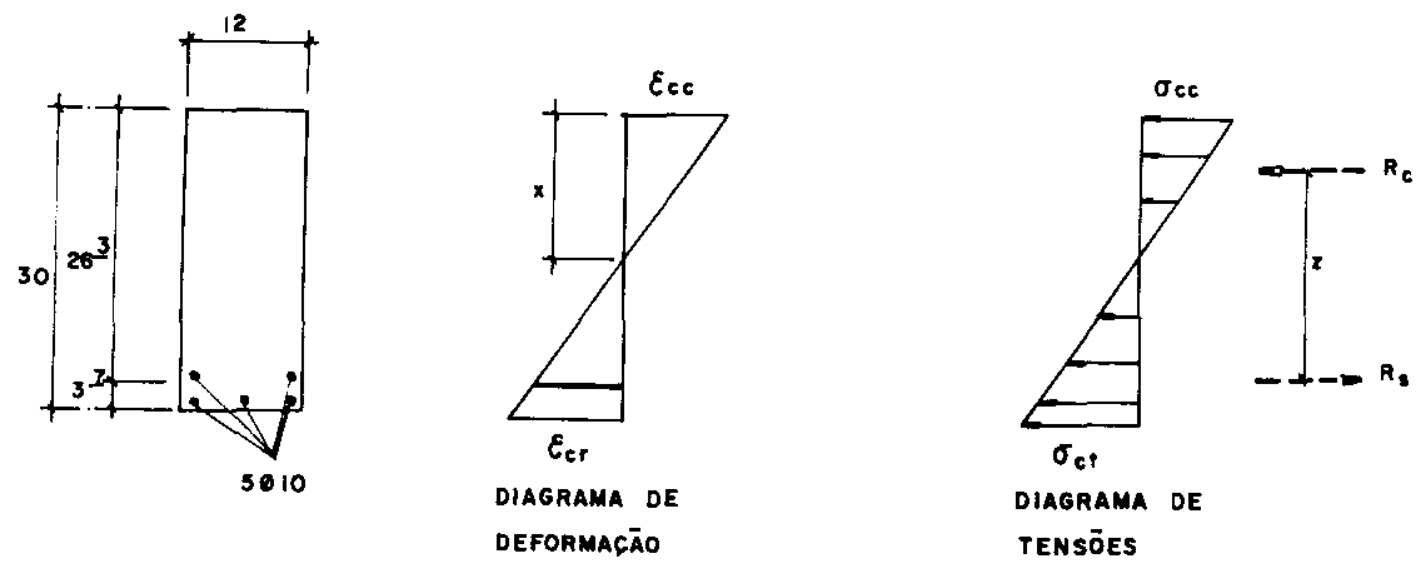

Fig. 7.5 - CALCULO DO MOMENTO DE Fisisuraçä́ 


\section{a) Momento fletor de fissuraçăo segundo a NBR $7197 / 89$}

Considerando a área de aço igual a $4 \mathrm{~cm}^{2}, 5 \phi 10$, sendo módulo de deformação do concreto na origem 32286 MPa e o módulo de deformação longitudinal do aço $210 \mathrm{GPa}$, item 6.5.1, tem-se:

$$
\begin{aligned}
& f_{c K}=23,93 \mathrm{MPa} \\
& f_{c t K}=2,14 \mathrm{MPa} \\
& f_{c t M}=3,2 \mathrm{MPa} \\
& E_{c}=6600 \cdot\left(f_{c}\right)^{1 / 2}=32286 \mathrm{MPa} \\
& \alpha_{e}=\frac{E_{s}}{E_{c}}=6,50
\end{aligned}
$$

A posição da linha neutra pode ser determinada em função das caracteristicas geometricas da seça transversal. Fazendo o momento estatico da seção homogeneizada, em relação a linha neutra, igual a zero, conforme item 6.3 .1 , obtem-se:

$x_{1}=15,76 \mathrm{~cm}$

Conhecendo-se a posiçăo da linha neutra, calcula-se o momento de inécia da seção homogeneizada, item 6.3.2:

$I_{1}=30097 \mathrm{~cm}^{4}$

Portanto, o momento de fissuraçăo segundo o item 6.5 .2 é dado por:

$M_{r}=676,34 \mathrm{kNcm}$ 
Logo:

$F_{r}=\frac{3 M_{r}}{\ell}=8,46 \mathrm{kN}$

Para os outros dois casos considerados, $3 \phi 10$ e $7 \phi 10$, o momento de fissuração determinado foi igual a $648,40 \mathrm{kNcm}$ e $687,82 \mathrm{kNcm}$, respectivamente.

b) Momento fletor de fissuraçăo segundo o CEB-90

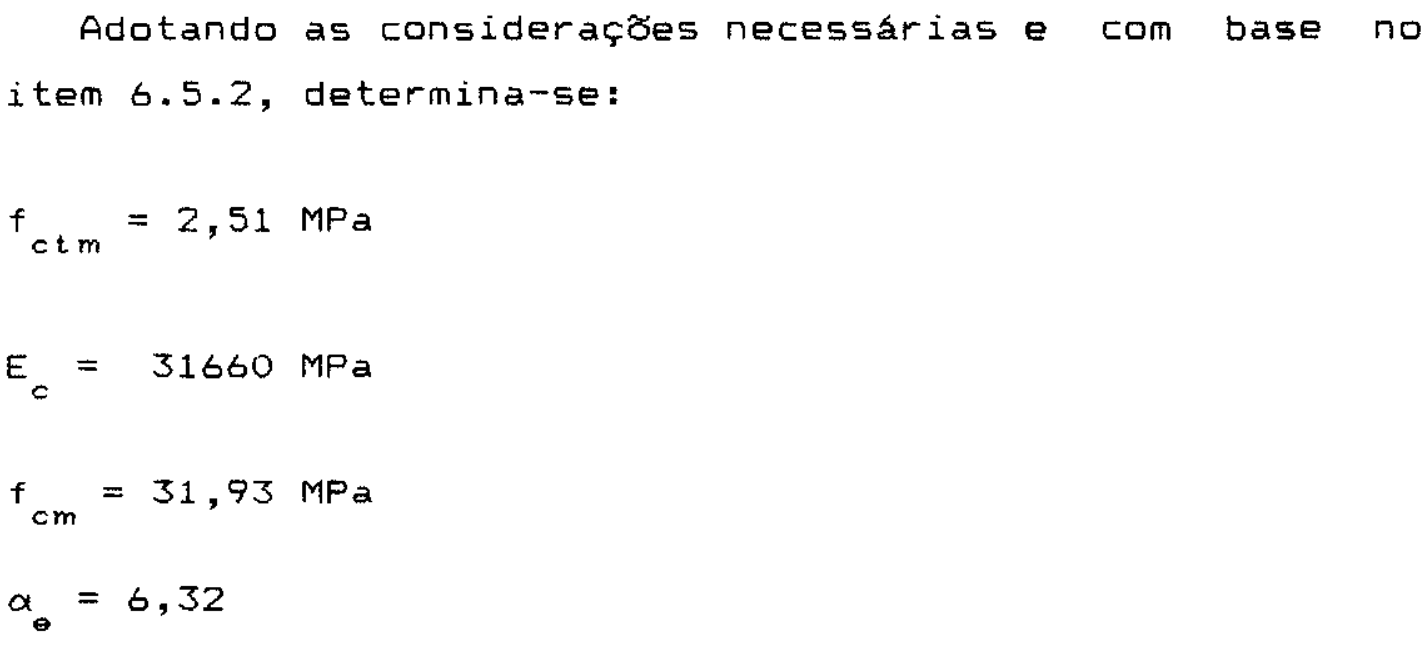

Portanto, o momento de fissuração e dado por:

$M_{r}=528,33 \mathrm{kNcm}$

Logo, a força correspondente ao momento de fissuraçăo e de $6,60 \mathrm{kN}$.

Analogamente, determinou-se o momento de fissuraçăo, $507,10 \mathrm{kNcm}$ e $536,83 \mathrm{kNcm}$, para os outros dois casos considerados, respectivamente. 


\section{6 - TENSOES E DEFORMAÇOES}

Determinada a posição da linha neutra e o momento de inércia da seçăo transversal em relação a ela, calcula-se a tensão em qualquer ponto da seção, item 6.3.3. Admitindo-se a validade da Lei de Hooke para ambos os materiais, tem-se as deformações.

$\mathrm{Na}$ determinaçăo das tensðes e das deformaç㐅es, os incrementos de carga utilizados são os mesmos registrados em laboratório e a seção considerada no cálculo está localizada no meio do vão (tabelas 7.1 a 7.3).

\section{a) Tensðes a deformaçðes segundo a NBR 7197/89}

Conforme determinado anteriormente, ate a forca alcançar o valor de $8,46 \mathrm{kN}$, a peça encontra-se no estádio I. De acordo com os itens 6.3 .3 e 6.3 .4 e considerando os cálculos anteriores, tem-se:

$$
\begin{aligned}
& M=80 \mathrm{~F} \\
& \alpha_{\theta}=6,50 \\
& I_{1}=30097 \mathrm{~cm}^{4} \\
& x_{1}=15,76 \mathrm{~cm} \\
& E_{c}=32286 \mathrm{MPa}
\end{aligned}
$$

Tensð̈es e deformaçZ̃es segundo a NBR 7197/89, considerando a peça trabalhando no estádio I: 


$$
\begin{aligned}
& \sigma_{c}=\frac{M}{30097}(15,76) \quad \longrightarrow \quad \varepsilon_{c}=\frac{\sigma_{c}}{32286 \times 10^{2}} \\
& \sigma_{s}=\frac{M}{30097}(10,54) \quad \longrightarrow \quad \varepsilon_{s}=\frac{\sigma_{s}}{32286 \times 10^{2}}
\end{aligned}
$$

Com a força ultrapassando o valor de 8,46 kN, ocorre fissuração e adota-se a hipótese de resistência do concreto à tração ser nula, estádio II. Conforme os itens 6.4 .1 e 6.4.2, determina-se a posição da linha neutra e o momento de inércia. o módulo de deformação do concreto é tomado como sendo o secante.

$$
\begin{aligned}
& E_{c}^{*}=29057 \mathrm{MPa} \\
& x_{2}=9,10 \mathrm{~cm} \\
& I_{2}=11570 \mathrm{~cm}^{4} \\
& E_{s}=210 \mathrm{GPa} \\
& \alpha_{0}=7,23 \\
& M=80 \mathrm{~F}
\end{aligned}
$$

\footnotetext{
Conforme os 1 tens 6.3 .3 e 6.3 .4 e considerando os cálculos anteriores, determinam-se as tenszes $e$ as deformaçôes, no concreto e no aço, estadio II.
}

$$
\begin{aligned}
& \sigma_{c}=\frac{M \cdot(9,10)}{11570} \\
& \sigma_{s}=\frac{M}{11570}(17,20) \cdot 7,23 \longrightarrow \varepsilon_{c}=\frac{\sigma_{c}}{29057 \times 10^{2}} \\
& \varepsilon_{s}=\frac{\sigma_{s}}{210000 \times 10^{2}}
\end{aligned}
$$


b) Tensర̃es e deformaçס̃es segundo o CEB-90

Conforme mencionado anteriormente, tem-se estádio I para forças com valores inferiores a $6,60 \mathrm{kN}$. Segundo os 1tens 6.3 .3 e 6.3 .4 , tem-se:

$$
\begin{aligned}
& E_{c}=31660 \mathrm{MPa} \\
& x_{1}=15,74 \mathrm{~cm} \\
& I_{1}=30016 \mathrm{~cm}^{4} \\
& a_{\theta}=6,32 \\
& M=80 \mathrm{~F}
\end{aligned}
$$

Tensơes e deformações no concreto e no aço considerando estádio I:

$$
\begin{aligned}
& \sigma_{c}=\frac{M}{30016}(15,74) \quad \longrightarrow \quad \varepsilon_{c}=\frac{\sigma_{c}}{31660 \times 10^{2}} \\
& \sigma_{s}=\frac{M}{30016}(10,56) \longrightarrow \varepsilon_{s}=\frac{\sigma_{s}}{31660 \times 10^{2}}
\end{aligned}
$$

Para forcas com intensidade maior que $6,60 \mathrm{kN}$, a peça encontra-se no estádio II. 0 módulo de deformação do concreto considerado e o secante.

$$
\begin{aligned}
& E_{c}^{*}=26911 \mathrm{MPa} \\
& I_{2}=11805 \mathrm{~cm}^{4} \\
& x_{2}=9,20 \mathrm{~cm} \\
& \alpha_{\theta}=7,43 \\
& M=80 \mathrm{~F}
\end{aligned}
$$

Tensbes e deformaçöes no concreto e no aço 
considerando a peça trabalhando no estádio II.

$$
\begin{aligned}
& \sigma_{c}=\frac{M}{11805}(9,20) \quad \longrightarrow \quad \varepsilon_{c}=\frac{\sigma_{c}}{26911 \times 10^{2}} \\
& \sigma_{s}=\frac{M}{11805}(17,10) \cdot 7,43 \longrightarrow \varepsilon_{s}=\frac{\sigma_{s}}{200000 \times 10^{2}}
\end{aligned}
$$

\section{7 - FLECHA NO MEIO DO VAO}

Na determinação das flechas, os incrementos de carga utilizados são os mesmos registrados em laboratório e a seção considerada no cálculo esta localizada no meio do vão, tabelas 7.4 a 7.6 .

Conforme esquema de ensaio, figura 7.1, as vigas ensaiadas foram submetidas a duas forcas concentradas aplicadas equidistantes dos apoios. Para este caso, a flecha elástica máxima é dada pela equação (NASH, 1977):

$a=\frac{23 \cdot F \cdot t^{3}}{648 \cdot E_{c} \cdot I_{1}}$

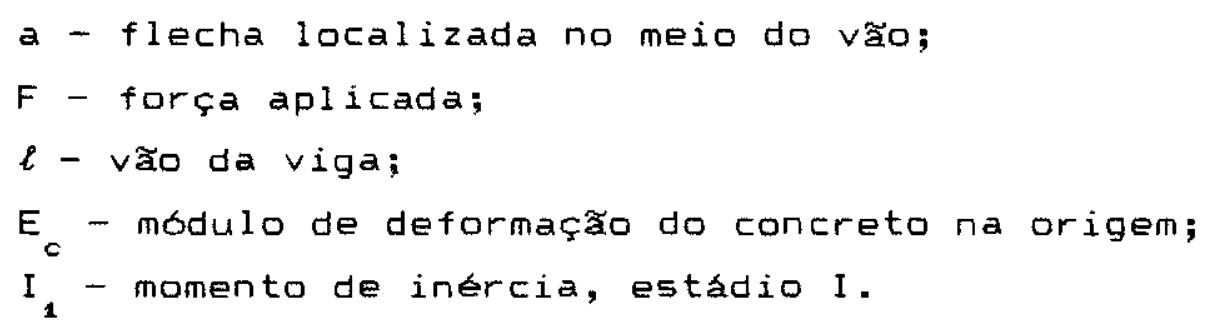


de inércia a ser considerado e o momento de inercia equivalente, o módulo de deformação do concreto e o módulo secante e a flecha no meio do vão é dada por:

$a=\frac{23 \cdot F \cdot \ell^{3}}{648 \cdot E_{\varepsilon}^{*} \cdot 1}$

$E_{c}^{*}$ - módulo de deformação secante do concreto;

I - momento de inercia equivalente, dado pela formula de Branson:

$I_{e}=\left(\frac{M_{r}}{M}\right)^{3} \cdot I_{1}+\left[1-\left(\frac{M_{r}}{M}\right]^{3}\right] \cdot I_{2} \leq I_{1}$

$M_{r}$ - momento de fissuração;

$M=80 \mathrm{~F}$

I - momento de inercia, estádio I;

$\mathrm{I}_{2}$ - momento de inércia, estádio II;

a) Flecha segundo a NBR 7197/89

Considerando a viga no estádio I e a força aplicada menor que $8,46 \mathrm{kN}$, tem-se:

$M=80 F$
$I_{1}=30097 \mathrm{~cm}^{4}$
$E_{c}=32286 \mathrm{MPa}$

Com base na equação 7.9, obtém-se os deslocamentos para cada incremento de carga: tabelas 7.4 a 7.6 . 
Estando a viga trabalhando no estádio II $e$ considerando as equaçóes 7.10 e 7.11 , determinam-se as flechas: tabelas 7.4 a 7.6 .

\section{Conforme os cálculos anteriores, tem-se:}

$$
\begin{aligned}
& M=80 \mathrm{~F} \\
& M_{r}=676,34 \mathrm{kNcm} \\
& E_{c}^{*}=29058 \mathrm{MPa}
\end{aligned}
$$

\section{b) Flecha segundo o CEB/90}

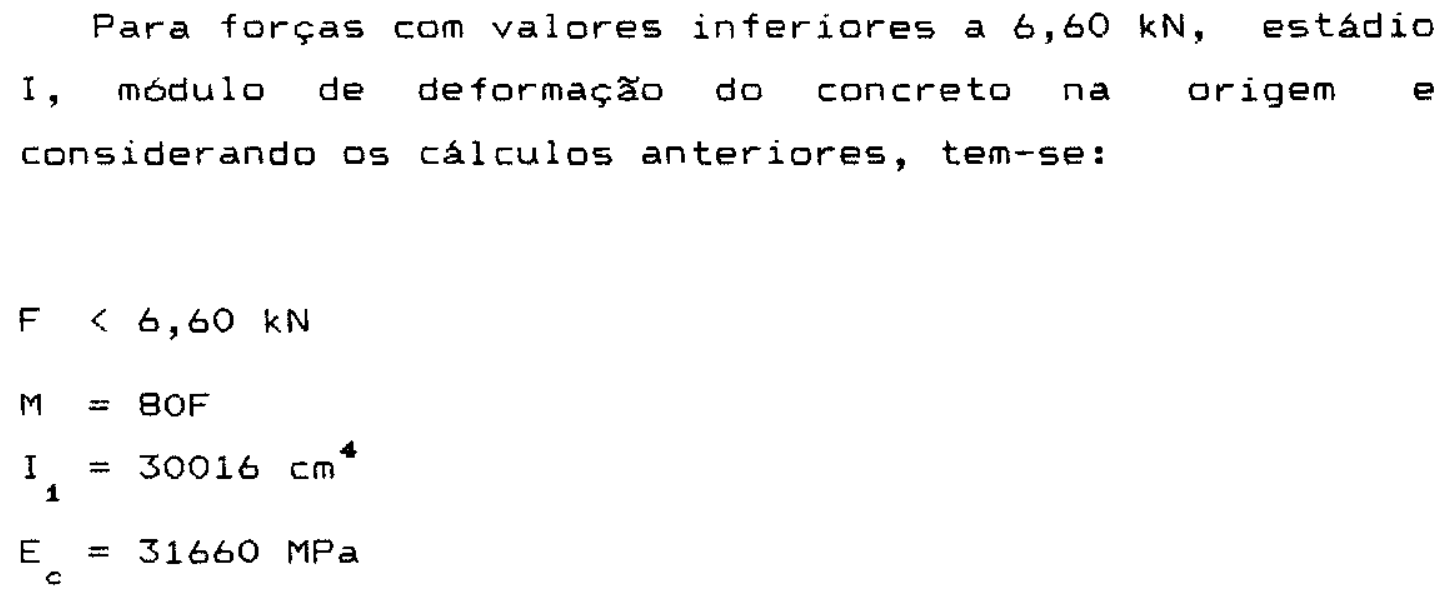




$$
\begin{aligned}
& I_{2}=11805 \mathrm{~cm}^{4} \\
& E_{c}=31600 \mathrm{MPa} \\
& E_{c}^{*}=26911 \mathrm{MPa}
\end{aligned}
$$

\section{8 - RESULTADOS OBTIDOS}

As tabelas 7.1 a 7.3 apresentam os valores obtidos das deformaçöes, no concreto e no aço, correspondentes aos ensaios realizados e aos calculados.

Analogamente, as tabelas 7.4 a 7.6 apresentam os valores das flechas.

Com base nos resultados expressos nas tabelas, determinaram-se os diagramas $F \times \varepsilon_{c}, F \times \varepsilon_{s}$ e $\times$ a que se encontram após a apresentação de cada tabela, respectivamente.

En cada diagrama encontram-se tres curvas. A curva experimental foi obtida com os resultados de laboratório, as teóricas referem-se aos valores encontrados segundo a NBR $7197 / 89$ e, analogamente, tem-se a curva referente ao CEB/90.

E importante ressaltar que os valores experimentais, expressos em todas as tabelas, foram obtidos atraves da média aritmética dos valores encontrados nos ensaios. Isto se deve ao fato de terem sido ensaiadas duas vigas de cada grupo e obtidos valores muito próximos. Quanto aos valores teoricos, a resistencia do concreto utilizada foi a encontrada experimentalmente e não a estimada. 
TABELA 7.1. - FORÇAS X DEFORMAÇÉS: $9 \Phi 10$

\begin{tabular}{|c|c|c|c|c|c|c|}
\hline \multirow[t]{2}{*}{$\begin{array}{l}\text { FORGA } \\
(K N)\end{array}$} & \multicolumn{3}{|c|}{$\begin{array}{c}\text { DEF ORMAÇOES-CONCRETO } \\
\varepsilon_{C}(\mu)\end{array}$} & \multicolumn{3}{|c|}{$\begin{array}{c}\text { DEFORMAÇOES - AÇO } \\
\varepsilon_{\mathrm{s}}(\mu)\end{array}$} \\
\hline & NBR & EXP. & CEB & NBR & EXP. & CEB \\
\hline 2,20 & 26,22 & 45,50 & 26,79 & 20,24 & 27,67 & 20,70 \\
\hline 4,00 & 52,44 & 93,25 & 53,55 & 40,48 & 58,33 & 41,40 \\
\hline 6,00 & 78,65 & 152,00 & 80,33 & 60,71 & 125,50 & 62,10 \\
\hline 8,00 & 104,71 & 240,00 & 207,15 & 80,95 & 223,67 & 534,47 \\
\hline 10,00 & 246,69 & 311,50 & 258,94 & 685,10 & 364,00 & 668,08 \\
\hline 12,00 & 296,03 & 381,50 & 310,73 & 822,11 & 520,33 & 801,70 \\
\hline 14,00 & 345,37 & 438,50 & 362,52 & 959,13 & 678,83 & 935,32 \\
\hline 16,00 & 394,71 & 503,25 & 414,31 & 1096,14 & 920,33 & 1068,94 \\
\hline 18,00 & 444,05 & 569,50 & 466,10 & 1233,16 & 973,50 & 1202,55 \\
\hline 19,95 & 492,15 & 631,75 & 516,59 & 1366,75 & 1141,17 & 1332,83 \\
\hline 22,47 & 554,32 & 669,50 & 581,84 & 1539,40 & 1425,33 & 1501,19 \\
\hline 24,95 & 615,49 & 771,75 & 646,06 & 1709,30 & 1520,67 & 1666,87 \\
\hline 27,53 & 679,14 & 021,50 & 712,86 & 1886,05 & 1801,67 & 1839,24 \\
\hline 30,00 & 740,07 & 105,00 & 776,82 & 2055,27 & 1912,83 & 2004,25 \\
\hline 32,53 & 802,86 & 189,50 & 842,33 & 2228,60 & 2184,67 & 2173,28 \\
\hline 35,00 & 863,42 & 285,00 & 906,29 & 2397,81 & 2318,83 & 2338,30 \\
\hline 37,47 & 924,35 & 388,00 & 970,25 & 2567,03 & 2516,67 & 2503,31 \\
\hline
\end{tabular}




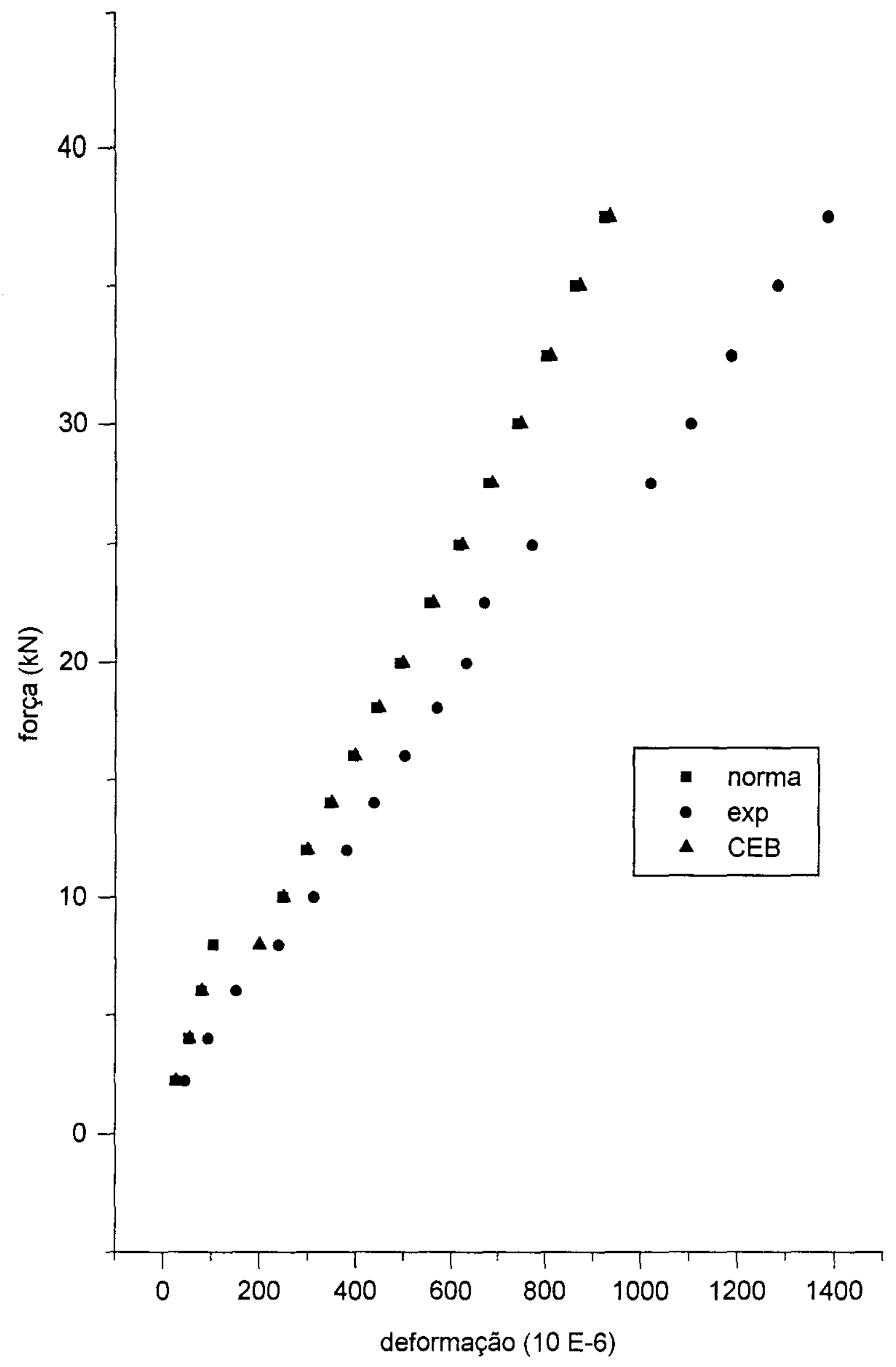

FIG. 7.6 - Diagrama $F \times \varepsilon_{c}-3 \phi 10 \mathrm{~mm}$ 


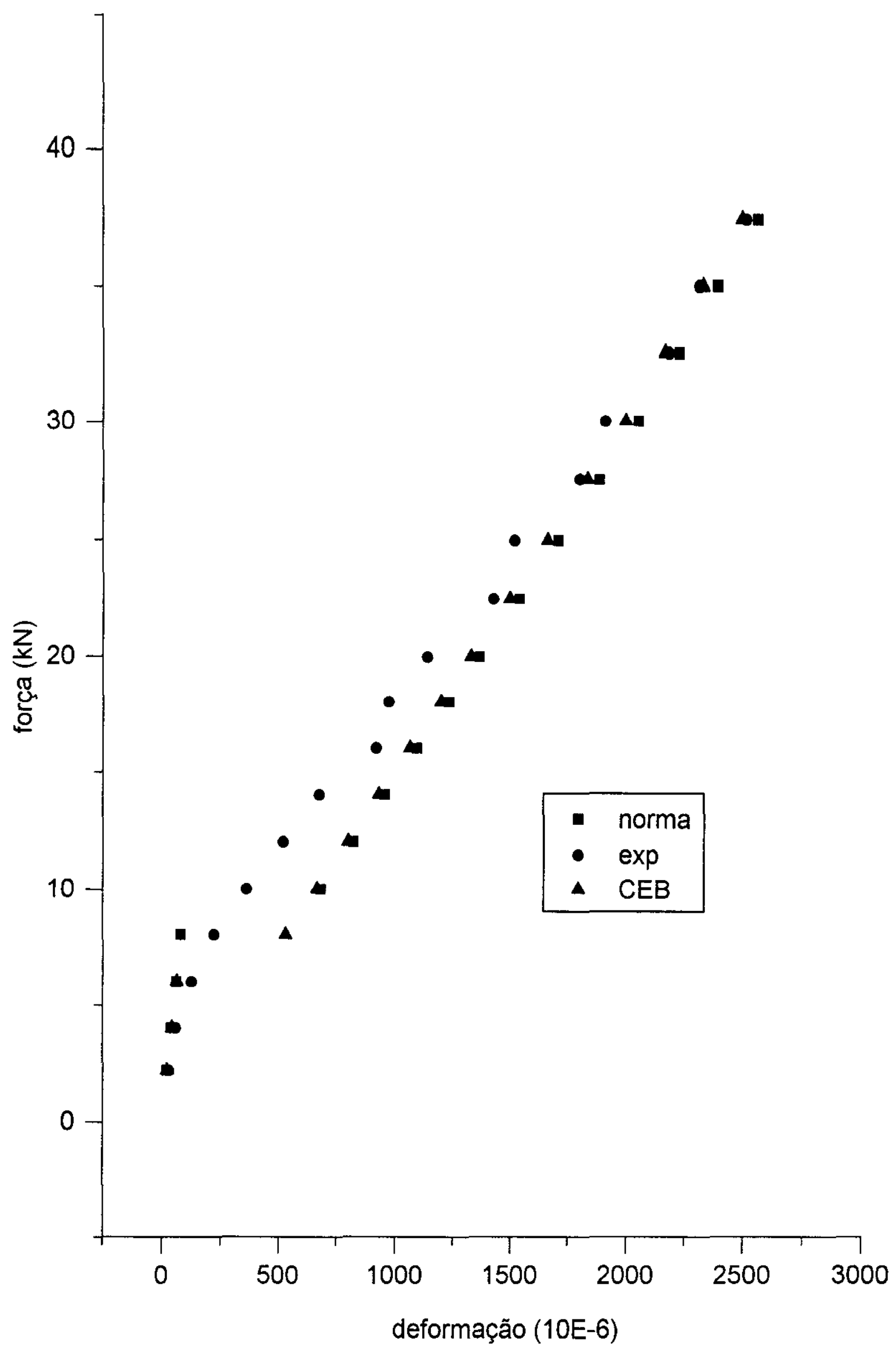

FIG.7.7 - Diagrama de $F \times \varepsilon_{s}-3 \phi 10 \mathrm{~mm}$ 
TABELA 7.2 . FORÇAS X DEFORMAÇচES : $5 \Phi 10$

\begin{tabular}{|c|c|c|c|c|c|c|}
\hline \multirow{2}{*}{$\begin{array}{l}\text { FORG }(\mathrm{kN}) \\
\end{array}$} & \multicolumn{3}{|c|}{$\varepsilon_{c}(\mu)$} & \multicolumn{3}{|c|}{$\varepsilon_{s}(\mu)$} \\
\cline { 2 - 7 } & NBR & EXP. & CEB & NBR & EXP. & CEB \\
\hline 4,95 & 64,22 & 44,25 & 65,59 & 42,95 & 47,60 & 44,00 \\
\hline 7,47 & 96,92 & 71,00 & 155,71 & 64,82 & 91,10 & 316,51 \\
\hline 12,42 & 268,95 & 127,50 & 258,89 & 508,64 & 227,40 & 526,25 \\
\hline 15,00 & 324,82 & 211,00 & 312,66 & 614,18 & 431,10 & 635,30 \\
\hline 19,95 & 432,00 & 335,75 & 415,84 & 816,86 & 772,40 & 845,30 \\
\hline 24,95 & 540,28 & 453,50 & 520,06 & 1021,59 & 1041,80 & 1057,52 \\
\hline 30,00 & 649,63 & 524,50 & 625,32 & 1228,36 & 1262,20 & 1271,12 \\
\hline 34,95 & 756,82 & 704,00 & 728,50 & 1431,04 & 1565,80 & 1480,86 \\
\hline 40,00 & 866,18 & 838,50 & 833,76 & 1637.81 & 1620,50 & 1694,83 \\
\hline 45,00 & 974,45 & 991,75 & 937,98 & 1842,54 & 2101,90 & 1694,83 \\
\hline 49,95 & 1081,64 & 1222,75 & 1041,16 & 2045,22 & 2385,00 & 2116,42 \\
\hline 54,89 & 1188,61 & 2033,00 & 1144,13 & 2247,49 & 2527,00 & 2325,74 \\
\hline$\mu=10-6$ & & & & & \\
\hline
\end{tabular}




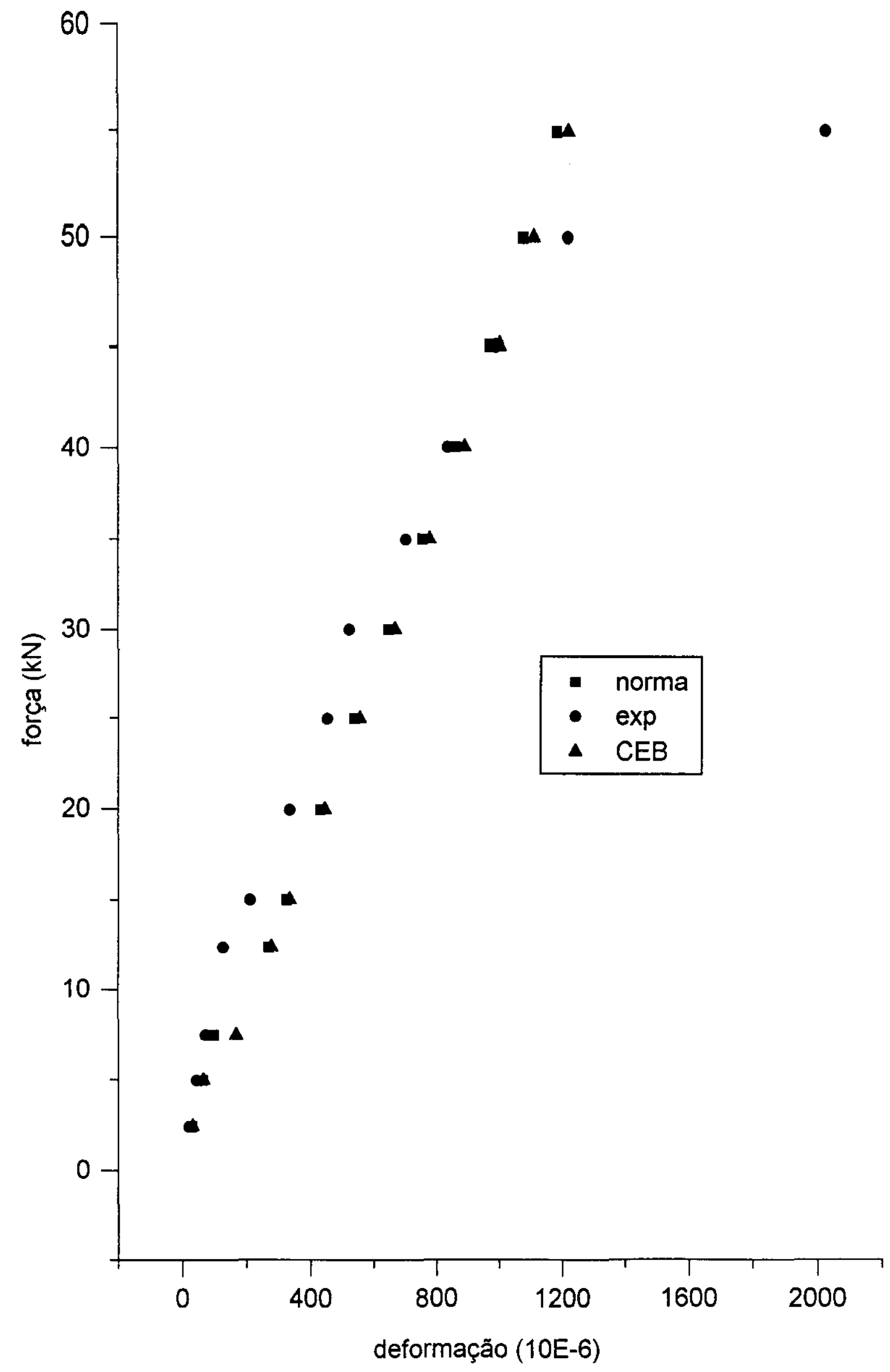

FIG. 7.8 - Diagrama $F \times \varepsilon_{c}-5 \phi 10 \mathrm{~mm}$ 


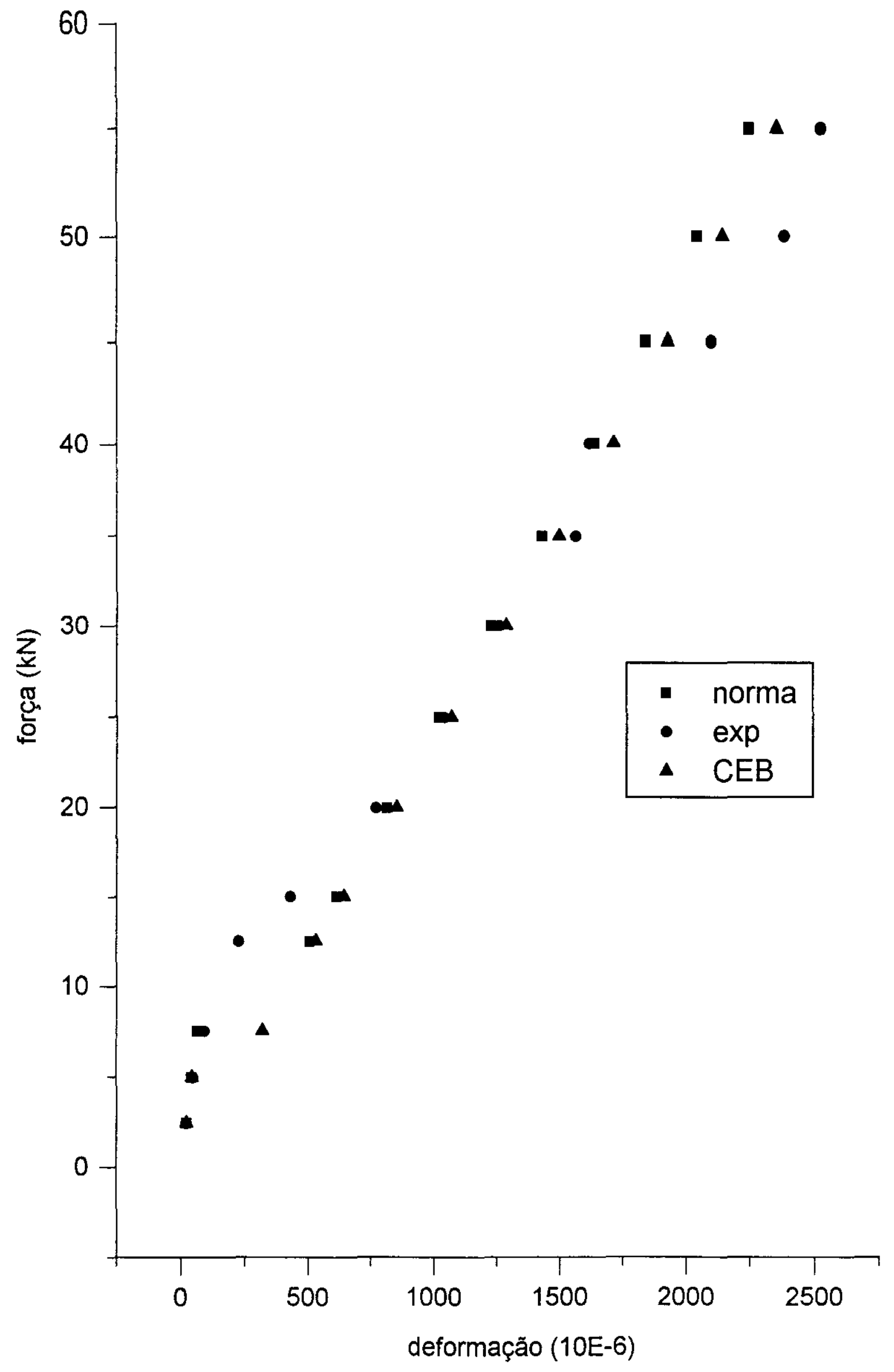

FIG. 7.9 - Diagrama $F \times \varepsilon_{s}-5 \phi 10 \mathrm{~mm}$ 
TABELA 7.3 - FORĢAS X DEFORMAÇŐES : $7 \phi 10$

\begin{tabular}{|c|c|c|c|c|c|c|}
\hline \multirow[t]{2}{*}{$\begin{array}{l}\text { FORĢA } \\
(\mathrm{kN})\end{array}$} & \multicolumn{3}{|c|}{$\begin{array}{c}\text { DEFORMAÇOES - CONGRETO } \\
\varepsilon_{e}(\mu)\end{array}$} & \multicolumn{3}{|c|}{$\begin{array}{c}\text { DEFORMAÇOES - AÇO } \\
\varepsilon_{\mathrm{s}}(\mu)\end{array}$} \\
\hline & NBR & EXP. & GEB & NBR & EXP. & CEB \\
\hline 2,16 & 28,53 & 17,00 & 29,12 & 14,78 & 16,50 & 15,14 \\
\hline 3,95 & 52,17 & 32,75 & 53,26 & 27,03 & 33,21 & 27,69 \\
\hline 6,00 & 79,51 & 51,50 & 80,90 & 41,05 & 57,36 & 42,06 \\
\hline 7,95 & 105,01 & 75,25 & 192,95 & 54,39 & 112,00 & 273,90 \\
\hline 9,95 & 224,39 & 102,75 & 240,24 & 325,96 & 185,50 & 342,80 \\
\hline 12,00 & 270,63 & 133,25 & 289,74 & 393,11 & 265,64 & 413,43 \\
\hline 13,95 & 314,60 & 169,50 & 336,82 & 457,00 & 353,21 & 480,61 \\
\hline 16,00 & 360,84 & 210,75 & 386,32 & 524,15 & 445,14 & 551,24 \\
\hline 18,00 & 405,74 & 252,25 & 434,61 & 589,67 & 529,93 & 620,15 \\
\hline 20,00 & 451,04 & 298,50 & 482,90 & 655,19 & 621,86 & 689,05 \\
\hline 22,00 & 496,15 & 345,50 & 531,19 & 720,71 & 713,86 & 757,96 \\
\hline 25,00 & 563,80 & 404,25 & 603,63 & 818,99 & 833,43 & 861,32 \\
\hline 30,00 & 676,57 & 509,75 & 724,35 & 982,79 & 1048,50 & 1033,58 \\
\hline 35,00 & 789,33 & 618,50 & 845,08 & 1146,58 & 1257,21 & 1205,84 \\
\hline 39,95 & 900,96 & 734,75 & 964,59 & 1308,74 & 1461,57 & 1376,38 \\
\hline 45,00 & 1014,85 & 852,50 & 1086,53 & 1474,18 & 1665,71 & 1550,37 \\
\hline 50,00 & 1127,61 & 980,00 & 1207,25 & 1637,98 & 1871,07 & 1722,63 \\
\hline 55,00 & 1240,37 & 1119,50 & 1327,98 & 1801,77 & 2081,00 & 1894,90 \\
\hline
\end{tabular}




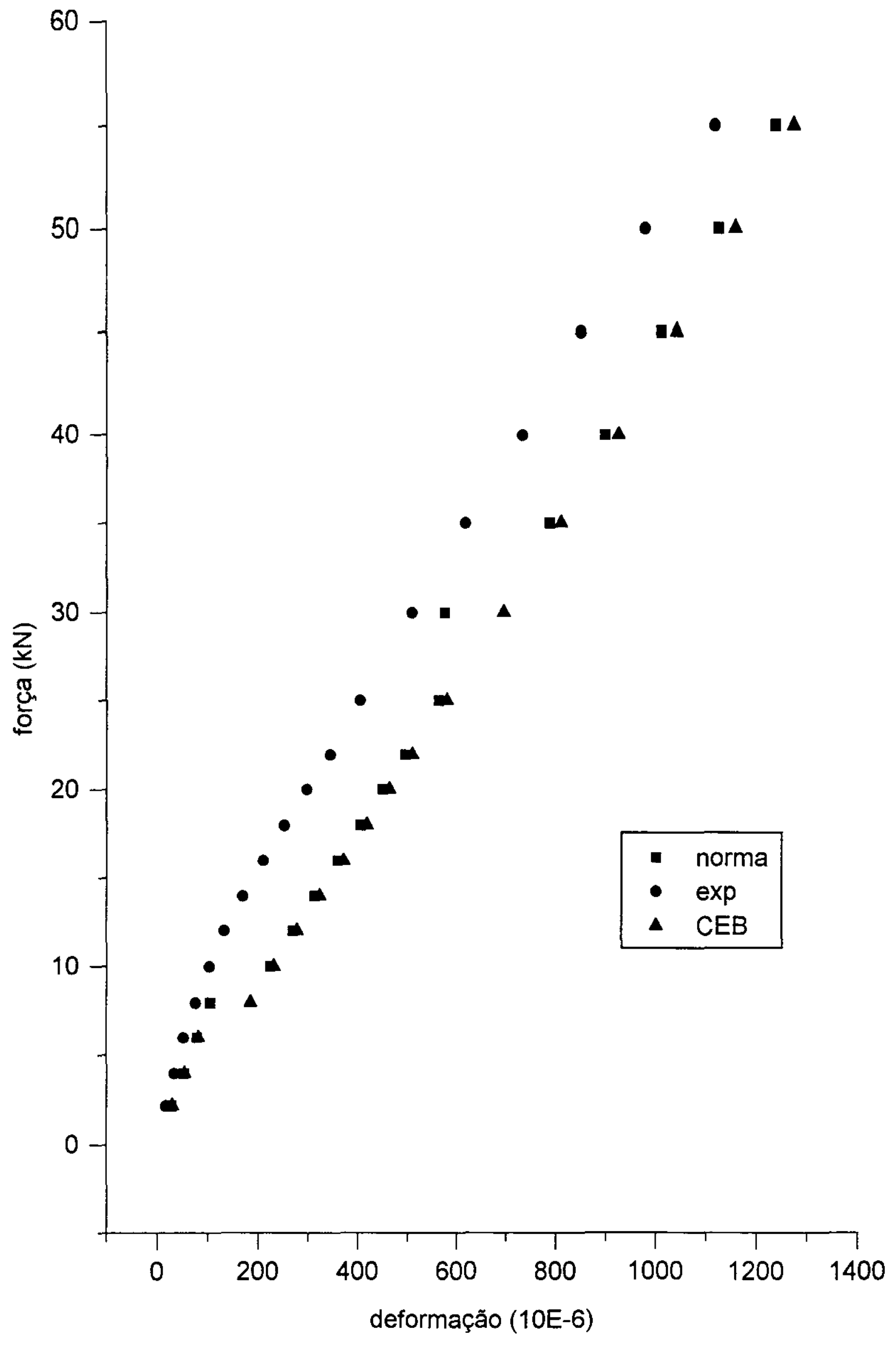

FIG. 7.10 - Diagrama F x $\varepsilon_{\mathrm{c}}-7 \phi 10 \mathrm{~mm}$ 


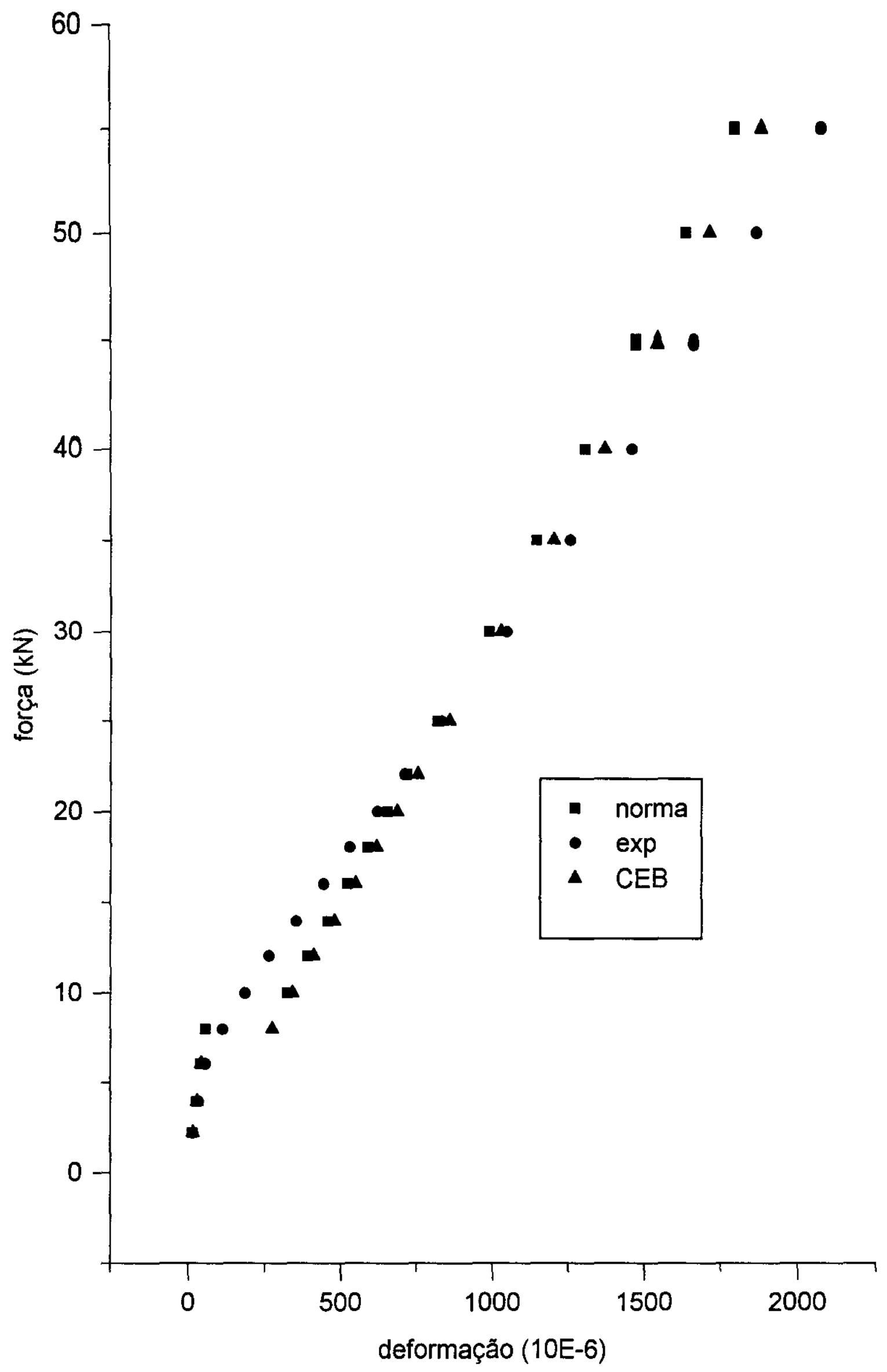

FIG. 7.11 - Diagrama $F \times \varepsilon_{s}-7 \phi 10 \mathrm{~mm}$ 
TABELA 7.4 - FORÇAS X DESLOCAMENTOS : $3 \Phi 10$

\begin{tabular}{|c|c|c|c|}
\hline $\begin{array}{c}\text { FORGA } \\
(\mathrm{kN})\end{array}$ & $\begin{array}{c}\text { EXPER IMENTAL } \\
(\mathrm{mm})\end{array}$ & $\begin{array}{c}\text { NBR } \\
(\mathrm{mm})\end{array}$ & $\begin{array}{c}\text { CEB } \\
(\mathrm{mm})\end{array}$ \\
\hline 2,20 & 0,11 & 0,11 & 0,11 \\
\hline 4,00 & 0,26 & 0,21 & 0,21 \\
\hline 8,00 & 0,51 & 0,41 & 0,77 \\
\hline 10,00 & 0,82 & 0,87 & 1,30 \\
\hline 12,00 & 1,22 & 1,37 & 1,85 \\
\hline 14,00 & 1,71 & 1,91 & 2,38 \\
\hline 16,00 & 2,15 & 2,45 & 2,89 \\
\hline 18,00 & 2,72 & 2,98 & 3,38 \\
\hline 20,00 & 3,18 & 3,49 & 3,85 \\
\hline 22,50 & 3,75 & 4,10 & 4,42 \\
\hline 25,00 & 4,36 & 4,69 & 4,98 \\
\hline 27,50 & 5,05 & 5,26 & 5,53 \\
\hline 30,00 & 5,62 & 5,82 & 6,07 \\
\hline 32,50 & 6,34 & 6,37 & 6,61 \\
\hline 35,00 & 7,00 & 6,91 & 7,45 \\
\hline 37,50 & 7,73 & 7,49 & 6 \\
\hline
\end{tabular}




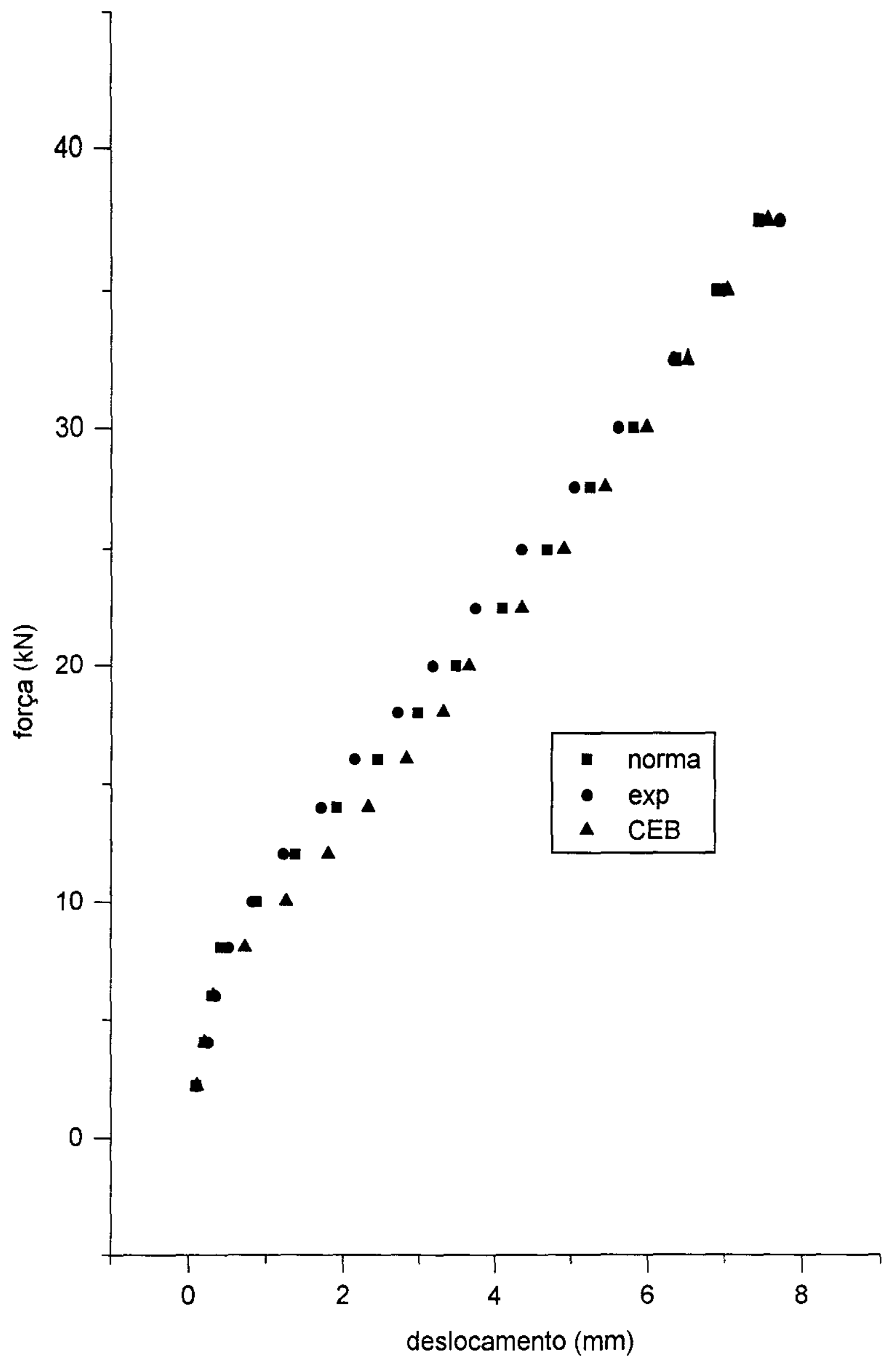

FIG.7.12 - Diagrama Forças x Deslocamentos - $3 \phi 10 \mathrm{~mm}$ 
TABELA 7.5 - FORÇAS X DESLOGAMENTOS: $5 \Phi 10$

\begin{tabular}{|c|c|c|c|}
\hline $\begin{array}{c}\text { FOR GAA } \\
(\mathrm{kN})\end{array}$ & $\begin{array}{c}\text { EXPER IMENTAL } \\
(\mathrm{mm})\end{array}$ & $\begin{array}{c}\text { NBR } 7197 / 89 \\
(\mathrm{~mm})\end{array}$ & $\begin{array}{c}\text { GEB }-90 \\
(\mathrm{~mm})\end{array}$ \\
\hline 2,42 & 0,10 & 0,12 & 0,18 \\
\hline 4,95 & 0,37 & 0,25 & 0,26 \\
\hline 7,47 & 0,58 & 0,38 & 0,56 \\
\hline 12,42 & 0,83 & 1,20 & 1,56 \\
\hline 15,00 & 1,20 & 1,70 & 2,05 \\
\hline 19,95 & 1,85 & 2,60 & 2,92 \\
\hline 24,95 & 2,65 & 3,43 & 3,75 \\
\hline 30,00 & 3,00 & 4,23 & 4,56 \\
\hline 34,95 & 3,95 & 4,99 & 5,34 \\
\hline 40,00 & 5,02 & 5,75 & 6,13 \\
\hline 45,00 & 6,04 & 6,50 & 6,92 \\
\hline 49,95 & 7,30 & 7,23 & 7,69 \\
\hline 54,89 & 8,15 & 7,96 & 8,45 \\
\hline
\end{tabular}




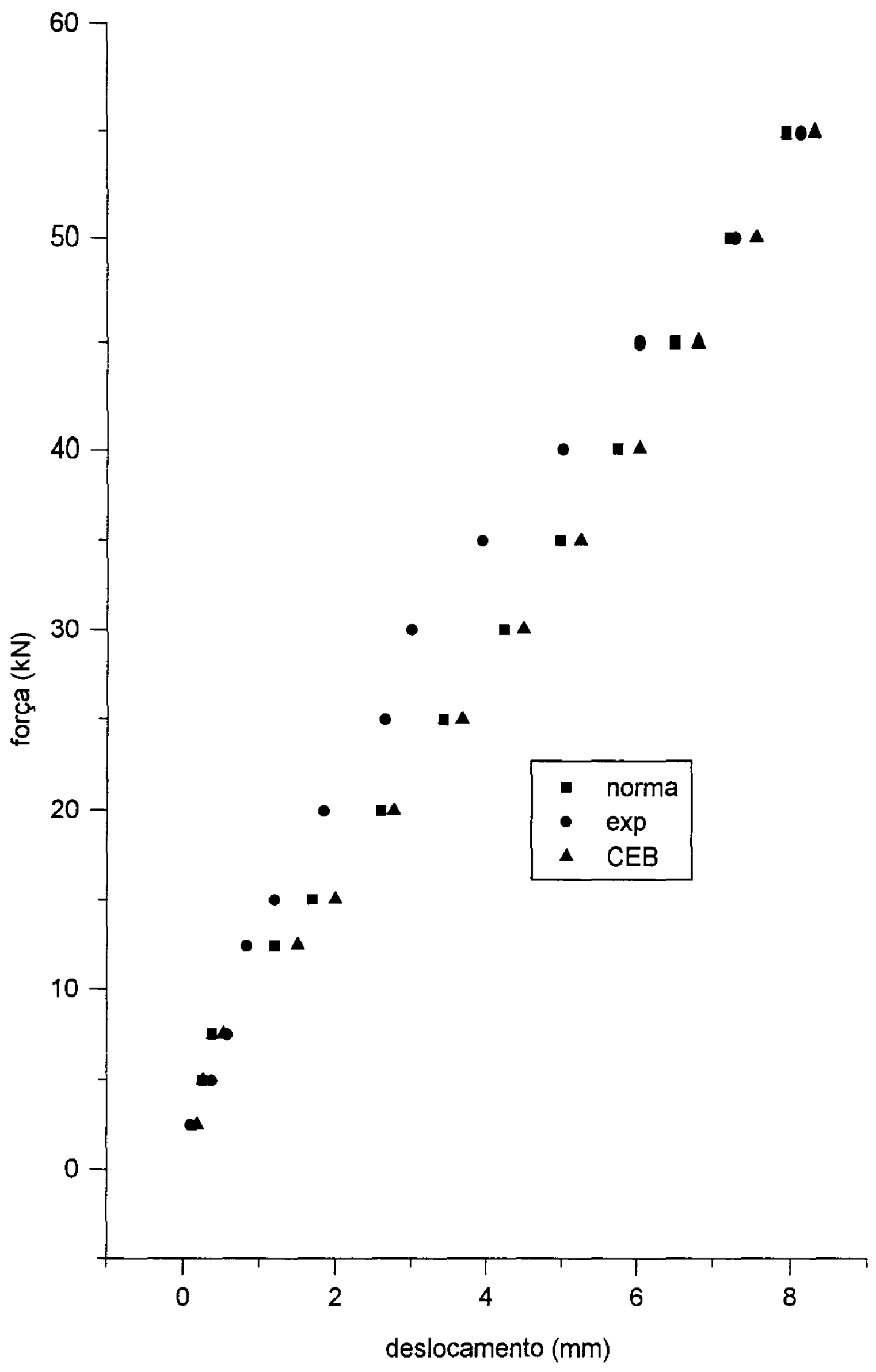

FIG. 7.13 - Diagrama Forças x Deslocamentos - $5 \phi 10 \mathrm{~mm}$ 
TABELA 7. 0 - FORÇAS X DESLOCAMENTOS : 7 10

\begin{tabular}{|c|c|c|c|c|}
\hline $\begin{array}{c}\text { FORĢA } \\
(k N)\end{array}$ & $\begin{array}{c}\text { EXPER I MENTAL } \\
(\mathrm{mm})\end{array}$ & NBR & $\begin{array}{l}7107 / 80 \\
(\mathrm{~mm})\end{array}$ & $\begin{array}{c}\text { CEB }-90 \\
(\mathrm{~mm})\end{array}$ \\
\hline 2,16 & 0,29 & & 0,11 & 0,11 \\
\hline 3,95 & 0.40 & & 0,20 & 0,21 \\
\hline 6,00 & 0,48 & & 0,31 & 0,31 \\
\hline 7,95 & 0,63 & & 0,41 & 0,66 \\
\hline 9,95 & 0,79 & & 0,75 & 1,06 \\
\hline 12,00 & 0,89 & & 1,13 & 1,46 \\
\hline 13,95 & 1,03 & & 1,49 & 1,82 \\
\hline 16,00 & 1,28 & & 1,86 & 2,18 \\
\hline 18,00 & 1,54 & & 2,21 & 2,52 \\
\hline 20,00 & 1,82 & & 2,55 & 2,79 \\
\hline 25,00 & 2,31 & & 3,34 & 3,58 \\
\hline 30,00 & 3,23 & & 4,10 & 4,34 \\
\hline 35,00 & 3,92 & & 4,84 & 5,09 \\
\hline 39,95 & 4,65 & & 5,56 & 5,83 \\
\hline 45,00 & 5,29 & & 6,29 & 6,58 \\
\hline 50,00 & 6,12 & & 7,01 & 7,32 \\
\hline 55,00 & 7,10 & & 7,72 & 8,06 \\
\hline
\end{tabular}




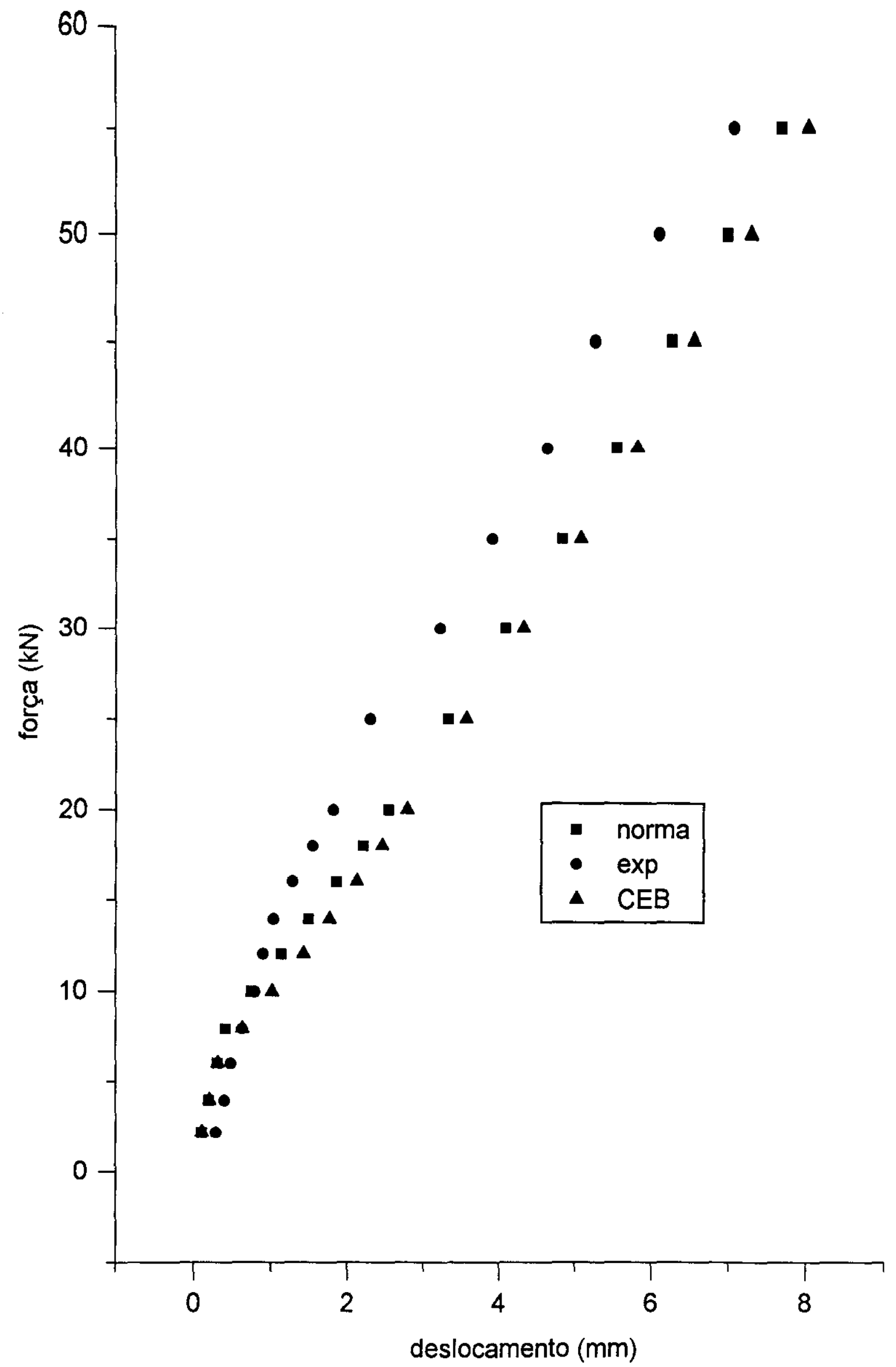

FIG. 7.14 - Diagrama Forças x Deslocamentos - $7 \phi 10 \mathrm{~mm}$ 


\section{8 - ANALISE DOS RESULTADOS E CONCLUSOES}

\section{1 - ANÁLISE dOS RESULTADOS DOS ENSAIOS}

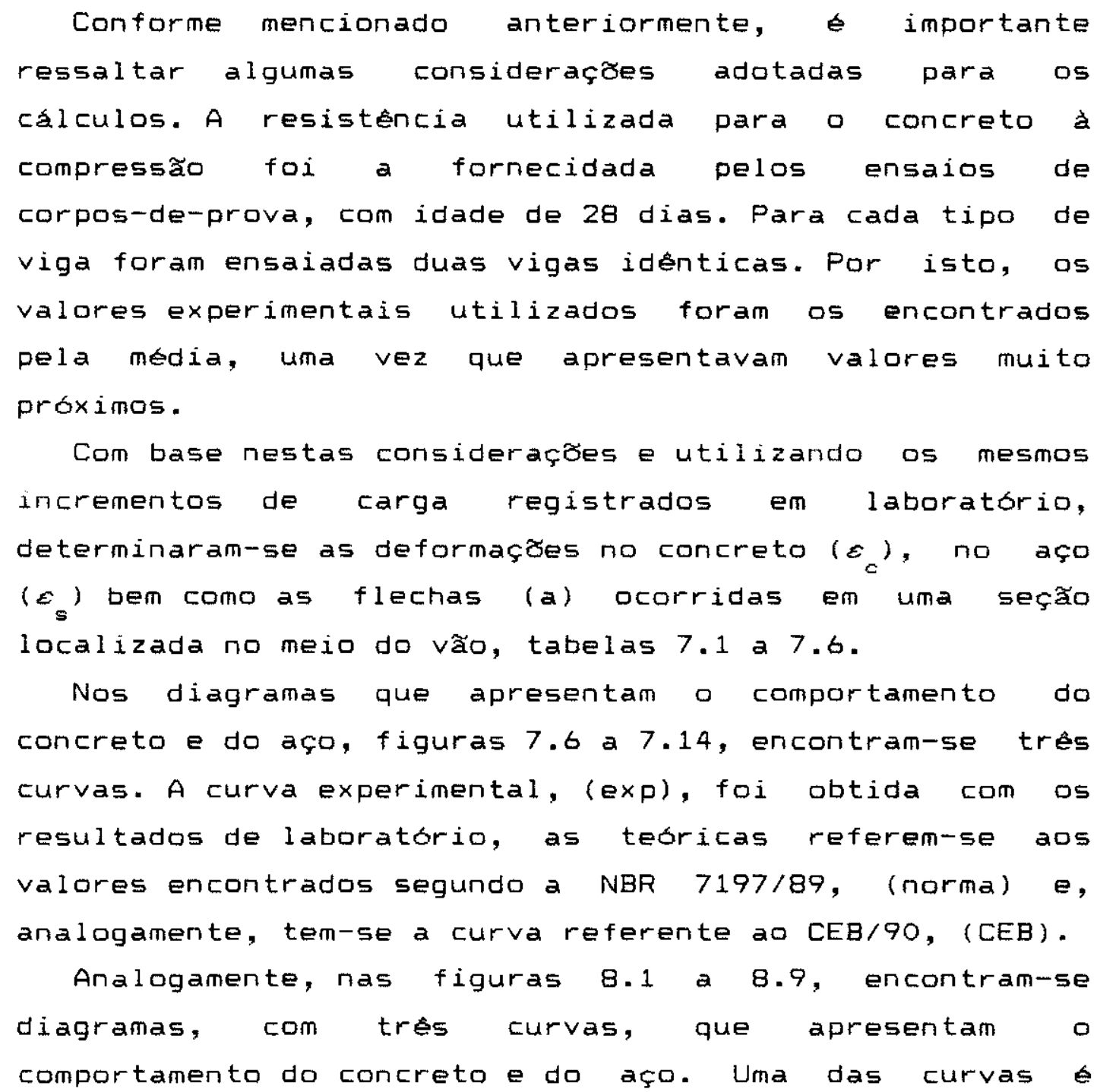


obtida quando, utilizando a NBR $7197 / 89$, se considera o módulo de deformação do aço igual a $200 \mathrm{GPa}$, (nor.mod.), cujos valores encontram-se nas tabelas 8.1 a 8.3 . A outra, refere-se a NBR $7197 / 89$ conforme dito anteriormente. Encontra-se também a curva experimental, cujos valores encontram-se dispostos nas tabelas 7.1 a 7.6 . 
TABELA 8.1. - DEFORMAÇOES E DESLOCAMENTOS PARA

VIGA GOM $9 \Phi$ 10 NBR $97 / 89$

\begin{tabular}{|c|c|c|c|c|c|c|}
\hline$F$ & \multicolumn{2}{|c|}{$\varepsilon_{c}(\mu)$} & \multicolumn{2}{c|}{$\left.\varepsilon_{s} \mu\right)$} & \multicolumn{2}{c|}{$a(\mathrm{~mm})$} \\
\cline { 2 - 7 }$(\mathrm{kN})$ & $200 \mathrm{GPa}$ & $210 \mathrm{GPa}$ & $200 \mathrm{GPa}$ & $210 \mathrm{GPa}$ & $200 \mathrm{GPa}$ & $210 \mathrm{GPa}$ \\
\hline 2,20 & 26,32 & 26,22 & 20,37 & 20,24 & 0,11 & 0,10 \\
\hline 4,00 & 52,64 & 52,44 & 40,75 & 40,48 & 0,21 & 0,21 \\
\hline 6,00 & 78,90 & 78,65 & 61,12 & 60,71 & 0,31 & 0,31 \\
\hline 8,00 & 105,28 & 104,71 & 81,50 & 80,95 & 0,42 & 0,4 \\
\hline 10,00 & 246,79 & 246,69 & 666,30 & 685,10 & 0,88 & 0,87 \\
\hline 12,00 & 296,15 & 296,03 & 799,56 & 822,11 & 1,38 & 1,37 \\
\hline 14,00 & 345,51 & 345,37 & 932,82 & 959,13 & 1,92 & 1,91 \\
\hline 16,00 & 394,87 & 394,71 & 1066,10 & 1096,14 & 2,46 & 2,45 \\
\hline 18,00 & 444,23 & 444,05 & 1199,34 & 1233,16 & 2,66 & 2,98 \\
\hline 19,95 & 492,35 & 492,15 & 1329,27 & 1366,75 & 3,48 & 3,49 \\
\hline 22,47 & 554,54 & 554,32 & 1497,18 & 1539,40 & 4,10 & 4,10 \\
\hline 24,95 & 615,75 & 615,49 & 1662,43 & 1709,30 & 4,68 & 4,69 \\
\hline 27,53 & 679,42 & 679,14 & 1834,33 & 1886,05 & 5,27 & 5,26 \\
\hline 30,00 & 740,38 & 740,07 & 1998,91 & 2055,27 & 5,82 & 5,82 \\
\hline 32,53 & 802,81 & 802,86 & 2167,48 & 2228,60 & 6,38 & 6,37 \\
\hline 35,00 & 863,77 & 863,42 & 2332,06 & 2397,81 & 6,91 & 6,91 \\
\hline 37,47 & 924,73 & 924,35 & 2496,64 & 2567,03 & 7,44 & 7,45 \\
\hline
\end{tabular}

$$
\mu=10^{-6}
$$




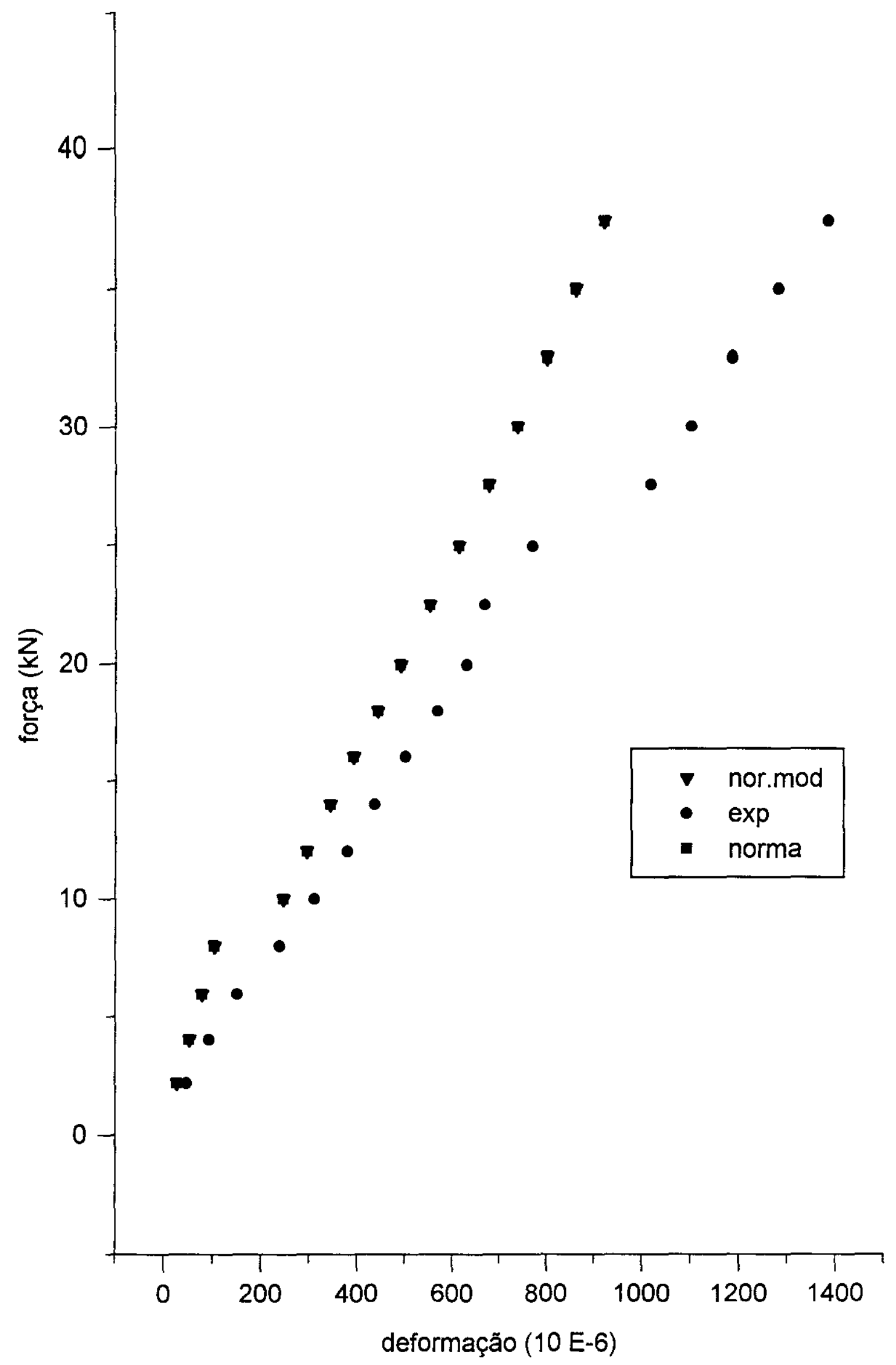

FIG. 8.1 - Diagrama $F x \varepsilon_{c}-3 \phi 10 \mathrm{~mm}$ 


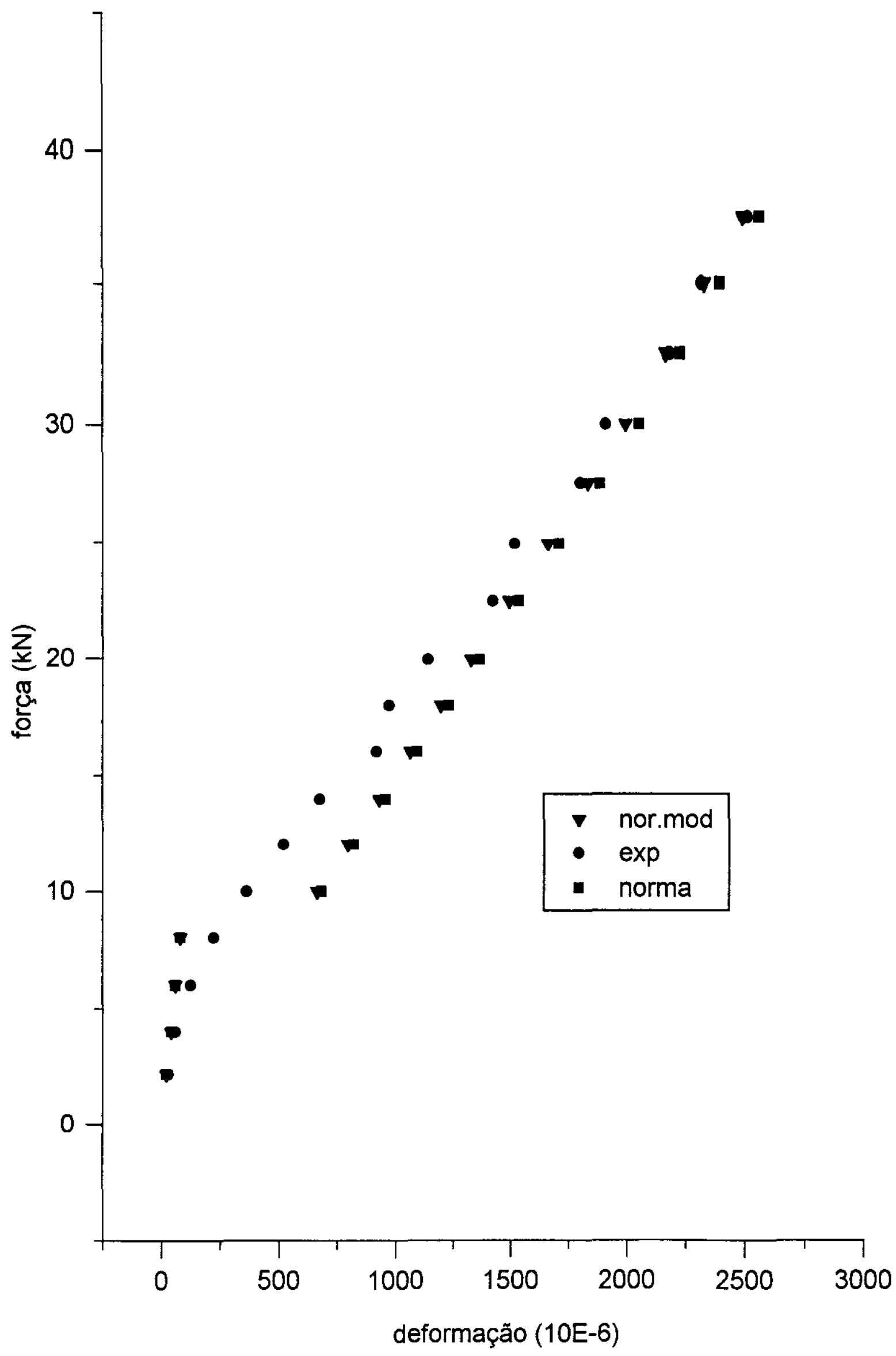

FIG. 8.2 - Diagrama de $F \times \varepsilon_{\mathrm{s}}-3 \phi 10 \mathrm{~mm}$ 


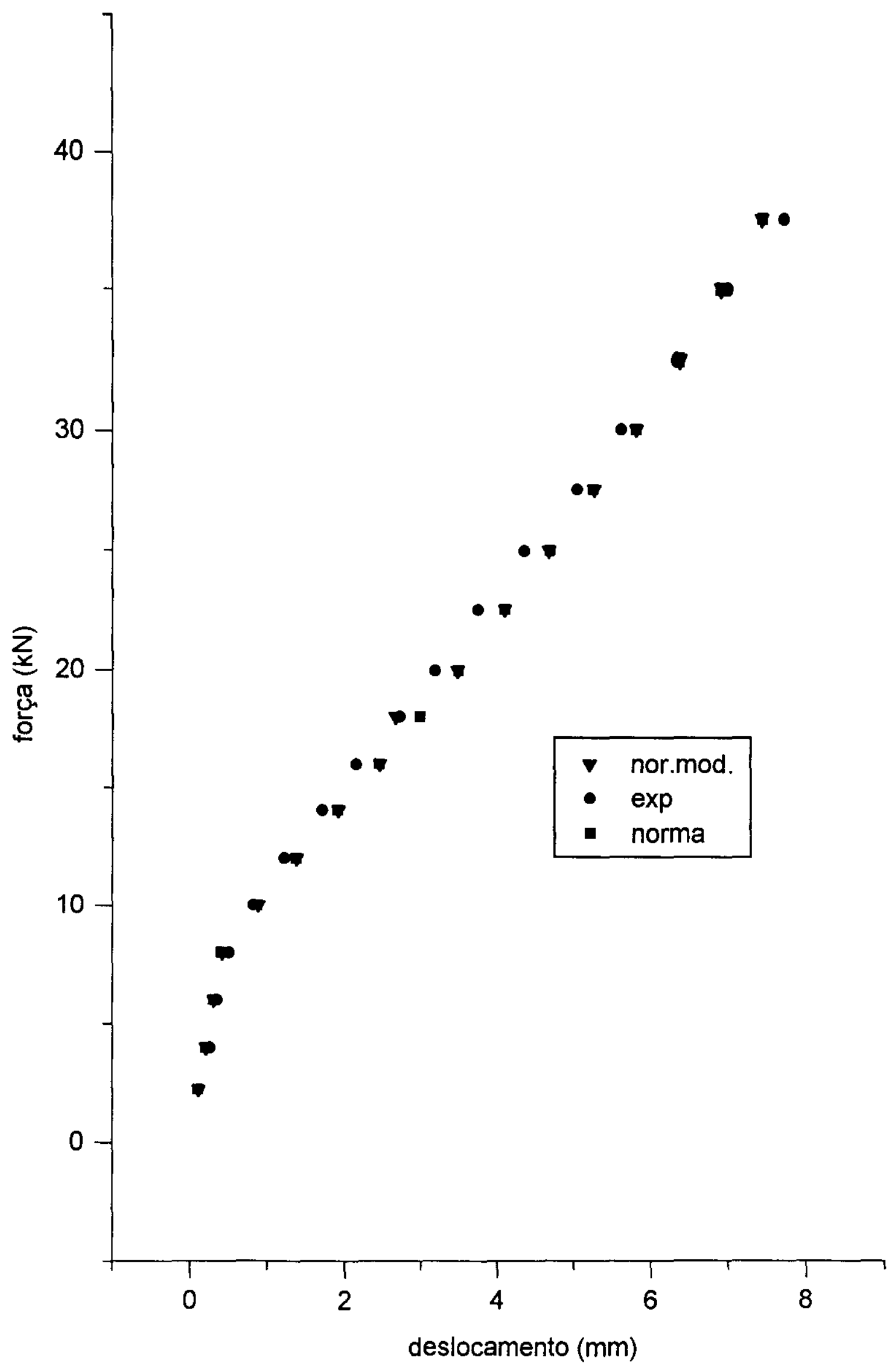

FIG.8.3 - Diagrama Forças x Deslocamentos - $3 \phi 10 \mathrm{~mm}$ 
TABELA 8.2 - DEFORMAÇסES E DESLOCAMENTOS PARA

VIGA COM $5 \Phi$ 10 NBR $197 / 60$

\begin{tabular}{|c|c|c|c|c|c|c|}
\hline \multirow{2}{*}{$\begin{array}{l}F \\
(k N)\end{array}$} & \multicolumn{2}{|c|}{$\varepsilon_{c}(\mu)$} & \multicolumn{2}{|c|}{$\varepsilon_{S}(\mu)$} & \multicolumn{2}{|c|}{$a(\mathrm{~mm})$} \\
\hline & $200 G P a$ & $210 \mathrm{GPa}$ & $2006 P_{2}$ & $210 \mathrm{GPa}$ & $200 \mathrm{GPa}$ & $210 \mathrm{GPa}$ \\
\hline 2,42 & 31,53 & 31,40 & 21,19 & 21,00 & 0,12 & 0,12 \\
\hline 4,95 & 64,49 & 64,22 & 43,34 & 42,95 & 0,25 & 0,25 \\
\hline 7,47 & 97,32 & 96,92 & 65,40 & 64,81 & 0,40 & 0,38 \\
\hline 12,42 & 273,94 & 268,95 & 532,58 & 508,54 & 1,24 & 1,20 \\
\hline 15,00 & 330,85 & 324,82 & 643,21 & 614,18 & 1,75 & 1,70 \\
\hline 19,95 & 440,03 & 432,00 & 855,48 & 816,86 & 2,68 & 2,60 \\
\hline 24,95 & 550,31 & 540,28 & 1069,89 & 1021,59 & 3,60 & 3,43 \\
\hline 30,00 & 661,69 & 649,63 & 1286,64 & 1228,36 & 4,45 & 4,23 \\
\hline 34,95 & 770,87 & 756,82 & 1498,70 & 1431,04 & 5,27 & 4,99 \\
\hline 40,00 & 882,26 & 866,18 & 1715,25 & 1637,81 & 6,07 & 5,75 \\
\hline 45,00 & 992,54 & 974,45 & 1929,65 & 1842,54 & 6,87 & 6,50 \\
\hline 49,95 & 1101,72 & 1081,64 & 2141,91 & 2045,22 & 7,66 & 7,23 \\
\hline 54,89 & 1210,68 & 1188,61 & 2353,75 & 2247,49 & 8,42 & 7,96 \\
\hline
\end{tabular}

$\mu=10^{-6}$ 


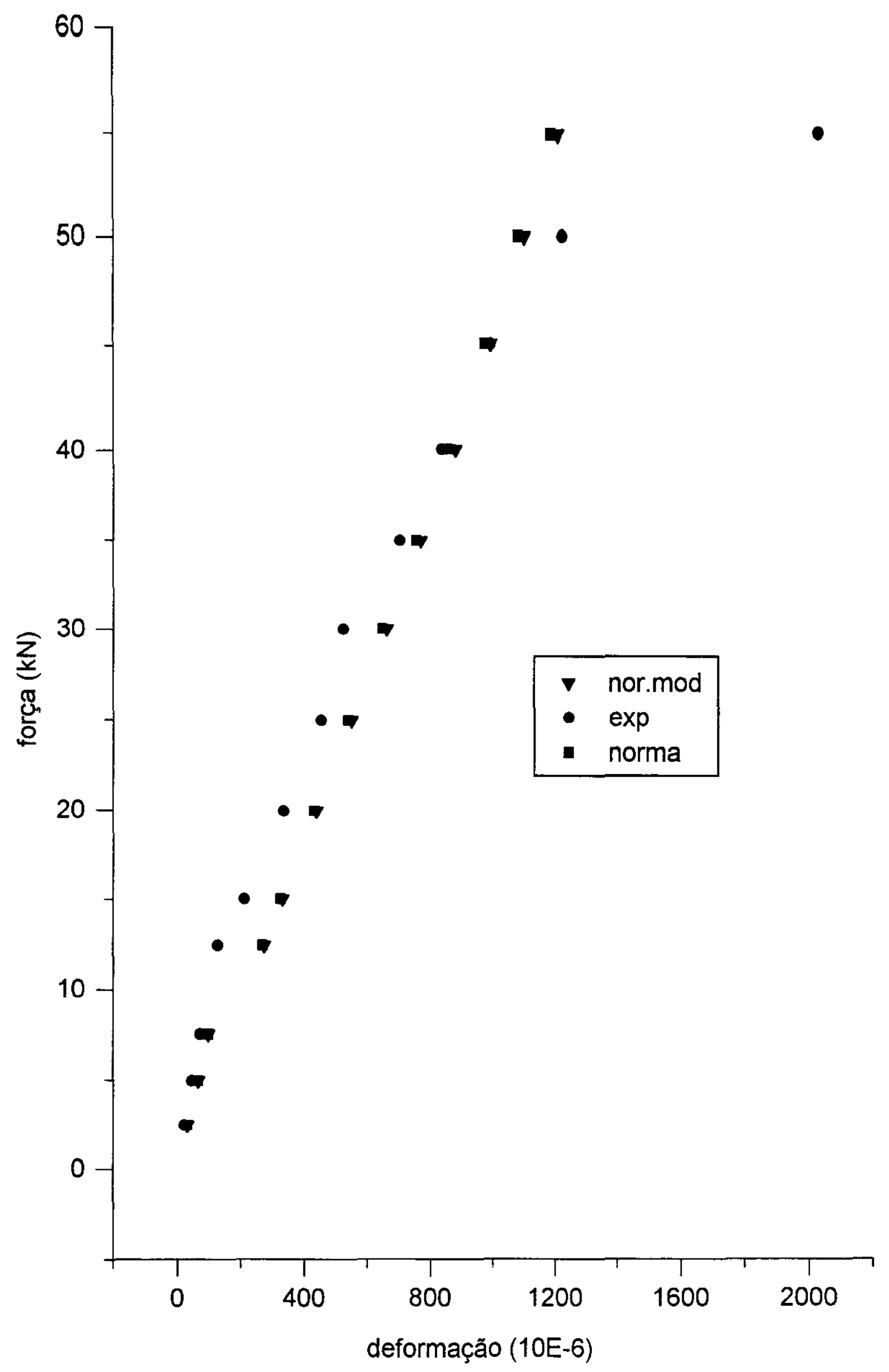

FIG. 8.4 - Diagrama $F \times \varepsilon_{c}-5 \phi 10 \mathrm{~mm}$ 


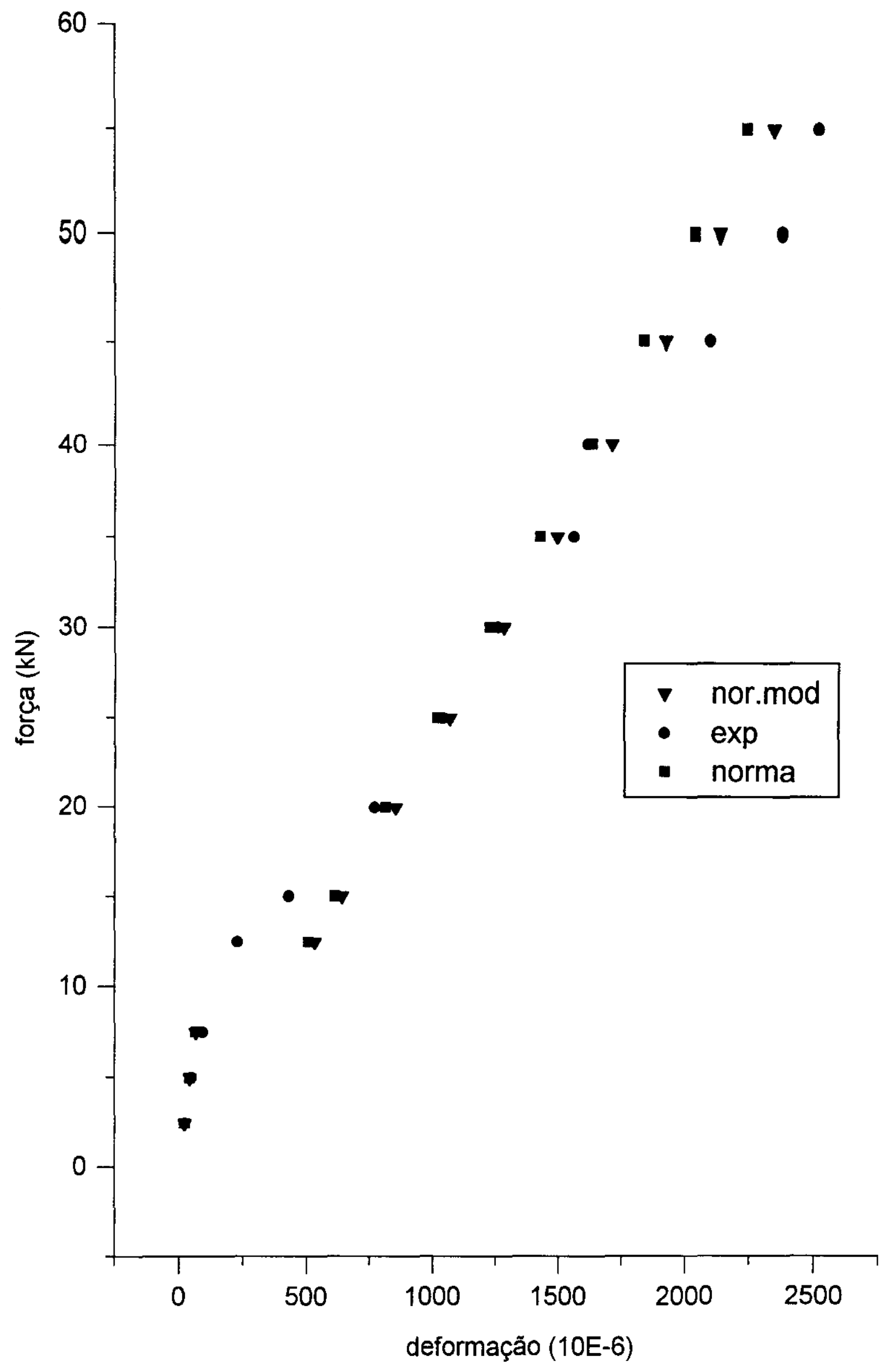

FIG. 8.5 - Diagrama $F \times \varepsilon_{\mathrm{s}}-5 \phi 10 \mathrm{~mm}$ 


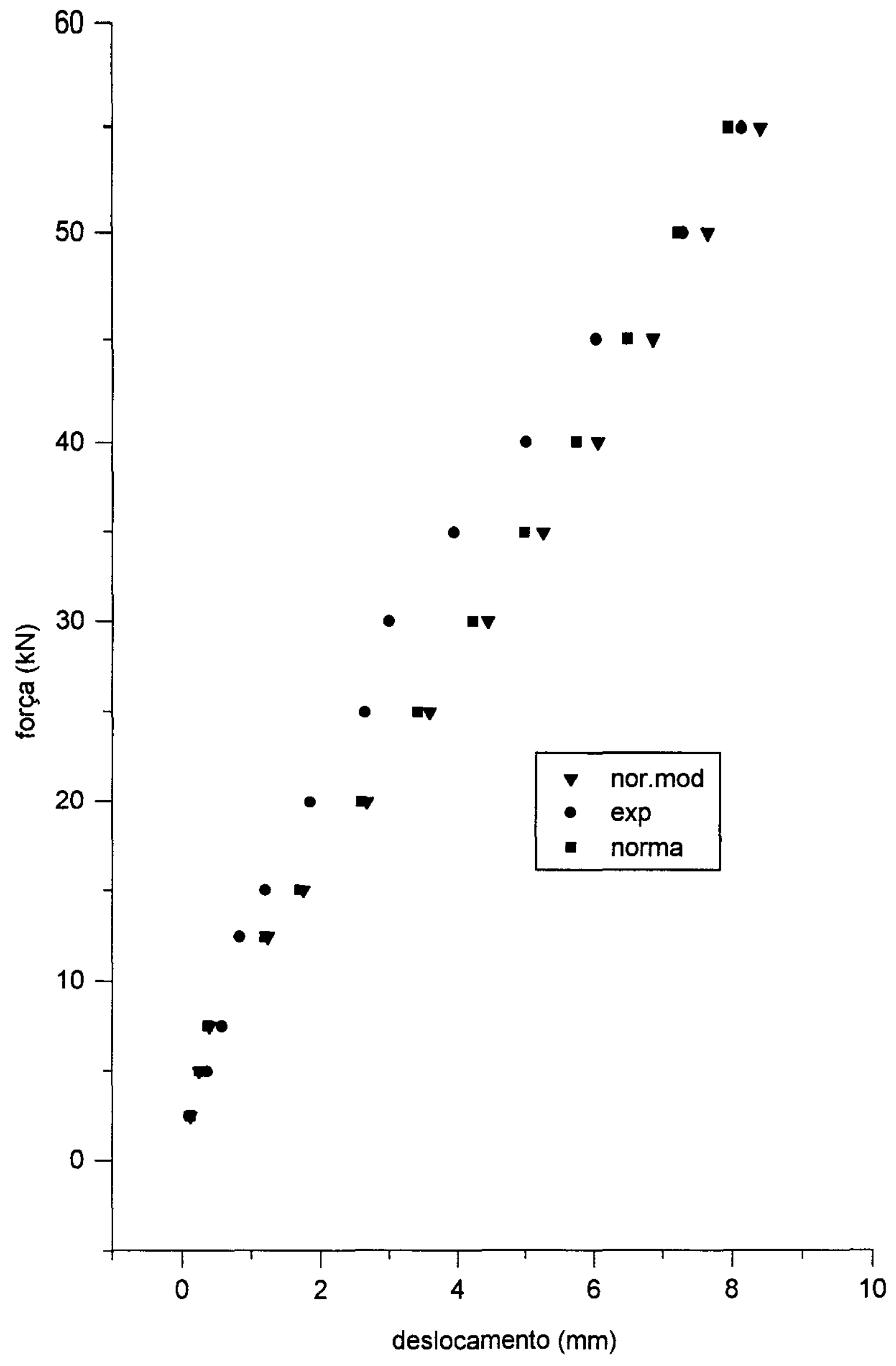

FIG.8.6 - Diagrama Forças X Deslocamentos - $5 \$ 10 \mathrm{~mm}$ 
TABELA B.9 - DEFoRMAĢEES E DESLOCAMENTOS PARA VIGA COM $7 \Phi$ IO NBR $197 / 89$

\begin{tabular}{|c|c|c|c|c|c|c|}
\hline \multirow{2}{*}{$\begin{array}{c}F \\
(k N)\end{array}$} & \multicolumn{2}{|c|}{$\varepsilon_{c}(\mu)$} & \multicolumn{2}{|c|}{$\varepsilon_{s}(\mu)$} & \multicolumn{2}{|c|}{$a(\mathrm{~mm})$} \\
\hline & $200 \mathrm{GPa}$ & $210 \overline{P P a}$ & $200 \mathrm{GPa}$ & $210 G P a$ & $200 G P a$ & $210 \mathrm{GPa}$ \\
\hline 2,16 & 28,24 & 28,53 & 16,12 & 14,78 & 0,11 & 0,11 \\
\hline 3,95 & 51,65 & 52,17 & 29,48 & 27,03 & 0,20 & 0,20 \\
\hline 6,00 & 78,45 & 79,51 & 44,79 & 41,05 & 0,30 & 0,30 \\
\hline 7,95 & 103,94 & 105,01 & 59,34 & 54,39 & 0,40 & 0,41 \\
\hline 9,95 & 214,53 & 224,39 & 328,28 & 325,96 & 0,71 & 0,75 \\
\hline 12,00 & 258,73 & 270,63 & 395,91 & 393,11 & 1,07 & 1,13 \\
\hline 13,95 & 300,78 & 314,60 & 460,25 & 457,00 & 1,42 & 1,49 \\
\hline 16,00 & 344,98 & 360,84 & 527,88 & 524,15 & 1,77 & 1,86 \\
\hline 18,00 & 388,10 & 405,94 & 593,87 & 589,67 & 2,10 & 2,21 \\
\hline 20,00 & 431,22 & 451,04 & 659,85 & 655,19 & 2,42 & 2,55 \\
\hline 22,00 & 474,34 & 496,15 & 725,84 & 720,71 & - & - \\
\hline 25,00 & 517,46 & 563,80 & 824,81 & 818,99 & 3,18 & 3,34 \\
\hline 30,00 & 646,83 & 676,57 & 989,78 & 989,79 & 3,90 & 4,10 \\
\hline 35,00 & 754,63 & 789,33 & 1154,74 & 1146,58 & 4,60 & 4,84 \\
\hline 39,95 & 861,36 & 900,96 & 1318,05 & 1308,74 & 5,29 & 5,56 \\
\hline 45,00 & 970,24 & 1014,19 & 1484,66 & 1474,18 & 5,98 & 6,29 \\
\hline 50,00 & 1078,05 & 1127,61 & 1649,63 & 1637,98 & 6,66 & 7,01 \\
\hline 55,00 & 1185,85 & 1240,37 & 1814,59 & 1801,77 & 7,34 & 7,72 \\
\hline
\end{tabular}

$\mu=10^{-6}$ 


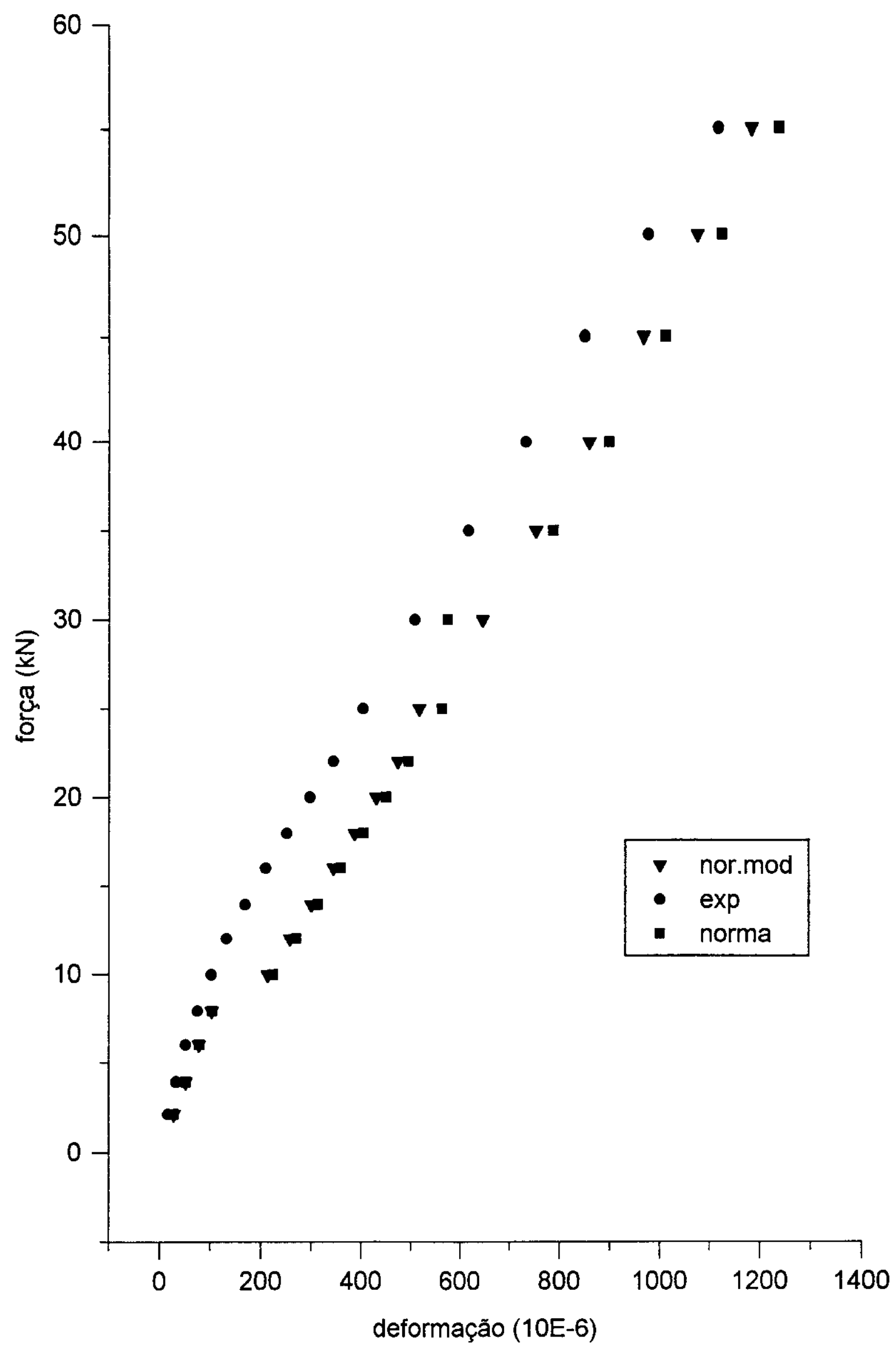

FIG. 8.7 - Diagrama $F x \varepsilon_{c}-7 \phi 10 \mathrm{~mm}$ 


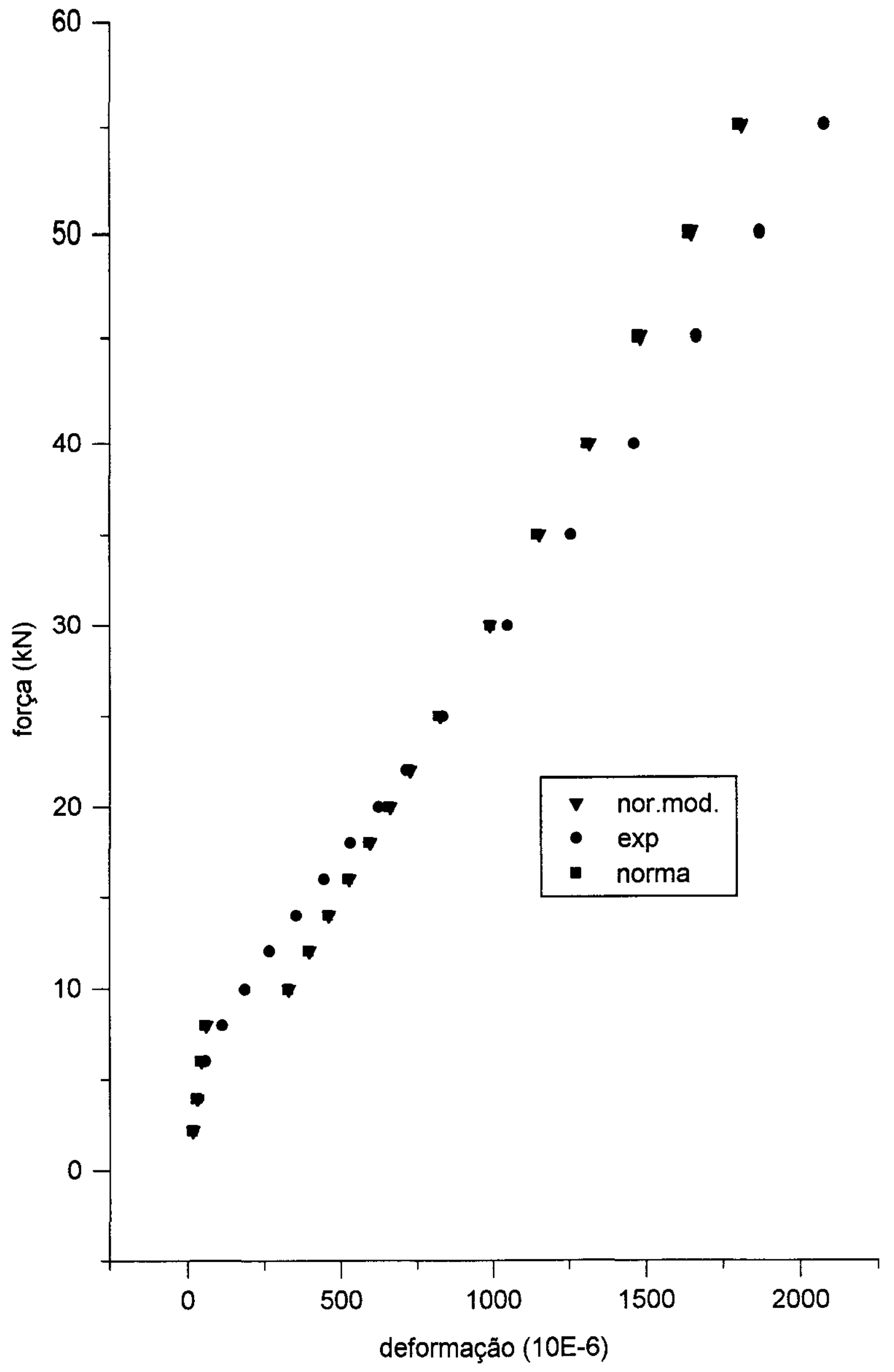

FIG. 8.8 - Diagrama $F \times \varepsilon_{\mathrm{s}}-7 \phi 10 \mathrm{~mm}$ 


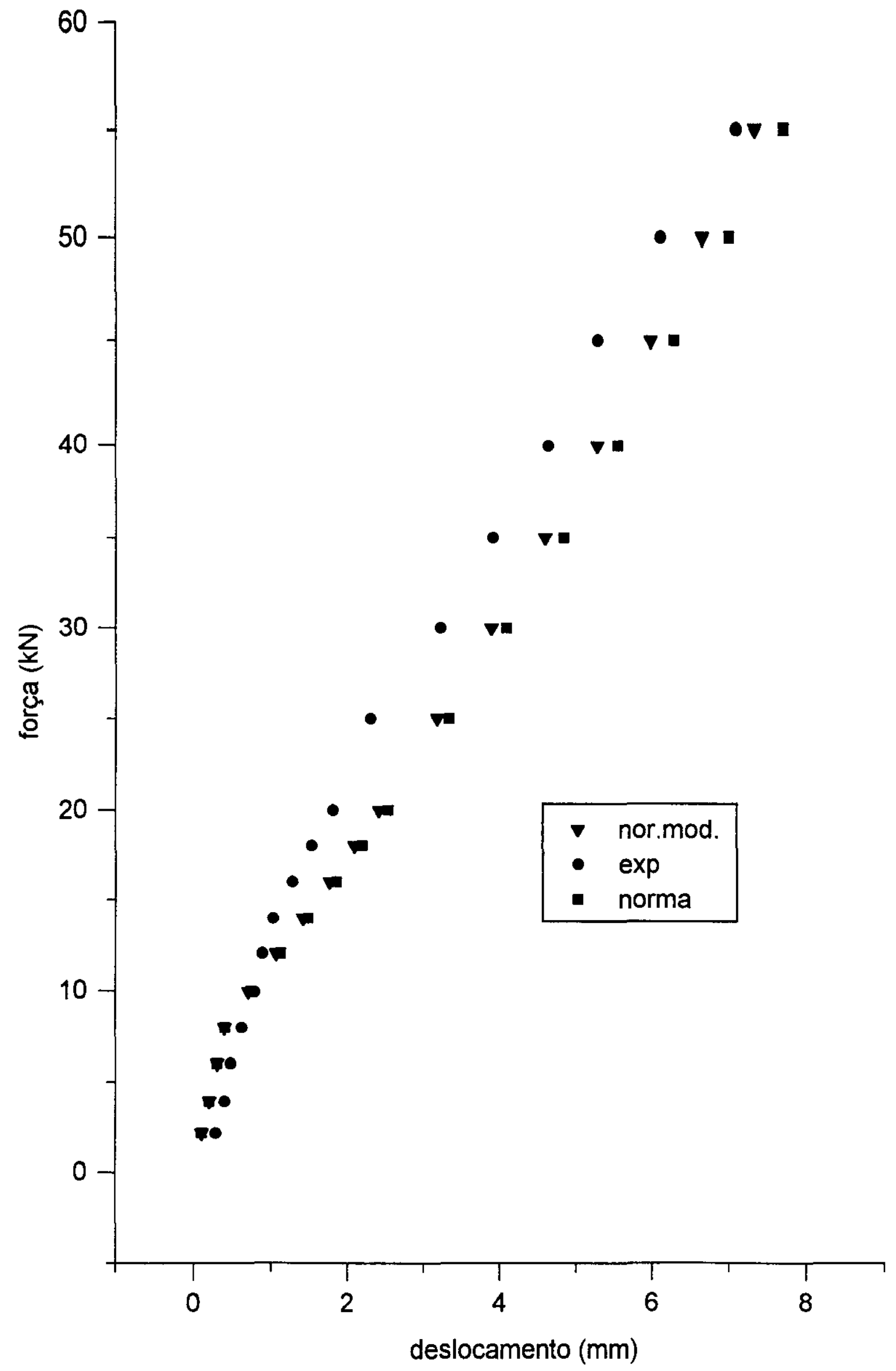

FIG.8.9 - Diagrama Forças X Deslocamentos - $7 \phi 10 \mathrm{~mm}$ 
Para o cálculo das deformaçóes tanto a NBR 7197/89 como o CEB apresentam processos de calculo que buscam fornecer resultados próximos aos valores encontrados experimentalmente. Vários parâmetros săo considerados nos cálculos, conforme demonstrado anteriormente, parametros estes que interferem direta ou indiretamente nos cálculos das deformaçốes e dos deslocamentos. Logicamente, estudar todos acarretaria em um extenso trabalho. Portanto, questiona-se apenas o módulo de deformação longitudinal do aço, que é dado como sendo $210 \mathrm{GPa}$. Com base em ensaios realizados em várias barras de aço, constatou-se que dificilmente este valor alcançado, fato este que permitiu concluir que é melhor utilizar o valor do módulo de deformação como sendo 200 GPa.

Apresentam-se, a seguir, comentarios sobre as resultados obtidos.

\section{a) Deformaçชes no concreto}

Com base nos diagramas $F \times \varepsilon_{c}$, figuras $7.6,7.8$ e 7.10, percebe-se que quando se comparam os valores teóricos com os valores experimentais, a viga com menor taxa de armadura fornece os piores resultados, ou seja, os valores calculados ficam aquem dos encontrados experimentalmente. Para as vigas com maior taxa de armadura, observa-se que a situaça se inverte. Nota-se também que a utilização do módulo de deformaçăo longitudinal do aço igual a 200 GPa acarreta em um aumento nas deformações (figuras: $8.1,8.4$ e 8.7).

b) Deformações no aço

Analogmente, nos diagramas $F \times \varepsilon_{s}$, figuras $7.7,7.9$ e 7.11, verifica-se as tres curvas teóricas encontram-se 
muito próximas. Quando se compara com os valores experimentais, observa-se que a viga com menor taxa de armadura também apresenta os piores resultados. Para os outros dois casos considerados, $5 \phi 10$ e $7 \phi 10$, observam-se duas fases bem caracteristicas. Na primeira fase, os valores das deformaçōes determinadas teoricamente são maiores que os valores experimentais, portanto, satisfatórios. Na segunda fase, com o acréscimo da carga, a situação se inverte, ou seja, as deformaçðes teoricas passam a apresentar valores inferiores aos determinados em laboratório. Tal comportamento fica bem acentuado para a viga que apresenta a maior taxa de armadura. A utilização do modulo de deformação do aço igual a 200 GPa contribui, de modo geral, com um aumento nas deformaçós (figuras: $8.2,8.5$ e 8.8 ).

\section{c) Flechas}

Dbservando-se os diagramas forças $x$ deslocamentos, figuras 7.12 a 7.14 , verifica-se que as tres curvas teoricas encontram-se muito proximas. Quando se compara com a curva experimental, nota-se que as tres teoricas, independente da taxa de armadura, fornecem valores muito superiores. E importante ressaltar que por apresentarem valores muito superiores torna-se questionável, uma vez que o interessante $b$ apresentar valores proximos aos experimentais. Analogamente, a utilizaçăo do módulo de deformação do aço igual a $200 \mathrm{GPa}$ acarreta em um aumento nos valores das flechas calculadas (figuras: 8.3, 8.6 e 8.9). 


\section{2 - CONCLUSOES}

Sabe-se que os ensaios procuram reproduzir, em laboratório, o comportamento das estruturas quando estas são submetidas a solicitaç̧̋es. Com base nos resultados experimentais, métodos de cálculo são desenvolvidos com o objetivo de representar, analiticamente, estes resultados. Vários parâmetros 5 ăo considerados nos Cálculos e a variaçăo de um deles acarreta em alteraçós nos resultados. O melhor metodo de cálculo sera aquele que mais se aproximar dos resultados experimentais. Com base nisto, foram analisados o comportamento de três vigas com diferentes taxas de armaduras e as conclusöes encontram-se a seguir.

\section{a) QUANTO AS DEFORMACOES PROVOCADAS POR FORCAS EXTERNAS}

\footnotetext{
No estádio I, praticamente săo coincidentes todas as curvas, diagramas $F \times \varepsilon_{c}, F \times \varepsilon_{c} e F \times a .0$ calculo no estádio II precisa ser verificado, principalmente quanto a deformaçăo no concreto e no aço para pequenas armaduras de flexăo. Importante verificar tambem a deformaça no aço para vigas com alta taxa de armadura e carregamento elevado.

Considerar o módulo de deformação do aço igual a 200 GPa e minorar a resistência alcançada poderá ser uma soluçă una vez que o aumento da resistêcia acarreta numa diminuição das deformaçöes.
}

b) QUANTO A RETRAÇAO E A FLUENCIA

Para a retraçăo e para a deformaça imediata, item 
2.9, os resultados decorrentes da NB-1/93, do Eurocode e do CEB são muito próximos, para o exemplo considerado. Porém, para a retração, com estas três normas resultam valores muito elevados em relação à Norma Brasileira NBR 7197, atualmente en vigor. Com respeito à fluência, as quatro normas analisadas apresentam resultados divergentes. A NB-1/93 é a que mais se aproxima da NBR 7197.

Vários parâmetros interferem nos cálculos e devem ser estudados cuidadosamente. Conforme dito anteriormente, uma simples alteração em um dos parămetros acarreta em consideráveis variaçóes.

Portanto, novos estudos devem ser realizados, visando adequar melhor os cálculos das deformaçzes.

o trabalho apresentado representa uma contribuição ao calculo das deformaçōes, no concreto e no aço, e que pode ser complementado com base nas sugestð̈es mencionadas. 


\section{REFERENCIAS BIBLIOGRAFICAS}

AMERICAN CONCRETE INSTitute. Committee 318. (1989). Building code requirements for reinforced concrete ( $A C I$ 318-89) and commentary (ACI 318R-89). Detroit, American Concrete Institute. 353 p.

AMARAL, N.A. (1979) Construçöes de concreto I. Săo Paulo. Grémio Politecnico da Escola Politecnica.v. 1.

ASSOCIAÇÃO BRASILEIRA DE NORMAS TECNICAS (1984). NBR 5738

- Confecça e cura de corpos-de-prova de concreto cilinaricos ou prismaticos: método de ensaio. Rio de Janeiro.

ASSUCIAÇÃO BRASILEIRA DE NORMAS TECNICAS (1980). NBR 5739 - Ensaio de compressão de corpos cilindricos de concreto: metodo de ensaio. Rio de Janeiro.

ASSOCIAÇAO BRASILEIRA DE NORMAS TECNICAS. (1978). NBR o118 - Projeto $e$ execufaa de obras de concreto armado. Rio de Janeiro.

ASSOCIAÇÃO BRASILEIRA DE NORMAS TECNICAS (1989). NBR 7197 - Projeto de estruturas de concreto protendido. Rio de Janeiro.

ASSOCIAÇATO BRASILEIRA DE NORMAS TECNICAS (1978). NBR 7480 - Barras e fios de aço destinados a armaduras para concreto armado. Rio de Janeiro.

ASSOCIAÇÃO BRASILEIRA DE NORMAS TÉCNICAS (1984). NBR 8196 - Aços e seguranca nas estruturas: procedimento. Rio de Janeiro. 
COMITE EURO-INTERNATIONAL DU BETON (1991). CEB-FIP modeI code 1990: final draft. Bulletin d"Information, n. 203.

CHEN, W.F. (1982). Plasticity in reinforced concrete. New York, Ed. MEGraw-Hill.

CHIAVERINI, V. (1981). Afos e ferros fundidos. São Paulo, Associaçăo Brasileira de Metais.

EUROCODE No.2. (1989). Design of concrete structures. part. 1: General rules and rules for buildings.

FusCO, P.B. (1976). Estruturas de concreto: fundamentos do projeto estrutural. Săo Paulo, MeGraw-Hill.

FUSCO, P.B. (1981). Estruturas de concreto: solicitaçzes normais. Rio de Janeiro, Guanabara Dois.

LEONHARDT, F.; MONNIG, E. (1982). Construç8es de concreto: - Principios basicos do dimensionamento de estruturas de concretos armado. Rio de Janeiro.

MACGREGOR, J.G. (1992). Reinforced concrete: mechanics and design. 2. ed. Englewood cliffs, Prentice Hall.

NASH, W. A. (1977). Resistencia dos materiais: resumo da teoria, problemas resolvidos, problemas propostos. Traduzido por Jaime Ferreira da Silva. São Paulo, McGraw-Hill do Brasil.

SANTOS, L.M. (1983). Cálculo de concreto armado, segundo a nova $N B-1$ e o CEB, Săo Paulo, LMS.

MONTOYA, P.J.; MESEguer, A.g.; CABRE, F.M. (1976). Hormigon armado. Barcelona, Gustavo Gili. 
PINHEIRO, L.M. (1986). Concreto armado: propriedade dos materiais. Săo Carlos, EESC - USP.

POLILLO, A. (1973). Dimensionamento de concreto armado. Rio de Janeiro, Editora Cientifica. $v .1$.

RÜSCH, H. (1981). Concreto armado e protendido: propriedade dos materiais e dimensionamento. Rio de Janeiro, Campus.

SÜSEKIND, J. C. (1987). Curso de concreto armado. Rio de Janeiro, Globo. $\vee .1$. 